Universidad de Lima

Facultad de Comunicación

Carrera de Psicología

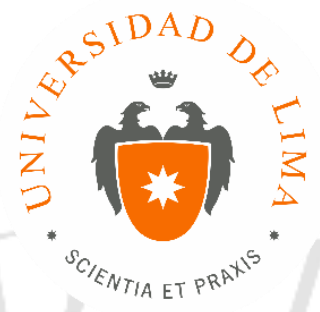

\title{
ADAPTACIÓN DE LA ESCALA DE IDENTIDAD PARA LESBIANAS, GAYS Y BISEXUALES (LGBIS) EN UN GRUPO DE LESBIANAS, GAYS Y BISEXUALES DEL PERÚ
}

Tesis para optar el título profesional de Licenciada en Psicología

\section{Jessica Marialaura Vinces Guillén}

Código 20053060

\section{Asesor}

Luis Miguel Escurra Mayaute

Lima - Perú

Julio de 2016 


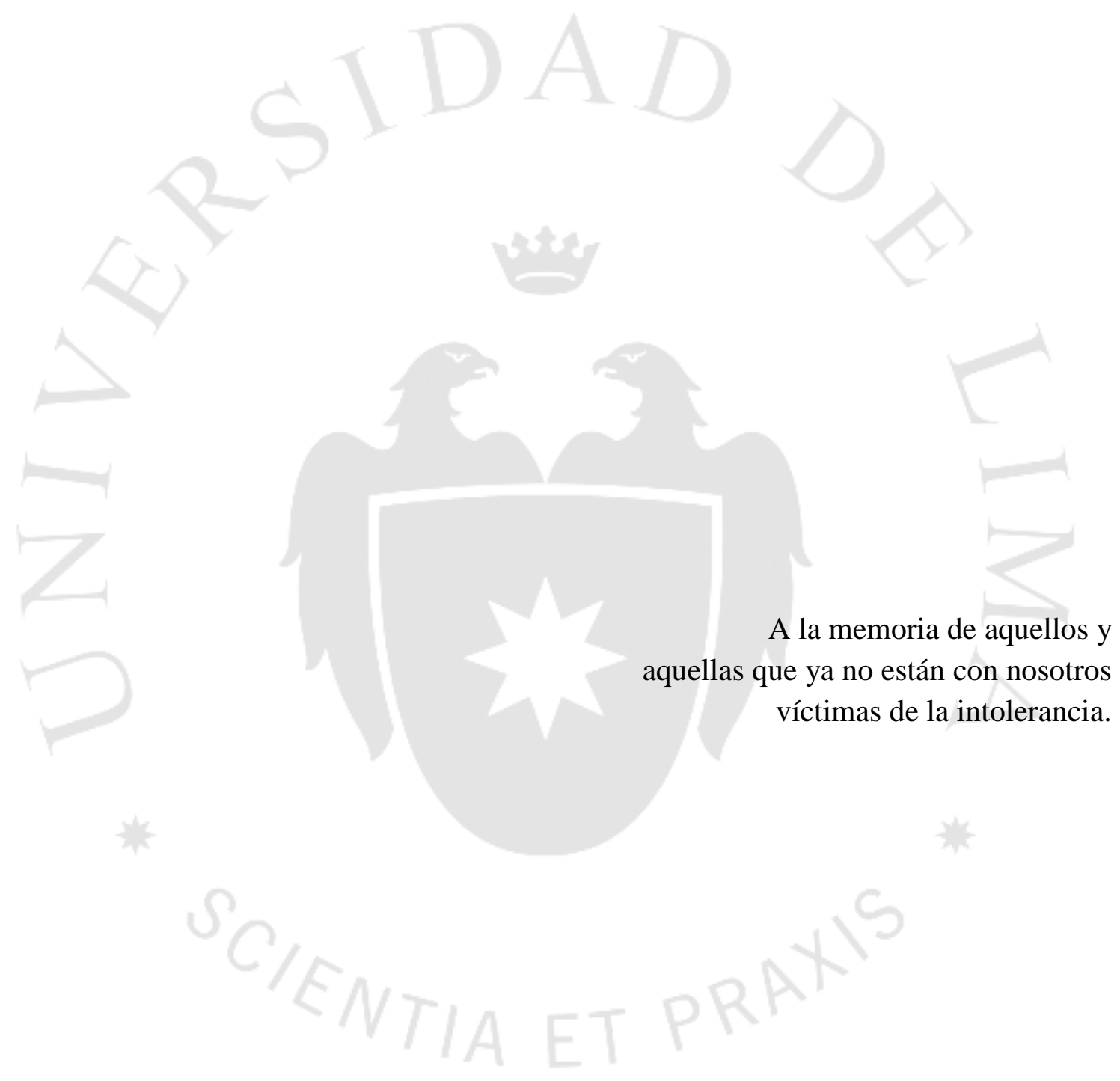




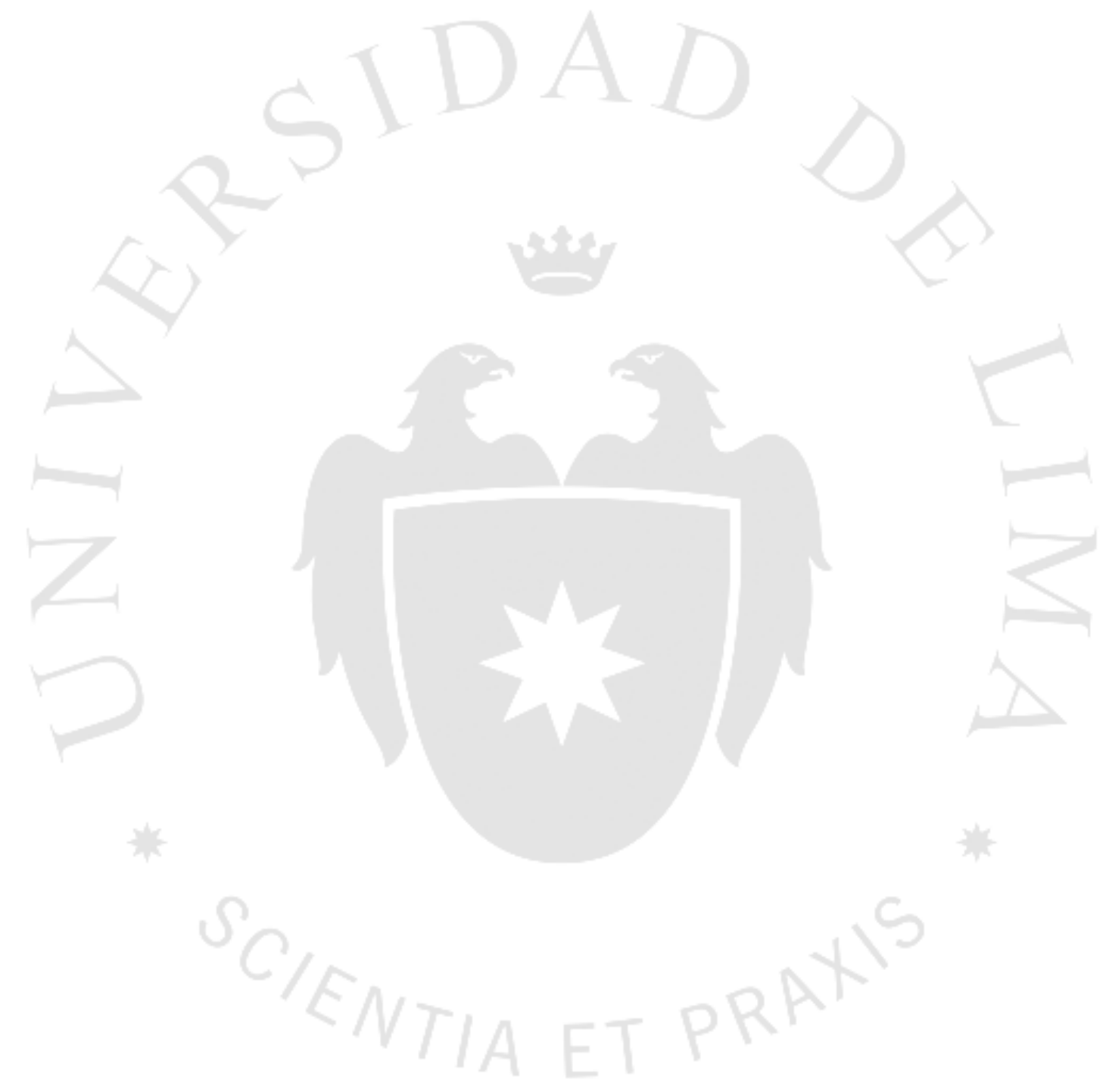




\section{AGRADECIMIENTOS}

La adaptación de la Escala de Identidad de Orientación Sexual (LGBIS) propuesta por Mohr y Kendra (2011) para la presente investigación no hubiera sido posible sin el apoyo de diferentes actores que contribuyeron durante el proceso.

Quisiera agradecer a Jonathan Mohr por haberme concedido la autorización para adaptar la LGBIS y a la vez por su disposición para compartir material bibliográfico actual y relevante para esta tesis. También a Edwin Salas por su apoyo en la etapa inicial de este proyecto. A Irma Altez, con quien pudimos profundizar y organizar gran parte del marco teórico. A Ricardo Braun por su paciencia, disposición y buen humor para reunirse innumerables veces conmigo para concretar la versión final en español de la LGBIS. A Liz Pajares, con quien tuve la oportunidad de trabajar el proceso de adaptación lingüística, estudio piloto y análisis psicométrico preliminar; y quien además estuvo siempre muy pendiente de mis avances hasta el final. A cada uno de los jueces expertos que participaron tanto en el proceso de adaptación lingüística como también en el proceso de obtención de evidencias de validez vinculadas al contenido.

A cada uno de los participantes de este estudio que motivados por su lucha y desafíos asumidos día a día, me dieron diez minutos de su tiempo. Ustedes han sido el motor de esta investigación.

Un agradecimiento especial a Miguel Escurra; mi asesor, por haberme guiado y apoyado con los aspectos psicométricos de este trabajo; estando siempre muy pendiente de mis avances y brindándome información invaluable. Además, debo agradecerle por haber tenido la capacidad de contener mis preocupaciones y angustias en la etapa final de este proceso.

Además, le agradezco a Andrés Burga y Sandra Inurritegui, por sus oportunas sugerencias y correcciones en la etapa final.

A mis amigos Álvaro Chang y Víctor Talavera quienes me brindaron su apoyo desinteresado en la etapa final de esta tesis con sugerencias sumamente valiosas.

A mis amigas Sylvia Rivera, María Luisa Miró Quesada, Catalina Saba e Isabel Crespo quienes estuvieron muy de cerca durante todo este largo proceso y quienes fueron una fuente incuantificable de soporte emocional en aquellos momentos en los que el agotamiento y frustración me invadían. 
Finalmente, quisiera agradecer en particular a: Daniel; mi abuelo, por haber cultivado en mí el amor por la lectura y por la psicología. A Elsita; mi mamá, por su abnegada dedicación y esfuerzo por sacarnos adelante y ofrecernos diversas oportunidades académicas para nuestro desarrollo. Pero sobre todo por ayudarnos a convertirnos en seres humanos capaces de entender, amar y respetar la diversidad de la vida. A Darren, mi compañero de vida, por su paciencia y soporte incondicional. A Rolando; mi hermano, quien durante las últimas semanas se desveló conmigo acompañándome, cantando "Walking on a dream" y apoyándome con correcciones de redacción. Y finalmente a Nerón, quien me acompañó al pie de la mesa y me mantuvo despierta gracias a sus eventuales ladridos.

A todos y todas ustedes les estaré siempre muy agradecida. 


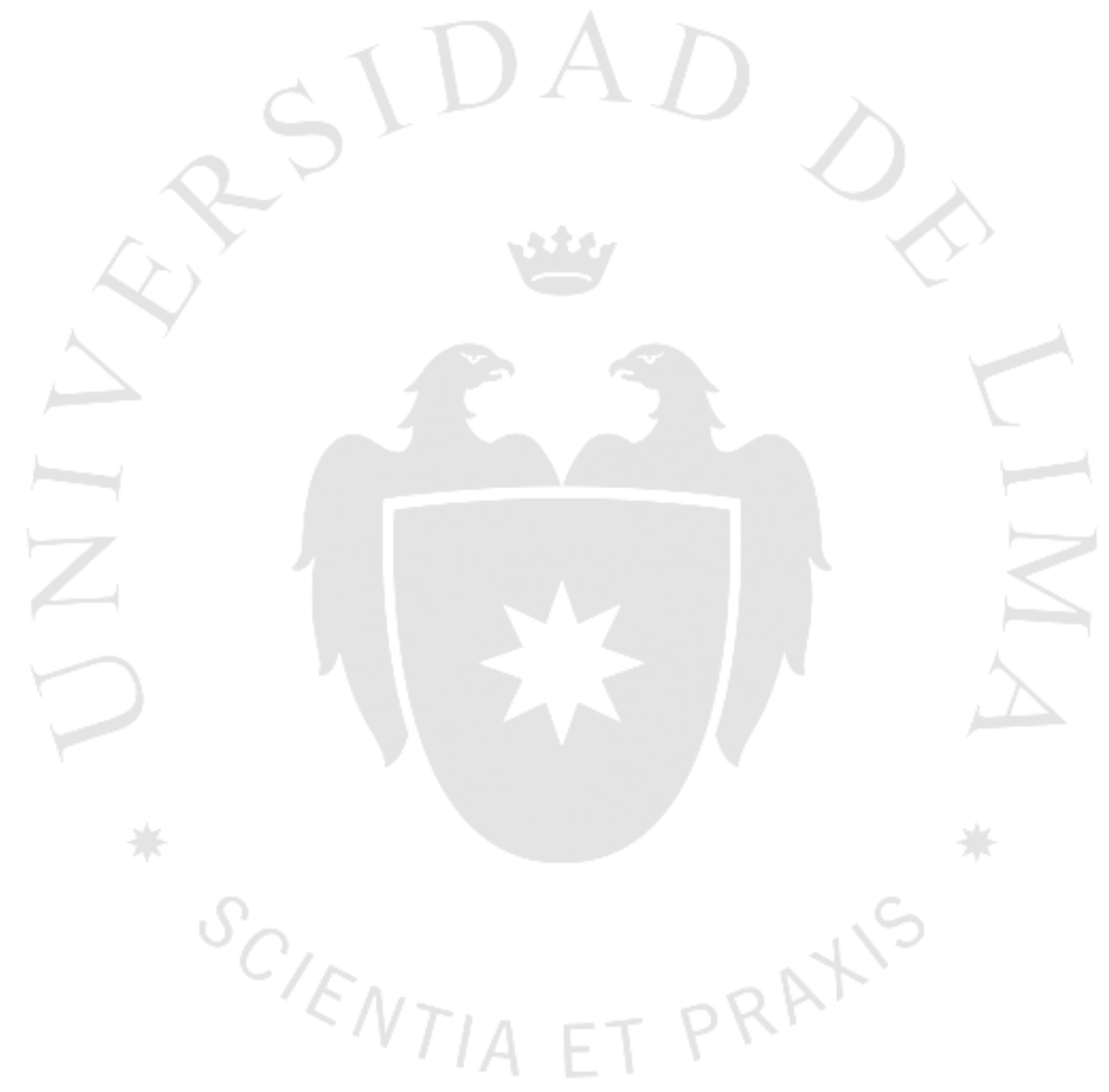




\section{ADAPTACIÓN DE LA ESCALA DE IDENTIDAD PARA LESBIANAS, GAYS Y BISEXUALES (LGBIS) EN UN GRUPO DE LESBIANAS, GAYS Y BISEXUALES DEL PERÚ}




\section{TABLA DE CONTENIDO}

CAPÍTULO I: PLANTEAMIENTO DEL PROBLEMA........................................... 14

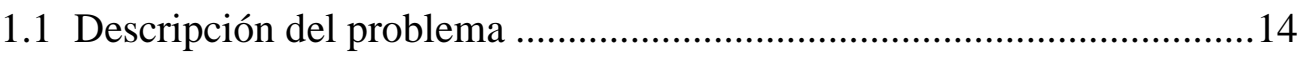

1.2 Justificación y relevancia ..................................................................... 17

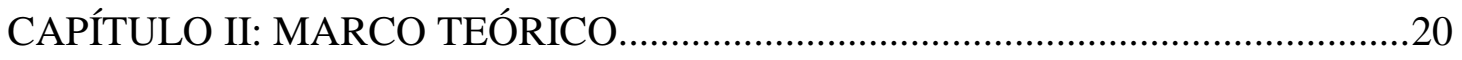

2.1 La Orientación Sexual y la Identidad de Otientación sexual ..................20

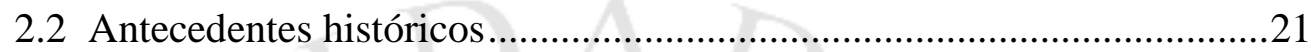

2.3 Enfoque actual del tema y Psicología LGBT ........................................22

2.4 Modelos teóricos de la Identidad de Orientación sexual ......................23

2.4.1 Modelos Lineales de la Identidad de Orientación Sexual ..............24

2.4.2 Modelos dimensionales de la Identidad de Orientación Sexual...28

2.5 Investgaciones previas sobre la Identidad de Orientación sexual............34

CAPÍTULO III: OBJETIVOS, HIPÓTESIS Y DEFINICIÓN DE VARIABLES .......39

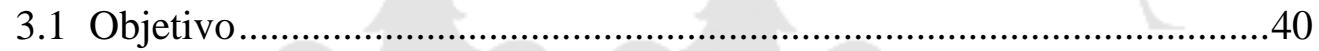

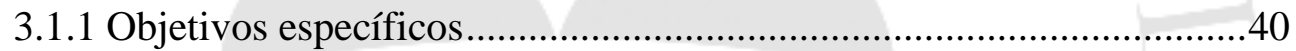

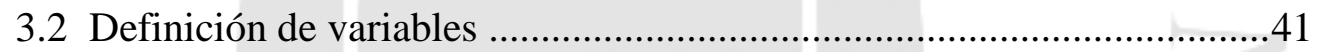

3.2.1 Definición conceptual de Identidad de Orientación sexual y

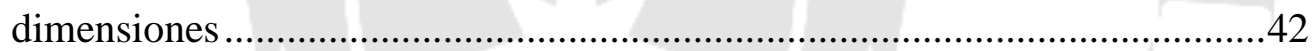

3.2.2 Definición operacional de Identidad de Orientación sexual ...............42

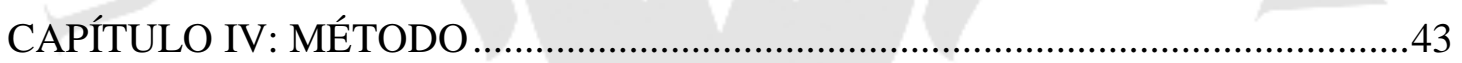

4.1 Tipo y diseño de investigación...........................................................43

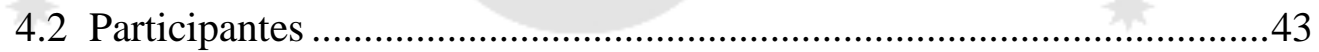

4.3 Técnicas de recolección de datos ........................................................45

4.3.1 Escala de Identidad para Lesbianas, Gays y Bisexuales (LGBIS) ......45

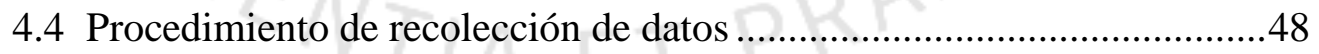

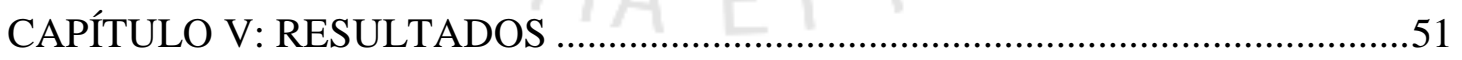

5.1 Adaptación de la LGBIS .......................................................................53

5.2 Evidencias de validez vinculadas al contenido .....................................53

5.3 Evidencias de validez vinculadas a la estructura interna .......................55

5.4 Estimación de la confiabilidad en función de las puntuaciones

obtenidas de la aplicación de los ítems que conforman la LGBIS .59 
5.5 Análisis de discriminación ítem-test .................................................60

5.6 Elaboración de Baremos ........................................................................61

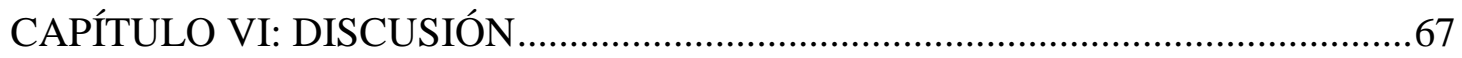

6.1 Proceso de adaptación y propiedades psicométricas.............................67

6.2 Estándares para la Evaluación Educativa y Psicológica (AERA, APA y

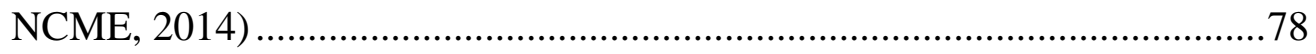

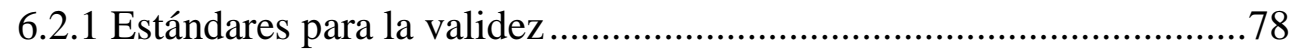

6.2.2 Estándares para la confiabilidad..................................81

6.2.3 Estándares para el diseño y desarrollo de una prueba.........................82

6.2.4 Estándares para la elaboración de normas ........................................85

6.2.5 Estándares para la administración, puntuación, reporte e

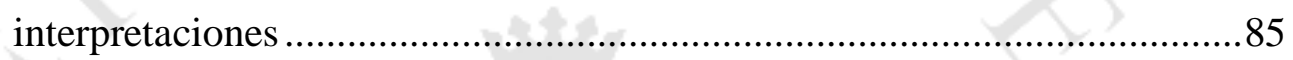

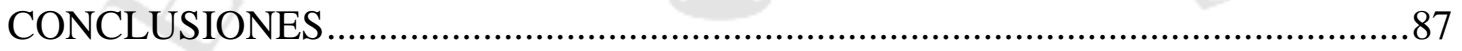

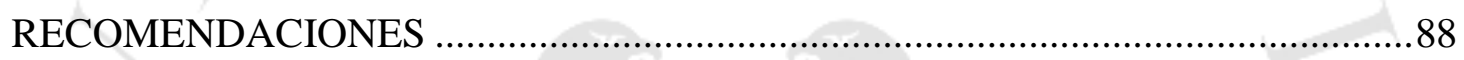

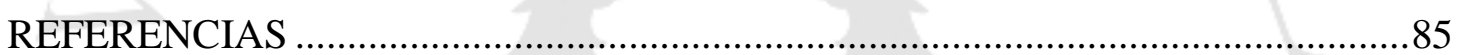




\section{ÍNDICE DE TABLAS}

Tabla 4.1. Dimensiones y respectivos ítems de la LGBIS .46

Tabla 5.1. Coeficiente V de Aiken para los ítems de la LGBIS

Tabla 5.2. Resultados del método de Hull para determinar el número de factores,

primer análisis. 56

Tabla 5.3. Carga factorial de los ítems de la LGBIS, primer análisis factorial

Tabla 5.4. Resultados del método de Hull para determinar el número de factores, segundo análisis

Tabla 5.5. Carga factorial de los ítems de la LGBIS, segundo análisis factorial 58

Tabla 5.6. Alfa de Cronbach, Alfa ordinal y EEM para las puntuaciones derivadas de los factores para toda la muestra

Tabla 5.7. Alfa de Cronbach, alfa ordinal y EMM para las puntuaciones derivadas de los factores según orientación sexual .... 60

Tabla 5.8. Correlación ítem-test de la EDOS-LGB 61

Tabla 5.9 Estadísticos descriptivos y prueba Shapiro-Wilk de bondad de ajuste a la curva normal según orientación sexual para los factores 1 y 2 ..................62

Tabla 5.10 Comparacón de los factores según orientación sexual ....................62

Tabla 5.11 Comparacón de pares según orientación sexual

Tabla 5.12. Percentiles para las puntuaciones obtenidas en el factor 1 y el factor 2 según la oritentación sexual .64

Tabla 5.13 Estadísticos descriptivos y prueba Shapiro-Wilk de bondad de ajuste a la curva normal según activismo para el factores 1 y factor 2 .......................65

Tabla 5.14 Comparacón de pares según activismo .65

Tabla 5.15. Percentiles para las puntuaciones obtenidas en el factor 1 y el factor 2 según activismo 66 


\section{ÍNDICE DE ANEXOS}

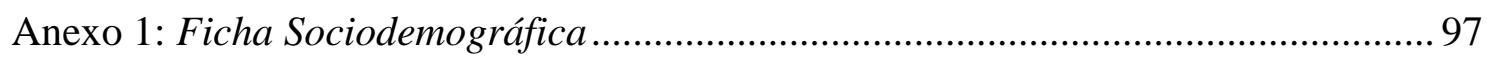

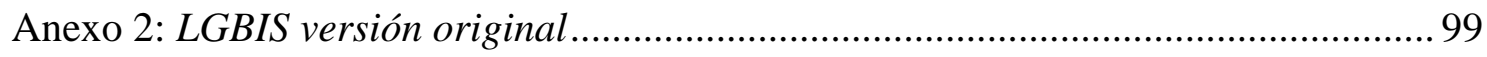

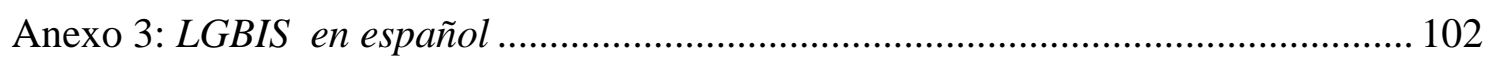

Anexo 4: Ficha Técnica y Propuesta de Prueba EDOS-LGB ..................................... 106

Anexo 5: Criterio de Jueces Comité Multidisciplinario .............................................. 109

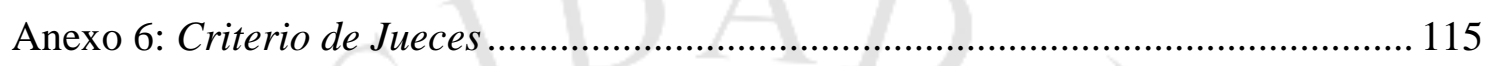

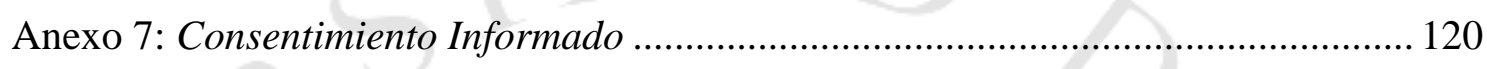




\section{RESUMEN}

La identidad de orientación sexual hace referencia a las formas tanto privadas como públicas de la auto-identificación a nivel de orientación sexual y es considerada como elemento multidimensional y central en la identidad de las personas. En este sentido, influye directamente en la toma de decisiones tanto en el ámbito personal como interpersonal. Sin embargo en el Perú no existe ninguna escala que evalué este constructo en personas lesbianas, gays y bisexuales (LGB). Por lo tanto la presente investigación tuvo como objetivo adaptar y estimar las propiedades psicométricas de la Escala de Identidad de Orientación Sexual (LGBIS) propuesta por Mohr y Kendra (2011) en una muestra de 378 personas LGB peruanas. En primer lugar se llevó a cabo la adaptación lingüística de la escala. Posteriormente, por medio del criterio de 6 jueces se hallaron evidencias de validez vinculadas al contenido. Además en relación a las evidencias de validez vinculadas a la estructura interna, se encontró un modelo multidimensional de dos factores o dimensiones diferentes a la propuesta de los autores. Las dos dimensiones encontradas fueron: Incertidumbre y preocupación por la aceptación $(\alpha$ ordinal $=.88, \mathrm{EEM}=3.29)$ e integración de la identidad $(\alpha$ ordinal $=.91$, $E E M=1.86$ ).En función a la nueva estructura hallada, se propuso La escala de Dimensiones de Identidad de Orientación Sexual (EDOS-LGB). Finalmente, a partir de estos resultados se puede concluir que las interpretaciones de las puntuaciones obtenidas mediante la adaptación de la EDOS-LGB presentan evidencias de validez y confiabilidad en personas lesbianas, gays y bisexuales del Perú.

Palabras clave: Lesbianas, gays, bisexuales, identidad de orientación sexual, multidimensionalidad, LGBIS, adaptación, evidencias de validez, confiabilidad, EDOSLGB. 


\begin{abstract}
Sexual orientation identity involves private and public ways of self-identification therefore it is considered as a key multidimensional element in the identity of people. Moreover, it has direct influence in making decisions in the personal and interpersonal sphere. Nevertheless, in Peru there is no scale that evaluates this construct in lesbian, gay and bisexual (LGB) people. Therefore, this research aimed to adapt and assess the psychometric properties of the Lesbian, Gay and Bisexual Identity Scale (LGBIS) proposed by Mohr and Kendra (2011) on a sample of 378 LGB Peruvian people. First of all, a linguistic adaptation of the scale was done. Later, appropriate validity evidence based on test content was assessed by 6 experts in the topic. Validity evidence based on internal structure was estimated by an exploratory factor analysis which showed a multidimensional solution of two factors. Consequently, this structure differed from the original version. The two dimensions were identified as: uncertainty and acceptance concerns (ordinal $\alpha=.88, \mathrm{EEM}=3.29$ ) and identity integration (ordinal $\alpha=.91 \mathrm{EEM}=$ 1.86), According to these results, a new scale was proposed: "The Lesbian, gay and bisexual dimensions of Sexual Orientation Identity Scale” (EDOS-LGB). In conclusion, results showed that interpretations based on the scores obtained by adapting the EDOSLGB presents validity and reliability evidence in lesbian, gay and bisexual people from Perú.
\end{abstract}

Keywords: Lesbian, gay, bisexual, sexual orientation identity, multidimensionality, LGBIS, adaptation, validity evidence, reliability, EDOS-LGB. 


\section{CAPÍTULO I: PLANTEAMIENTO DEL PROBLEMA}

\subsection{Descripción del problema}

A pesar que en la actualidad en nuestro medio se observa una mayor visibilidad de las personas lesbianas, gays y bisexuales (LGB), la mayoría de personas de estas minorías sexuales se desarrollan y se desenvuelven en un contexto social y cultural donde prevalece la estigmatización y en donde, a su vez, predomina una visión de la orientación sexual basada en la heterosexualidad como norma.

Según el "Informe anual sobre derechos humanos de las personas trans, lesbianas, gays y bisexuales (TLGB)" llevado a cabo por el Centro de Promoción y Defensa de los Derechos Sexuales y Reproductivos (PROMSEX), las personas TLGB continúan siendo víctimas de discriminación y violencia tanto física como psicológica en nuestro país. De la misma forma, a pesar de las diferentes recomendaciones realizadas por diferentes organismos internacionales, el Estado Peruano muestra oposición para incorporar alternativas de solución que tengan como principal objetivo elevar el estándar de protección de las personas TLGB (PROMSEX, 2014). Por otro lado, nuestro país no cuenta con una Plan Nacional de Derechos Humanos que dentro de sus políticas considere indicadores y metas que salvaguarden que los derechos de las personas TLGB sean garantizados y respetados (PROMSEX, 2012). Estos datos confirman la existencia de un entorno donde se encuentra instaurada la falta de reconocimiento, intolerancia, prejuicios, estigma y rechazo hacia las personas TLGB pues se considera que no es normal y por ende no es aceptable tener una orientación sexual diferente a la heterosexual. Al respecto Herek (1988) plantea que una de las causas principales de este fenómeno de rechazo e incluso odio; es que la atracción hacia personas del mismo sexo y las posibles relaciones sentimentales que se pueden establecer son marginalizadas en la mayoría de las culturas occidentales. Siendo esta una realidad también presente en nuestro país. 
Entonces, ¿cuáles serían las consecuencias de vivir en una sociedad como la nuestra con marcadas actitudes homofóbicas, lesfóbicas y bifóbicas? Para Herek (1988), las actitudes homofóbicas influyen en la formación de un ambiente sociocultural en donde predomina el rechazo y la discriminación hacia estas minorías sexuales. Por lo tanto, este grupo minoritario tiene que enfrentarse y adaptarse a este status estigmatizador; mientras que a la par tratan de desarrollar una identidad positiva de ellos mismo. Si de por sí, el desarrollo de la identidad de cada personas es una tarea bastante difícil, evidentemente este proceso se hace más complejo y con mayores retos en las personas LGB.

En el Perú se evidencia interés por parte de algunas instituciones nacionales e internacionales por promover propuestas en temas de derechos humanos, salud, sexualidad y derechos legales en la población LGB. Por ejemplo cada año PROMSEX en cooperación con la Red Peruana TLGB y otras entidades realizan el "Informe anual sobre derechos humanos de personas trans, lesbianas, gays y bisexuales" en donde se reporta las dificultades de esta población, muertes y asesinatos por cuestiones de discriminación y estigma, como además las medidas que podrían considerarse para lograr alcanzar mejoras a nivel de políticas públicas y legislaciones siguiendo las recomendaciones de la Corte Interamericana de Derechos Humanos (CIDH) y la Organización de Estados Americanos (OEA). Asimismo, existen otras iniciativas como el Observatorio de Derechos Humanos LGBT y VIH/SIDA del Instituto de Estudios de Salud, Sexualidad y Desarrollo Humano (IESSDEH) que busca informar sobre casos de vulneración. Por otro lado, a nivel legal entre el año 2013 y 2014 se presentó el proyecto de ley $\mathrm{N}^{\mathrm{o}}$ 2647/2013 Unión Civil No Matrimonial para Personas del Mismo Sexo. Igualmente, a nivel político la organización política Frente Amplio ha sido la única organización que ha incluido explícitamente a la orientación sexual como causal prohibida de discriminación (PROMSEX, 2014). Sin embargo, se observa poca iniciativa por llevar a cabo investigaciones que tengan como principal objetivo alcanzar un mejor conocimiento de las características 
psicológicas propias de las personas LGB. Evidenciándose también un escaso interés por la creación y adaptación de instrumentos psicométricos específicos para este grupo minoritario.

Es así, que de la gama de instrumentos en otros idiomas específicos para acceder a información sobre la identidad de orientación sexual de las personas LGB; destacamos el instrumento: The Lesbian, Gay, and Bisexual Identity Scale (LGBIS), elaborado por Mohr y Kendra (2011). Se decide seleccionar este instrumento para la presente investigación en ventaja a otros instrumentos similares pues la LGBIS se encuentra diseñada para poder ser utilizada en la población LGB, a diferencia de otras escalas que solo son diseñadas para hombres gays o mujeres lesbianas. Por otro lado, la LGBIS tiene como soporte teórico una conceptualización multidimensional de la identidad de orientación sexual. Esta conceptualización busca centrarse en diferentes aspectos de la identidad de orientación sexual y no en etapas estáticas obligatorias por las cuales toda persona LGB debería atravesar. Así, al adaptar dicha escala al contexto peruano se podría contar con un instrumento de gran utilidad para la población LGB.

Por lo tanto, la presente investigación buscará responder las siguientes preguntas de investigación:

¿Cuáles son las evidencias de validez que soportan las inferencias y usos de la Escala de Identidad para Lesbianas, Gays y Bisexuales (LGBIS) en una muestra de personas LGB que se encuentran en el rango de edades de 18 años y 45 años?

¿Cuáles son las evidencias de confiabilidad que soportan las inferencias y usos de la Escala de Identidad para Lesbianas, Gays y Bisexuales (LGBIS) en una muestra de personas LGB que se encuentran en el rango de edades de 18 años y 45 años? 


\subsection{Justificación y relevancia}

Haciendo uso de términos claves como "identidad de orientación sexual" se llevó a cabo una búsqueda en bases de datos tales como: Dialnet, EBSCOhost, APA PsycNET, ProQuest y ebrary para indagar si existían investigaciones previas relacionadas a ese constructo llevadas a cabo en el Perú. La ausencia de resultados al respecto es una evidencia que en nuestro país no existe ningún instrumento que mida aspectos de la identidad de orientación sexual a nivel multidimensional ni tampoco constructos similares.

Por lo tanto, se considera relevante y necesaria la adaptación del instrumento "The Lesbian, Gay and Bisexual Identity Scale" (LGBIS) conjuntamente con el análisis de sus propiedades psicométricas obtenidas a partir de las puntaciones alcanzadas después de su aplicación.

En el campo científico, el trabajo de adaptación de instrumentos psicométricos es una tarea de suma importancia que nos permite elaborar nuevas herramientas teniendo en consideración las características particulares del grupo de personas y contexto socio cultural para los cuales se pretende adaptar el instrumento.

Igualmente, adaptar dicho instrumento para la comunidad peruana LGB sería un gran aporte pues permitiría llevar a cabo futuras investigaciones correlacionales entre las diferentes dimensiones de la identidad y otros constructos psicológicos tales como auto-aceptación, estrés minoritario, bienestar psicológicos, entre otros. En esta misma línea, llevar a cabo investigaciones de este tipo son sumamente relevantes pues brindan diversos hallazgos que permiten ampliar el campo de estudio de la psicología LGBTQ desde un enfoque afirmativo teniendo en consideración diversos contextos sociales (Clarke, Ellis, Peel y Riggs, 2010). Al respecto cabe señalar que la mayor cantidad de antecedentes y trabajos en población LGB son de origen estadounidense y europeo, por lo cual estudios como la presente investigación permite ampliar el campo de la psicología LGB en nuestro país. 
Además la ventaja de este instrumento multidimensional es la conceptualización de aspectos de la identidad de las personas LGB desde una perspectiva de auto identificación destacando aspectos privados; pero a la vez considerando elementos de identificación colectiva teniendo en cuenta lo público. Es así que se puede acceder a diferentes facetas de las vidas de las personas LGB a nivel de creencias, pensamientos y acciones teniendo en cuenta su estatus minoritario.

En el ámbito de la práctica clínica; la adaptación del presente instrumento es relevante ya que ofrece la oportunidad de contar con una herramienta adaptada al idioma español y a la población LGB peruana que permite conocer más de cerca las características presentes a lo largo del desarrollo de la identidad de orientación sexual LGB. Consecuentemente, este instrumento facilitara el planteamiento de una intervención apropiada desde un enfoque psicológico afirmativo con un marco de trabajo que involucre los siguientes aspectos: a) Aceptación y apoyo incondicional a los pacientes siendo empáticos y promoviendo un auto-concepto positivo de ellos mismos. b) Llevar a cabo evaluaciones comprensivas que tengan en consideración la individualidad personal, histórica, social y contextual de cada persona. Explorar el impacto negativo que tiene el estigma, discriminación y prejuicios en el auto-concepto. c) Promover estrategias de afrontamiento efectivas tanto a nivel cognitivo, emocional y conductual para fomentar el bienestar y aceptación de acuerdo a los objetivos propios de cada paciente (Glassgold et al., 2009). En este sentido se descarta y rechaza todo tipo de intervención y aproximación de tipo conversiva que conceptualice la homosexualidad como un desorden o psicopatología ya que va en contra del "Reporte de la Sociedad Americana de Psicología respecto a las Respuestas Terapéuticas Apropiadas a la Orientación Sexual" (Glassgold et al., 2009). Además, diversas investigaciones muestran que intervenciones de este tipo generan daño, incrementan la internalización del estigma y además limitan el desarrollo de las personas (Shidlo y Schroeder, 2002). 
Es a partir de todos estos puntos señalados que se destaca la utilidad del instrumento y del proceso de adaptación en la presente investigación. 


\section{CAPÍTULO II: MARCO TEÓRICO}

\subsection{La orientación sexual y la identidad de orientación sexual}

Dada a la complejidad conceptual del tema, en algunas investigaciones se observa una ausencia de diferenciación entre los constructos identidad sexual, identidad de orientación sexual y orientación sexual, por lo cual es frecuente que suelan confundirse y utilizarse indistintamente entre sí a pesar de ser constructos diferentes. A continuación se definirá conceptualmente la orientación sexual e identidad de orientación sexual pues la comprensión y diferenciación de ambos constructos son claves para la presente investigación.

La orientación sexual hace referencia a los patrones sexuales, románticos y afectivos de excitación y deseo basado en el género o características de sexo de una persona. Asimismo, se considera que la orientación sexual es una tendencia estable que se encuentra ligada a impulsos fisiológicos y sistemas biológicos que van más allá de una elección consciente. De la misma forma, se le relaciona con sentimientos emocionales profundos (Glassgold et al, 2009). Por otro lado, la identidad de orientación sexual hace referencia a la auto-exploración, autoconocimiento, auto-reconocimiento, pertenencia y afiliación grupal y a la cultura LGB. Asimismo, implica las formas privadas y públicas de la auto-identificación y es considerada como el elemento central para tomar decisiones tanto en el ámbito relacional e interpersonal a nivel de modelos de roles, amistades y parejas (Glassgold et al., 2009).

En este sentido se puede señalar que ambos constructos más que excluyentes, son complementarios pues la identidad de orientación sexual hace referencia a cómo la orientación sexual es vivenciada y expresada en los diferentes ámbitos de la vida personal. 


\subsection{Antecedentes históricos}

Las primeras conceptualizaciones de la homosexualidad se caracterizaron por un enfoque médico, el cual la consideraba como una desviación y enfermedad mental (Clarke et al., 2010). Así, en el año 1952 la Sociedad Americana de Psiquiatría decide incluir la homosexualidad en la segunda versión del Manual Diagnóstico y Estadístico de los Trastornos Mentales (DSM-II). Por esta razón, la mayoría de estudios e investigaciones de la época se enfocaron en tres preguntas fundamentales: ¿La Homosexualidad es una enfermedad?, ¿Cómo puede ser diagnosticada la homosexualidad? y ¿Cuáles son las causas de la homosexualidad? Asimismo, las terapias psicológicas estaban centradas en lograr la conversión de la población LGB a la heterosexualidad y además se utilizaban diferentes terapias conductuales de aversión, uso de hormonas, castración, clitoridectomía e incluso lobotomías (Clarke et al., 2010) con la finalidad de curar dicha supuesta desviación.

No obstante, esta postura de la homosexualidad fue confrontada por diversas investigaciones (Hooker, 1975; Hopkins, 1969; Thompson, McCandless y Strickland, 1971; Siegelman, 1972) las cuales demostraron que dichas conceptualizaciones patologizantes eran erradas pues hallaron que no existían diferencias significativas entre el ajuste psicológico de las personas homosexuales y heterosexuales.

Con el incremento de estudios similares y esfuerzos de movimientos activistas de la época, en el año 1973 la Asociación Americana de Psiquiatría retira la homosexualidad del DSM II. Posteriormente, la Asociación Americana de Psicología recomienda a todos los profesionales de la salud mental renunciar a prejuicios homofóbicos y conceptualizaciones de la homosexualidad como enfermedad y por el contrario garantizar el bienestar de la población LGB promoviendo ambientes libres de violencia y discriminación (Conger, 1975). Finalmente, en el año 1990 la Organización Mundial de la Salud (OMS) excluyó la homosexualidad de la Clasificación Estadística Internacional de Enfermedades y otros Problemas de Salud. 
A partir de estos eventos es que se va forjando un nuevo campo de estudio en la psicología; con la finalidad de poder entender y describir el comportamiento de la población LGB. Es así que en los últimos 30 años los enfoques sobre la homosexualidad y bisexualidad han ido evolucionando, permitiendo el surgimiento de innumerables estudios basándose en una perspectiva afirmativa.

\subsection{Enfoque Actual del tema y Psicología LGBT}

A pesar que pocos psicólogos se atreverían a catalogar la homosexualidad o bisexualidad como una enfermedad; aún prevalece ciertas presunciones hetero-sexistas en las teorías y modelos psicológicos (Clarke et al., 2010). Por lo tanto, en la actualidad la tendencia de la mayoría de estudios psicológicos con personas de diversas orientaciones e identidades sexuales tiene un enfoque que cuestiona y reta el privilegio que se le otorga a las conceptualizaciones heterosexitas y heteronormativas dentro de la psicología y en nuestra sociedad. Asimismo busca legitimar y promover un campo de estudio e investigación con personas LGBTQ (lesbianas, gays, bisexuales, transexuales y queer) promoviendo enfoques inclusivos dentro de la práctica y la investigación (Clarke et al., 2010).

A nivel de la práctica psicológica, específicamente en el ámbito clínico, surge la psicoterapia afirmativa. En el año 1997 la Asociación Americana de Psicología pública "La Resolución de Respuestas Terapéuticas Apropiadas hacia Orientación Sexual", la cual es revisada posteriormente en el año 2009. En este documento se postula que la psicoterapia afirmativa tiene un enfoque de trabajo con las minorías sexuales, teniendo como base conocimiento científico en cuatro puntos de análisis principales (Glassgold et al., 2009):

a) Tal y como señala Patterson (como se citó en Glassgold et al., 2009) la homosexualidad y la bisexualidad son estigmatizadas y este estigma es 
el que genera una variedad de consecuencias negativas en las personas LGB a lo largo de sus vidas.

b) La atracción sexual, comportamientos y la orientación sexual hacia personas del mismo sexo son variantes normales y positivas de la sexualidad humana y no son indicadores de desórdenes mentales o de desarrollo.

c) Los comportamientos y atracción sexual hacia personas del mismo sexo pueden presentarse dentro de un contexto de gran variedad de identidades de orientación sexual.

d) Las personas lesbianas, gays y bisexuales se encuentran en la capacidad de vivir vidas satisfechas, formar relaciones estables, comprometerse en relaciones sentimentales y familias; las cuales son equivalentes a las relaciones y a las familias heterosexuales en los aspectos esenciales.

En este sentido, si bien el enfoque afirmativo es complejo y abarca diferentes aspectos de la vida de las personas LGB un objetivo central es promover el desarrollo positivo de sus identidades y además ofrecerles espacios inclusivos donde cada persona tenga la posibilidad de decidir su propio proceso de desarrollo de identidad, la forma comportamental en la que quieren expresar su orientación sexual, los roles privados y públicos que quieren desempeñar, identidad y expresión de género, el sexo y el género de sus parejas y las características de sus relaciones (Glassgold et al., 2009). Por lo tanto, no es en vano que uno de los temas más trabajados por esta rama de la psicología sean los aspectos vinculados al desarrollo de la identidad de orientación sexual en las personas LGB.

\subsection{Modelos Teóricos de la Identidad de Orientación Sexual}

Para poder describir la identidad de orientación sexual LGB surgen diversas perspectivas y modelos teóricos que buscan detallar y explicar su desarrollo y la vez las diversas dimensiones involucradas a lo largo de la vida de las personas LGB. Este interés y preocupación por el desarrollo de 
modelos teóricos sobre la identidad de orientación sexual de las personas LGB se hace evidente por diversos investigadores pues se cuestionaban cómo las personas LGB desarrollaban una identidad de orientación sexual positiva de ellos mismos a pesar de las diversas dificultades y obstáculos a nivel social que se les podría presentar por pertenecer a un grupo minoritario en una sociedad predominantemente heterosexual.

\subsubsection{Modelos Lineales de la Identidad de Orientación Sexual}

Uno de los primeros modelos de desarrollo de la identidad homosexual, fue el modelo propuesto por Vivian Cass en el año 1979. Este modelo probablemente sea uno de los modelos más populares y a su vez el más citado ya que ha servido como base conceptual para otras propuestas que respaldan un enfoque del desarrollo de la identidad homosexual a través de una serie de etapas consecutivas a lo largo de la vida de las personas LGB (Clarke et al., 2010).

El Modelo de Cass estableció seis etapas de desarrollo de la identidad gay por las cuales la mayoría de individuos atravesaría para poder adquirir una "identidad gay" totalmente integrada al auto concepto. Para Cass (1979) lograr este desarrollo de identidad en las personas gay implicaría un complicado proceso cognitivo, el cual a su vez involucra una sensación de incongruencia que conllevan a que la persona piense críticamente sobre sus sentimientos, pensamientos y comportamientos. En este modelo, la incongruencia percibida tiene que ver con la orientación sexual de la persona, la cual no corresponde o encaja con los mensajes heterosexistas que la persona recibe de su ambiente cercano. Al respecto, se proponen seis etapas predominantes: La primera etapa de este modelo se denomina la etapa de la confusión de identidad la cual ocurre cuando la persona cuestiona su heterosexualidad, atravesando así tensión emocional que puede ser experimentada en forma de incertidumbre, desconcierto y ansiedad. La segunda etapa se denomina la etapa de la comparación de la identidad, ya que la persona se compara a sí mismo con el grupo 
heterosexual porque se siente diferente y a su vez marginado. La tercera etapa la denomina etapa de la tolerancia a la identidad; ya que la persona tolera su propia homosexualidad y busca a otras personas que compartan sus mismos intereses y gustos para así tener un grupo de soporte social cercano el cual influirá en la posterior auto afirmación, autoestima y las habilidades sociales de la persona y facilitara su paso a la siguiente fase. La cuarta etapa es la etapa de la aceptación de identidad, pues a persona se acepta a sí misma. La quinta etapa es la etapa de orgullo de identidad, ya que la persona es participe activo de la cultura homosexual y se siente satisfecho con ello. Y finalmente, la última etapa es denominada síntesis de identidad, que es la fase en la que la persona logra la integración de la homosexualidad como un elemento de sí mismo (Cass, 1979).

Posteriormente, siguiendo este mismo enfoque de desarrollo lineal surgen diversos modelos de etapas, entre los cuales se encuentran los modelos de Troiden (1979), Coleman (1982), Sophie (1987), D’Augelli (1994), entre otros (McCarn y Fassinger 1996). Se debe mencionar que la mayoría de los modelos lineales mencionados con anterioridad se basaban en la construcción de la identidad en función a la sexualidad de cada persona. Pero muy pocos de ellos tratan de integrar el desarrollo de la identidad teniendo en consideración también la pertenencia a un grupo de referencia.

Al respecto, McCarn y Fassinger (1996) plantean un modelo de fases. Esta conceptualización de fases busca evitar darle una connotación de rigidez al proceso de desarrollo de la identidad de orientación sexual. A su vez plantea dos vías de desarrollo: Una primera vía que involucra el incremento positivo de la identificación con uno mismo respecto a su sexualidad y una segunda vía de desarrollo que involucra la identificación con su grupo de referencia (grupo minoritario LGB). Este modelo difiere de otros modelos de identidad ya que se distingue la identidad sexual individual y la identidad de pertenencia a un grupo. Al respecto se argumenta que 
estos dos procesos se desarrollan recíprocamente pero no de manera simultánea.

En relación a esto, describe que durante el desarrollo de la identidad también se produce un cambio en las creencias y actitudes de las personas lesbianas y gays en función a dos objetivos fundamentales. Por un lado, las personas tienen que lidiar con la comprensión de la identidad sexual la cual es considerada como reprochable. Por otro lado, la persona también debe reconocer su pertenencia al grupo, y cambiar sus actitudes hacia el grupo minoritario al que pertenece. Por lo tanto, se concluye que el desarrollo de la identidad es una mezcla de auto-categorizaciones en relación a la identidad personal por un lado y por otro lado la identidad grupal en función al sentido de partencia a la comunidad LGB (McCarn y Fassinger, 1996). Los autores, a su vez, proponen cuatro fases para las dos vías de desarrollo: Reconocimiento, exploración, profundización/compromiso e internalización/síntesis.

Durante la fase de reconocimiento una mujer podría pensar, "Me siento atraído hacia las mujeres de una forma que no puedo comprender". Mientras que en la línea de pertenencia al grupo ella podría pensar," No tenía idea de que hubiera personas lesbianas. ". En la segunda fase la cual es la fase de exploración, el individuo considera sensaciones eróticas a nivel individual y posiblemente a nivel de grupo social. Un hombre gay puede decir: "Quiero estar más cerca de los hombres o de un hombre especifico". A nivel de pertenencia de grupo podría pensar: "Pienso mucho en como encajar como un hombre gay y como desarrollar mi propio estilo gay". En la tercera fase que es la fase de profundización o compromiso, el individuo se centra más en sus propios sentimientos sexuales, además hay un incremento de sentido de auto-conocimiento y la autorealización, y se involucra personalmente con su grupo de referencia. Durante esta etapa es que el individuo toma una perspectiva dicotómica en términos de la orientación sexual. Hay hombres 
homosexuales, pero también hay hombres heterosexuales. Finalmente en la última fase de internalización o síntesis, la persona comienza a integrar su orientación sexual como parte de su identidad y se asocia personas de grupos homosexuales pero también grupos heterosexuales (McCarn y Fassinger, 1996).

Al respecto, se puede señalar que los modelos lineales han sido una primera aproximación para explicar el desarrollo de la identidad sexual en las personas LGB. No obstante, a pesar de su acogida estos enfoques también han sido fuertemente criticados ya que representan lo que Cohler y Hammack (2007) denominan como la narrativa de lucha y el éxito. En los modelos lineares, lograr identificarse como lesbiana o gay es construido como normativo y en general es lo esperado o saludable al final de todo el proceso. Además, se asume que en todos los casos, la persona tiene que lidiar con el estigma social y a pesar de esto es capaz de desarrollar un sentido seguro y positivo de su propia sexualidad (Clarke et al., 2010). En este sentido, la mayoría de modelos lineares son criticados principalmente por cinco razones:

a) La sexualidad típicamente ha sido conceptualizada como una dicotomía entre heterosexualidad y homosexualidad; dejando de lado y restándole legitimidad a la noción de bisexualidad (Clarke et al., 2010).

b) No incluyen el rol que cumple los diferentes contextos sociales ni los procesos y coyunturas históricas como factores que promuevan o dificulten el desarrollo de la identidad de las personas LGB (Clarke et al., 2010).

c) Se asume que la sexualidad es innata y que mediante un proceso de introspección; la persona puede ser capaz de descubrir su "verdadera" identidad. Es así que el proceso de auto identificarse como una persona LGB se entiende como un proceso de autodescubrimiento en el cual la persona pasa de una "falsa identidad 
heterosexual" a identificarse correctamente como LGB (Clarke et al., 2010).

d) Las investigaciones más recientes sobre la diversidad de identidades de orientación sexual; critican la rigidez y unidireccionalidad de estos modelos. A pesar que el Modelo de fases McCarn y Fassinger (1996) es bidireccional y establece que se pueden presentar diferencias individuales en como los individuos atraviesan las diferentes fases de desarrollo y que incluso un individuo puede no atravesar todas las fases o puede encontrarse en diferentes fases al mismo tiempo. Los críticos destacan que en general, la estructura linear de la gran mayoría de los modelos de etapas implica que las personas pasan por una serie de fases en un determinado orden, sugiriendo que las personas que no completan dicha secuencia; fallan en completar el proceso de desarrollo de su identidad de orientación sexual (Clarke et al., 2010).

e) Estudios recientes demuestran que los comportamientos sexuales, la atracción sexual y la identidad sexual pueden ser etiquetados y expresados tanto de manera pública como privada de diferentes maneras (Glassgold et al., 2009). En relación a esto postulan el fenómeno conocido como "fluidez sexual" o "plasticidad sexual" (Clarke et al., 2010).

\subsubsection{Modelos Multidimensionales de la Identidad de Orientación Sexual}

Por lo tanto, dada la magnitud y naturaleza del constructo identidad de orientación sexual; se propone una conceptualización desde una perspectiva de la multidimensionalidad de los diferentes aspectos de la identidad de orientación sexual, pues se considera más pertinente y útil que un enfoque de etapas. Esta propuesta de dimensiones involucra diferentes sentimientos y creencias respecto a 
la propia orientación sexual, otras personas LGB y las personas con orientación sexual diferente a la LGB (Mohr y Fassinger, 2000).

Además, un enfoque multidimensional ofrece una perspectiva más completa de la identidad de orientación sexual de las personas LGB; describiendo diferentes ámbitos a lo largo de todo su proceso de desarrollo de la identidad. A su vez, el uso de este enfoque es recomendable, ya que se involucran aspectos intrapersonales, interpersonales y variables relacionadas a situaciones específicas que reconocen que las dificultades que las persona LGB pueden presentar son debido a la intolerancia social. Asimismo, a pesar que alguna de estas variables pueden ser indicadores del grado en que una persona ha logrado alcanzar una identidad LGB positiva de sí mismo, otras dimensiones no son indicadores positivos ni negativos de una identidad (Mohr y Fassinger, 2000).

En base a esta perspectiva multidimensional Mohr y Kendra (2011) recogiendo los primeros aportes de la Escala de Identidad para Lesbianas y Gays (LGIS, Mohr y Fassinger, 2000); plantean ocho dimensiones de la identidad de la orientación sexual relevantes en las personas LGB. Asimismo, estas dimensiones son la base teórica para la construcción de la LGBIS.

A continuación se detallará cada una de las dimensiones propuestas por este enfoque teórico:

La primera dimensión es la preocupación por la aceptación la cual pone en evidencia el temor que tienen las personas LGB de ser valorados y catalogados de una manera negativa por su orientación sexual. Maslow (1943) señala que la necesidad de aceptación social es una necesidad fundamental de los seres humanos, por lo cual es comprensible que las personas LGB anticipen cierto temor a no ser aceptados. Al respecto, la preocupación a ser rechazados principalmente ocurre cuando una persona siente que no cubre las expectativas y demandas del grupo externo. Por lo tanto, esta aceptación social se presenta como una dificultad en la mayoría de las 
personas LGB ya que la sociedad se encuentra dominada por una cultura heteronormativa obstaculizando la aceptación e integración de las personas no heterosexuales. Es así que en el caso de las personas LGB, se evidencia una mayor propensión o sensibilidad a sentirse estigmatizado. De la misma forma, se debe mencionar que la preocupación por la aceptación se encuentra negativamente correlacionada con la autoestima (Mohr y Fassinger, 2000). Esto sugiere que un factor de riesgo para una baja autoestima en la población LGB es la constante aflicción que experimentan por saber en qué grado su identidad de orientación sexual es aceptada por otras personas (Mohr y Fassinger, 2000). Asimismo, se postula que a mayor preocupación por la aceptación, se presenta una menor satisfacción con la vida y una menor seguridad en sí mismo. Por otro lado, se establece una correlación positiva entre esta dimensión y un funcionamiento psicológico negativo; incluyendo la depresión, culpa, miedo, hostilidad y tristeza (Mohr y Kendra, 2011).

La segunda dimensión es la motivación a la invisibilidad la cual representa el grado en que las personas LGB ocultan aspectos importantes de sí mismos. Diplacido (1998) señala que ocultar la identidad de orientación sexual puede traer beneficios aparentes para la personas pues la mantiene alejada de la discriminación y el rechazo. Al respecto, McCarn y Fassinger (1996) señalan que la tendencia a ocultar la identidad de orientación sexual en contraposición al descubrimiento de la misma es una opción más que una característica especifica de alguna etapa del desarrollo de la identidad de orientación sexual. Plantea que las diferentes realidades sociales y soporte social pueden facilitar o no esta apertura de la identidad de orientación sexual. Por otro lado Potoczniak, Aldea y DeBlaere (como se citó en Mohr y Kendra, 2011) hallaron que esta dimensión se encuentra correlacionada positivamente con ciertos rasgos de ansiedad social y con el negativismo respecto al soporte social que se puede recibir de los otros. 
La tercera dimensión es la incertidumbre de la identidad la cual en un primer momento se definió como "confusión de la identidad" en la primera versión del instrumento (LGIS). Se optó por modificar el nombre, ya que el término confusión podría ser considerado como peyorativo por algunas personas. Esta dimensión hace alusión a la inseguridad y desconcierto respecto a la orientación sexual de uno mismo (Mohr y Kendra, 2011). Para algunas personas esta incertidumbre puede referirse a dudar si son homosexuales o bisexuales; mientras que en otros casos esta disyuntiva se plantea entre la heterosexualidad y la homosexualidad (Mohr y Fassinger, 2006). Esta dimensión es relevante pues se sugiere que es un evento normativo en el desarrollo de las personas LGB (Worthington, Navarro, Savoy y Hampton, 2008).

Por otro lado, se plantea que superar esta confusión y tomar conciencia de la atracción que se puede sentir hacia personas del mismo sexo es complejo. Ya que además del estigma al que tienen que enfrentar las personas LGB, existe una carencia de modelos LGB que pueden ser tomados en cuenta como guía o modelos positivos (Eliason, 1996).

Además, se evidencia que las personas bisexuales frecuentemente presentan mayores niveles de incertidumbre de la identidad (Mohr y Kendra, 2011). Esto se debe a que las personas bisexuales no solo tienen que enfrentarse a las dificultades de establecer una identidad de orientación sexual diferente a la heterosexual. Además tienen que lidiar con las expectativas de las personas lesbianas y gays; quienes en muchos casos consideran que la bisexualidad en sí misma es un periodo de confusión y no una identidad de orientación sexual estable (Balsam y Mohr, 2007). Como consecuencia, en algunos casos el proceso de formación de la identidad de una persona bisexual es circular y se plantea un continuo proceso de incertidumbre de identidad. Esta situación no necesariamente es considerada como disfuncional, sin embargo va a 
ser una fuente de estrés para aquellas personas que se desarrollan en sociedades donde predominan las etiquetas de identidad de orientación sexual (Weinberg, Williams y Prior, 1994)

La cuarta dimensión, homonegatividad internalizada representa al fenómeno a través del cual la persona internaliza las creencias y pensamientos anti-LGB y los aplica a las conceptualizaciones del sí mismo. Con frecuencia, internalizar este tipo de pensamientos conlleva a que la persona se devalué a sí misma y a sus relaciones lo cual a su vez genera dificultades en la relación de pareja (Mohr y Fassinger, 2006). Esta dimensión también es considerada como normativa a lo largo de las personas LGB que se desarrollan en un contexto poco tolerante. Asimismo señala que las persona que se encuentra descubriendo su identidad de orientación sexual no solo se atribuirá una etiqueta como LGB sino que también le asignará una significado a la misma. Es así que en un medio lleno de prejuicios la persona estará propensa a internalizar las creencias anti-LGB. Por lo tanto, se plantea que esta dimensión es normativa a lo largo del proceso de desarrollo (McCarn y Fassinger, 1996). Por otro lado, Shidlo (1994) señala que la homonegatividad internalizada en diversas escalas es representada por el deseo de cambiar la propia orientación sexual. Por último, se establece una correlación positiva entre esta dimensión y un funcionamiento psicológico deficiente que involucra depresión, culpa, miedo, hostilidad y tristeza (Mohr y Kendra, 2011).

La quinta dimensión, dificultad en el proceso demuestra la percepción que tiene cada una de las personas respecto a lo difícil que ha sido el proceso de desarrollo de su identidad. Se plantea que existe una correlación positiva con la depresión, culpa, hostilidad y tristeza. Por otro lado se evidencia una correlación negativa entre esta dimensión y la satisfacción con la vida, seguridad en sí mismo y autoestima (Mohr y Kendra, 2011). 
La sexta dimensión, superioridad de la identidad, describe una perspectiva en la que las personas LGB, su cultura y sus instituciones son vistas como superiores. Es así que las personas LGB mostraran un compromiso muy profundo con la comunidad LGB y se definirán como mejores que sus pares heterosexuales (Mohr y Fassinger, 2006). Se cree que este fenómeno podría responder a un conjunto de estrategia compensatoria; como forma de enfrentar la estigmatización e incluso encubrir sentimientos subyacentes de inferioridad (Margnolies, Becker y Jackson-Brewer, 1987).

Por otro lado existe una correlación negativa entre esta dimensión y el grado de interés y proximidad que tienen las personas LGB por relacionarse con personas heterosexuales (Mohr y Kendra, 2011). Lo cual de cierta forma estaría limitando sus intercambios interpersonales con otras personas.

La séptima dimensión, afirmación de la identidad refleja el grado en el cual las personas LGB experimentan pensamientos y sentimientos positivos hacia su orientación sexual y hacia su integración y participación como miembros de comunidad LGB (Mohr y Kendra, 2011). Actualmente, varios estudios están centrando su atención en esta dimensión, ya que se le considera como una fuente de resiliencia en las personas LGB. (Riggle, Whitman, Olson, Rotosky y Strong, 2008)

Finalmente la octava dimensión, centralidad de la identidad muestra el grado en el cual la identidad de orientación sexual, es central y determinante para definir su identidad integral. Igualmente, afirmar este aspecto de la identidad puede ser un gran paso para reconocer y aceptar el self de cada persona. Esto a su vez le permite vivir una vida autentica; facilitando el crecimiento personal e incrementando el bienestar (Riggle y Rotosky, 2012). Aún no se sabe si la centralidad de la identidad influye directamente en el bienestar de las personas LGB, no obstante se sugiere que puede ser un factor moderador de los efectos del estrés minoritario (Meyer, 2003). 


\subsection{Investigaciones previas sobre la Identidad de Orientación}

\section{Sexual}

En relación a la linealidad de algunos modelos teóricos y las diferentes etapas por las cuales una persona LGB debe seguir para afirmarse como tal; en el año 2002 se llevó a cabo una investigación con jóvenes lesbianas, gays y/bisexuales a quienes se les aplicó un cuestionario que exploraba los hitos de su desarrollo de identidad a lo largo de sus vidas, revelación de la identidad de orientación sexual y autoestima. Los hallazgos determinan que el primer reconocimiento de atracción hacia una persona del mismo sexo, el primer contacto sexual con una persona del mismo sexo y la primera revelación de su identidad sexual varía en los participantes Por ejemplo, para un grupo de participantes la primera experiencia sexual con una persona de su mismo sexo ocurre simultáneamente al percatarse de su identidad LGB. Por lo tanto se plantea emplear otro tipo de enfoque donde se enfatice las diferencias individuales a lo largo del desarrollo de la identidad de orientación sexual (Maguen, Floyd, Bakeman y Armistead, 2002). En este sentido, se evidencian diferentes trayectorias individuales en lugar de una secuencia lineal invariable de experiencias a lo largo de la vida de todas las personas LGB.

Posteriormente Rosario, Schrimshaw y Hunter (2011), llevan a cabo una investigación longitudinal la cual buscaba conocer cuáles eran las implicancias de los diferentes patrones de desarrollo de la identidad de orientación sexual en el ajuste psicológico de un grupo de jóvenes lesbianas, gays y bisexuales. Los autores, teniendo en consideración la teoría de Erikson del Desarrollo de la identidad sexual plantean dos procesos de desarrollo: la formación de la identidad y la integración de la identidad (Rosario, Schrimshaw, Hunter y Braun, 2006). Los resultados muestran hallazgos que los jóvenes con niveles más altos de integración de la identidad de orientación sexual reportan menos síntomas depresivos y de ansiedad y mayores niveles de autoestima. Por otro lado, 
aquellos jóvenes que contaban con un grupo de soporte conformado por amigos o familiares experimentaban menos síntomas depresivos, menos problemas de conducta y mayores niveles de autoestima (Rosario et al., 2011). Por lo tanto, estos resultados indican que los jóvenes que habían alcanzado una mayor integración de su identidad de orientación sexual y que contaban con un buen soporte social de personas significativas presentaban un mejor ajuste psicológico que otros jóvenes (Rosario et al., 2011).

En relación a investigaciones que evalúan diferentes dimensiones de manera individual, en el año 1995 Meyer y Dean utilizaron la información de la base de datos del estudio longitudinal "AIDS Impact Project" para poder analizar algunos aspectos de la homofobia internalizada, intimidad y comportamientos sexuales en una muestra no clínica de hombres gays y bisexuales de Nueva York. Los hallazgos plantean que las personas con mayores niveles de homofobia internalizada tendían a involucrarse menos con grupos de la comunidad LGB y eran más propensos a evitar develar su identidad de orientación sexual. Asimismo estas personas presentaban dificultades para poder entablar relaciones de pareja y presentaban una mayor probabilidad de presentar problemas en el ámbito sexual tales como la inhibición del deseo sexual, excitación y orgasmo a lo largo del último año. De la misma forma, en las parejas en las que se presentaban mayores niveles de homofobia internalizada se encontró una predisposición a mantener relaciones por periodos cortos, evitar la convivencia con sus parejas, presentar problemas en su relación de pareja y pensar en interrumpir sus relaciones con mayor frecuencia. Respecto al ámbito de salud mental se halló que existe una correlación positiva entre la homofobia internalizada y la desmoralización con síntomas de ansiedad y depresión presentándose a su vez sentimientos de culpa e ideación y comportamientos suicidas (Meyer y Dean, 1995). Por otro lado, se plantea que las creencias o pensamientos auto-afirmativos se incrementan cuando hay una mayor afiliación con la comunidad gay, ya 
que esta última ofrece un medio de exposición a valores y normas afirmativas que pueden ayudar a disminuir el impacto de las actitudes en contra de la homosexualidad (Meyer y Dean, 1995).

Posteriormente, Diplacido (1998) llevó a cabo un estudio piloto en el cual buscaba conocer la situación de estrés minoritario experimentado por las personas LGB como consecuencia del heterosexismo, homofobia y discriminación. Al respecto encontró evidencias que la motivación a ocultar la propia orientación sexual, así como la inhibición emocional y la homofobia internalizada frecuentemente cumplen roles de estresores internos. Es así que es probable que las personas que aún no se muestran abiertamente como lesbianas, gays y bisexuales, experimenten menos eventos cotidianos negativos relacionados a discriminación por su orientación sexual ya que el entorno no sabe sobre su identidad de orientación sexual. Sin embargo, el estrés interno de estas personas que viven en una constante lucha por ocultar su orientación sexual es una fuente interna de estrés predominante en las minorías sexuales que no "salen del closet". Asimismo, se encontró que las personas que tienden a ocultar su identidad de orientación sexual presentan mayores niveles de afecto negativo. De la misma forma, las personas que presentaban más propensión a ocultar su identidad de orientación sexual evidenciaban niveles más altos de depresión. Igualmente las puntuaciones de homofobia internalizada se encontraban correlacionadas positivamente con los puntajes de depresión (Diplacido, 1998).

Por otro lado, también se han llevado a cabo investigaciones utilizando la LGIS y LGBIS para correlacionar sus dimensiones con otros constructos. Por ejemplo, en el año 2006 se llevó a cabo un estudio en el cual se buscaba correlacionar la identidad de orientación sexual y la calidad de la relación afectiva en parejas del mismo sexo. Los resultados establecen que en las relaciones de parejas del mismo sexo, la incertidumbre sobre la propia identidad de orientación sexual puede reflejar una ambivalencia hacia dicha relación o hacia la propia pareja, 
mermando así en la calidad de la relación. Por otro lado, los individuos que presentaron menores niveles de homonegatividad internalizada, sensibilidad a la estigmatización, superioridad de la identidad e incertidumbre de la identidad evidenciaron mayores niveles de calidad en su relación de pareja (Mohr y Fassinger, 2006).

Posteriormente Balsam y Mohr (2007) llevaron a cabo una investigación sobre la adaptación al estigma respecto a la orientación sexual entre un grupo de lesbianas y gays y otro grupo de bisexuales, para de esta forma encontrar diferencias o similitudes en las formas de adaptación a la estigmatización de las personas LGB. Dentro de los aspectos en común presentes en la muestra; los resultados apuntan que a mayores niveles de incertidumbre de la identidad y homonegatividad internalizada, el ajuste psicológico y social es menos eficaz y adaptativo. Por otro lado, respecto a la superioridad de la identidad, se evidencia que los participantes que consideran a las personas LGB mejores y por encima de los heterosexuales presentan bajos niveles de bienestar psicológico y de soporte social (Balsam y Mohr, 2007).

Asimismo, Bregman, Malik, Page, Makynen y Lindahl (2013) llevaron a cabo una investigación con 169 adolescentes y adultos LGB que buscaba encontrar evidencias de correlación entre el rol de la familia como soporte y los perfiles de identidad de las personas LGB. Los resultados demuestran que la aceptación por parte de los padres y el soporte social en función a la sexualidad de la persona son importantes fuentes protectoras durante el proceso de desarrollo de la identidad. Además se halló que los "perfiles afirmativos" de identidad se caracterizaron por niveles bajos en cinco dimensiones: homonegatividad internalizada, incertidumbre de la identidad, preocupación por la aceptación, dificultad en el proceso y motivación a la ocultación. Por lo tanto presentan indicios de mayor seguridad y confianza con su identidad LGB. Sin embargo los participantes con un "perfil de lucha" presentaron niveles más altos de homonegatividad internalizada, preocupación por la aceptación y dificultad en el proceso. No obstante, cabe destacar que en 
ambos perfiles se encontraron niveles bajos de incertidumbre de la identidad, lo cual evidencia que incluso en las personas con "perfiles de lucha" existe seguridad sobre su identidad y status como personas LGB a pesar de presentar dificultades en otras dimensiones.

Finalmente, se puede señalar que existen dos investigaciones de adaptación y validación de la LGBIS. La primera investigación se llevó a cabo en Portugal y tuvo como objetivo principal analizar las evidencias vinculadas a la validez del constructo de la LGBIS en una muestra portuguesa. El estudio fue online y se llevó a cabo con 808 participantes que fueron contactados por medio de asociaciones, universidades y partidos políticos. A partir del análisis factorial exploratorio realizado se reportó una solución que replica la escala original. Asimismo la confiabilidad de las dimensiones estuvo determinada por el coeficiente de alpha de Cronbach, el cual se encontró entre los valores de .62 y .83. Asimismo, se llevó a cabo un análisis factorial confirmatorio el cual corroboró la propuesta preliminar de dimensiones de Kendra y Mohr (2008), evidenciando que su modelo multidimensional también se replicaba con la muestra portuguesa que se trabajó (Oliveira, Lopes, Goncalves y Nogueira, 2012).

Asimismo, Molnar (2015) llevó a cabo una investigación que tuvo como objetivo adaptar y validar la LGBIS al contexto rumano y a la vez indagar si existían diferencias sociales y psicológicas entre lesbianas y gays durante el desarrollo y aceptación de su propia identidad. Este estudio también se realizó vía online y contó con la participación de 148 personas LGB de diferentes niveles educativos y con edades que se encontraban entre 18 y 56 años. El análisis factorial llevado a cabo respalda la propuesta de ocho dimensiones de Mohr y Kendra (2011) evidenciándose que dicho modelo también se cumple en la muestra rumana. A nivel de consistencia interna, los coeficientes de alfa de Cronbach de las dimensiones fluctuaron entre .74 para motivación a la ocultación y .94 para incertidumbre de la identidad. Además, a nivel de discriminación, cada una de las dimensiones incluye a los ítems 
respectivos propuestos en la versión original. Por último, se encontraron diferencias estadísticas significativas entre lesbianas y gays en las dimensiones preocupación por la aceptación, homonegatividad internalizada y afirmación de la identidad.

Las investigaciones presentadas tratan de generar y presentar evidencias de un amplio campo de estudios sobre la importancia de las dimensiones de la identidad de orientación sexual y cómo estas interactúan con diferentes constructos psicológicos para poder lograr una mejor comprensión de las personas LGB. Asimismo se presentan otras investigaciones utilizando la LGBIS y a su vez estudios de adaptación y validación de dicha escala en otros contextos e idiomas que corroboran la pertinencia de una propuesta teórica de multidimensionalidad de la identidad de orientación sexual. 


\section{CAPÍTULO III: OBJETIVOS, HIPÓTESIS Y DEFINICIÓN DE VARIABLES}

\subsection{Objetivos}

\subsubsection{Objetivo General}

- Adaptar y establecer las propiedades psicométricas de la escala "The Lesbian, Gay, and Bisexual Identity Scale" (LGBIS) en un grupo personas LGB que se encuentran en el rango de edades entre 18 años y 45 años.

\subsubsection{Objetivos Específicos}

- Realizar la adaptación lingüística de la escala "The Lesbian, Gay, and Bisexual Identity Scale” (LGBIS) del idioma ingles al idioma español.

- Obtener evidencias de validez referidas al contenido de la "Escala de Identidad de Orientación Sexual para Lesbianas, Gays y Bisexuales" mediante el métodos de criterio de jueces.

- Obtener evidencias de validez vinculadas a la estructura interna de la "Escala de Identidad de Orientación Sexual para Lesbianas, Gays y Bisexuales" a través de análisis factorial exploratorio.

- Estimar empíricamente la confiabilidad de las puntuaciones obtenidas de la "Escala de Identidad de Orientación Sexual para Lesbianas, Gays y Bisexuales" a través del método de consistencia interna por medio del coeficiente alfa de Cronbach clásico y alfa ordinal.

- Analizar la discriminación de los ítems de la "Escala de Identidad de Orientación Sexual para Lesbianas, Gays y Bisexuales”.

- Construir baremos provisionales de la "Escala de Identidad de Orientación Sexual para Lesbianas, Gays y Bisexuales”. 


\subsection{Definición de variables}

3.2.1 Definición conceptual de la identidad de orientación sexual y dimensiones

La identidad de orientación sexual es un constructo multidimensional que hace referencia a un conjunto de creencias, pensamientos y sentimientos que involucran aspectos intrapersonales, interpersonales y variables relacionadas a eventos específicos en relación a la propia orientación sexual (Mohr y Fassinger, 2006)

La LGBIS propuesta por Mohr y Kendra (2011) cuenta con ocho dimensiones:

- Preocupación por la aceptación: Refleja las expectativas o temores de ser evaluados por los otros negativamente debido a la orientación sexual de la persona.

- Motivación de ocultación: Refleja la preocupación y necesidad de las personas por proteger su vida privada y no develar públicamente su orientación sexual.

- Incertidumbre de identidad: Refleja la inseguridad, confusión e incertidumbre respecto a la orientación sexual de uno mismo.

- Homonegatividad internalizada: Refleja el mecanismo a través del cual la persona internaliza las creencias y pensamientos anti-LGB y los aplica a las conceptualizaciones del sí mismo, conllevando a que la persona se devalué a sí misma.

- Dificultad en el Proceso: Refleja la percepción de cada una de las personas respecto a lo difícil que ha sido el proceso de desarrollo de su identidad.

- Superioridad de identidad: Refleja el conjunto de estrategia compensatoria para poder incrementar la autoestima; como forma de enfrentar la estigmatización e incluso encubrir sentimientos subyacentes de inferioridad relacionados a la orientación sexual. 
- Afirmación de identidad: Refleja el grado en el cual las personas LGB experimentan pensamientos y sentimientos positivos hacia su orientación sexual y hacia su integración y participación como miembros de comunidades LGB.

- Centralidad de la identidad: Muestra el grado en el cual la identidad de orientación sexual, es central y determinante para definir su identidad integral.

\subsubsection{Definición operacional de la identidad de orientación sexual}

La identidad de orientación sexual fue evaluada a través de los puntajes obtenidos en cada una de las ocho dimensiones (preocupación por la aceptación, motivación a la ocultación, incertidumbre de la identidad, homonegatividad internalizada, dificultad en el proceso, superioridad de la identidad, afirmación de la identidad y centralidad de la identidad) de La Escala de Identidad de Orientación para Lesbianas, Gays y Bisexuales (Mohr y Kendra, 2011). 


\section{CAPÍTULO IV: MÉTODO}

\subsection{Tipo y diseño de investigación}

La presente investigación es de tipo psicométrico ya que en función a los puntajes obtenidos y sus respectivas interpretaciones después de la aplicación de la LGBIS se determinarán las propiedades psicométricas de dicha escala. Posteriormente se crearán los baremos necesarios de acuerdo a las características demográficas y subgrupos según lo que se considere pertinente (Alarcón, 2008).

Por otro lado, el diseño del presente estudio es de tipo no experimental ya que se observarán las características de la muestra tal y como se muestran en su contexto natural sin llevar a cabo ningún tipo de control de variables que posteriormente se incluirán en el análisis Asimismo, es de tipo transeccional ya que se buscará especificar y describir las dimensiones características relacionadas a la identidad de orientación sexual de la muestra, tal y como se presentan en un único determinado momento (Fernández, Hernández y Baptista, 2014).

\subsection{Participantes}

La población objetivo para el presente estudio cumplió con los siguientes criterios de inclusión:

a. Encontrarse en un rango de edad de 18-45 años.

b. Considerarse lesbiana, gay, bisexual o encontrarse en un periodo de duda respecto a su orientación sexual.

c. Tener una orientación sexual diferente a la heterosexual a pesar de no auto etiquetarse como lesbiana, gay o bisexual.

d. Haber nacido el Perú

e. Ser un residente Peruano 
Asimismo, es relevante señalar que al ser un estudio anónimo, se ha utilizado el criterio de "auto-identificación". Esta modalidad es la más utilizada en la mayoría de estudios LGBTQ; ya que de esta forma, se respeta el significado que cada persona le da a su propia identidad y orientación sexual (Clarke et al., 2010).

Se utilizó un método de muestreo no probabilístico de tipo accidental, considerando la accesibilidad a una determinada muestra y tomando en cuenta los criterios de inclusión anteriormente señalados con el fin de obtener una muestra representativa, dejando de lado los casos que no cumplen con dichas características (Kerlinger y Lee, 2002).

Además, se aplicó el método de "bola de nieve" ya que a través de algunos participantes se pudo contactar a otras personas que también se identificaron como lesbianas, gays y bisexuales.

Por otro lado, cabe señalar que a nivel nacional no existen datos cuantitativos del número de lesbianas, gays y bisexuales que residen en el Perú. Por lo tanto, para establecer el tamaño de la muestra se utilizó el criterio postulado por Nunnally (1987), el cual propone que para poder llevar a cabo un análisis factorial exploratorio es necesaria una muestra que sea equivalente a diez veces el número de ítems que forman parte del instrumento o test, pues lo que se busca con este criterio es reducir el error de muestreo. En este sentido dado que la Escala de Identidad de Orientación Sexual para Lesbianas, Gays y Bisexuales se encuentra conformada por 27 ítems, se requería un mínimo de 270 participantes. No obstante se obtuvo la participación de 384 personas, lográndose así superar el mínimo requerido por el criterio anteriormente mencionado.

A continuación se describen las características de la muestra seleccionada, cuyos datos fueron obtenidos a través de la ficha sociodemográfica diseñada para la presente investigación.

El presente estudio contó con una muestra conformada por 378 personas con un promedio de edad de 26.62 años $(D E=7.25)$. Con relación a la variable sexo, el $31.5 \%$ de la muestra es de sexo femenino 
mientras que el $68.5 \%$ es de sexo masculino. Con respecto a la variable orientación sexual; el $22.2 \%$ de personas se identifican como bisexuales, el $59.9 \%$ se identifican como gays, el $17.7 \%$ se identifican como lesbianas.

Así mismo, se encontró que en relación al grado de instrucción; el $12.1 \%$ de persona cuenta con estudios secundarios, el $71.2 \%$ cuenta con estudios superiores universitarios y el $16.7 \%$ con estudios superiores técnicos.

Por otro lado, el lugar de residencia de los participantes se distribuye de la siguiente manera: el $72 \%$ de participantes son residentes de Lima mientras que el $28 \%$ residen en alguna provincia de nuestro país. Finalmente, el $75.7 \%$ de la muestra no son activistas LGBT, mientras que el $24.3 \%$ restante de los participantes se consideran como activistas LGBT.

\subsection{Técnicas de recolección de datos}

Para la presente investigación que se llevó a cabo de manera online se utilizó el instrumento "Escala de Identidad para Lesbianas, Gays y Bisexuales" la cual es la versión en español de la escala original en el idioma inglés "The Lesbian, Gay, and Bisexual Identity Scale"(Morh y Kendra, 2011) (ver anexo 2)".

A continuación se describirá el instrumento utilizado así como también sus propiedades psicométricas.

\subsubsection{Escala de Identidad para Lesbianas, Gays y Bisexuales}

La LGBIS cuenta con ocho dimensiones: preocupación por la aceptación, motivación a la invisibilidad, incertidumbre de la identidad, homonegatividad internalizada, dificultad en el proceso, superioridad de la identidad, afirmación de la identidad y centralidad de la identidad. Asimismo, la escala cuenta con un total de 27 ítems, de los cuales sólo dos son formulados de manera inversa (ítem 23 e ítem 11). 
Tabla 4.1

Dimensiones y sus respectivos ítems de la LGBIS

\begin{tabular}{lccc}
\hline \multirow{2}{*}{ Dimensiones } & \multicolumn{2}{c}{ Ítems } & Total de \\
\cline { 2 - 3 } & Positivos & Negativos & ítems \\
\hline Preocupación por la aceptación & $5,9,16$ & 3 \\
Motivación a la invisibilidad & $1,4,19$ & 3 \\
Incertidumbre de la identidad & $3,8,14,22$ & 4 \\
Homonegatividad internalizada & $2,20,27$ & 3 \\
Dificultad en el proceso & 12,17 & 3 \\
Superioridad de la identidad & $7,10,18$ & 3 \\
Afirmación de la identidad & $6,13,26$ & 3 \\
Centralidad de la identidad & $11,15,21,24,25$ & 11 & 5 \\
\hline Total & & 2 & 27 \\
\hline
\end{tabular}

Nota: Adaptado de "Revision and Extension of a Multidimensional Measure of Sexual Minority Identity: The Lesbian, Gay and Bisexual Identity Scale", por J. Mhor y M. Kendra, 2011, Journal of Counselling Psychology, 2, p. 245. Copyright 2011 por the American Psychological Association.

A su vez, respecto al tipo de alternativas de respuesta, los ítems se encuentran redactados para que calcen con un formato de respuesta de escala Likert de 6 puntos, calificando los enunciados desde el puntaje 1 que es totalmente en desacuerdo hasta el puntaje 6 que es totalmente de acuerdo. La forma de calificación de dichas respuestas dependerá si el ítem está redactado en forma directa o en forma inversa, calificándose con el puntaje opuesto si es un ítem negativo.

Asimismo, es relevante señalar que la LGBIS (Mohr y Kendra, 2011); corresponde a la segunda versión de la LGIS (Mohr y Fassinger, 2000) Se destaca la segunda versión del instrumento en comparación de la primera pues los ítems fueron adaptados y expresados en un lenguaje inclusivo, para que también pueda ser aplicado a personas bisexuales. Además, se eliminaron y parafrasearon ítems que podían ser percibidos con cierta carga de estigma por parte de los participantes. Asimismo, como su propio nombre lo señala la prueba se encuentra dirigida a personas que se autodefinan como lesbianas, gays y bisexuales. 
Por otro lado, para poder llevar a cabo futuros estudios de comparabilidad de resultados con el estudio publicado por los autores de la escala original, es necesario mantener las siguientes instrucciones:

Para cada uno de los siguientes enunciados, marque la respuesta que mejor se ajusta a sus vivencias actuales como una persona LGB. Se le pide que sea lo más honesto posible: Indique cómo se siente realmente en la actualidad y no como cree que debería sentirse. No hay necesidad de pensar demasiado ninguna de sus respuestas. Responda cada pregunta de acuerdo a la primera reacción que le genera y luego continúe con la siguiente (Mohr y Kendra, 2011, p. 245).

De la misma forma, previamente a estas instrucciones, en alguna parte de la presentación del instrumento se debe incluir el siguiente enunciado:

En esta escala se utiliza las siglas LGB por conveniencia. Sabemos que algunos y algunas de ustedes en vez de identificarse como "Lesbiana, gay o bisexual" para describir su orientación sexual; podrían preferir utilizar otros nombres. Por esta razón pedimos su compresión en el caso que este término no represente su identidad sexual en su totalidad (Mohr y Kendra, 2011, p. 245).

A continuación se describirá las propiedades psicométricas de la versión original de la escala LGBIS (Mohr y Kendra, 2011).

Para poder analizar las evidencias de validez de la escala basada en la estructura interna, se utilizaron los métodos de análisis factorial exploratorio (EFA) y análisis factorial confirmatorio (CFA). En un primer estudio se contó con la participación de 654 estudiantes universitarios divididos en dos sub muestras para cada análisis $(N=297)$ y $(N=357)$ respectivamente. Asimismo, del total de participantes, 460 se identificaban como lesbianas y gays y 194 se identifican como bisexuales. Asimismo, los rangos de edades eran entre 18 y 52 años. El análisis factorial exploratorio llevado a cabo por Mohr y Kendra con una rotación 
ortogonal equamax planteó que la LGBIS contaba con 27 ítems que se distribuían en 8 sub-dimensiones. Asimismo a través de una estimación empírica de confiabilidad por consistencia interna, los valores de alfa de Cronbach de cada dimensión se encontraron en un rango de .77 a .89 . Posteriormente se llevó a cabo un análisis factorial confirmatorio el cual corroboró la estructura anteriormente mencionada.

Por otro lado, las evidencias de confiabilidad de la prueba se obtuvieron por medio de un segundo estudio en el cual se analizó la estabilidad de las puntuaciones por medio de test-re test en una muestra de 51 estudiantes. Seis semanas después de la primera aplicación, se volvió a aplicar la escala para realizar el análisis respectivo. A través de este estudio se obtuvo que los coeficientes de correlación encontrados se fluctúan entre el rango de .70 a .92. De la misma forma, el alfa de Cronbach estimado estuvo en un rango de .72 a .94 evidenciándose niveles moderados y altos de consistencia interna.

\subsection{Procedimiento de recolección de datos}

En primer lugar se contactó directamente a uno de los autores del instrumento original; Jonathan Mohr, para de esta forma solicitar un ejemplar de la LGBIS (Mohr y Kendra, 2011). Asimismo, se pidió su autorización para poder realizar la adaptación de dicho instrumento al idioma español utilizando una muestra peruana.

En segundo lugar, una vez otorgado el permiso y el ejemplar de la LGBIS, el autor envió la "Guía de lineamientos de traducción de encuestas o escalas para Investigaciones Tras-culturales" (J.J. Mohr, comunicación personal, 29 de Mayo, 2012) elaborada por el centro de medición y métodos de la Universidad de California-San Francisco. Este documento contaba con una serie de referencias bibliográficas; las cuales recomiendan ciertos requisitos metodológicos a seguir para una adecuada adaptación cultural y validación psicométrica de la escala. 
Para la aplicación se elaboró un consentimiento informado (ver anexo 7) en el cual se incluyó el objetivo de la investigación, en qué consistía la participación, por qué era importante la participación de cada persona, quién estaba a cargo del estudio y cómo contactarla vía telefónica y vía email, cuál sería el procedimiento a seguir, la ausencia de riesgos y la naturaleza voluntaria y confidencial del estudio. Asimismo se incluyó los criterios de inclusión. Finalmente se pidió la autorización a los participantes para utilizar los datos recogidos para fines académicos.

Se utilizó una ficha de datos socio demográficos (ver anexo 1) con la finalidad de establecer si las personas que participaban en el estudio, cumplían los criterios de inclusión previamente establecidos. Los datos que se recolectaron por medio de este instrumento fueron: edad, lugar de residencia, grado de instrucción, nivel socioeconómico, participación en activismo LGBTQ, sexo, orientación sexual y apertura respecto a su identidad de orientación sexual. Se debe destacar que no se incluyó datos de identidad personal en la ficha socio demográfica ya que estudios previos demuestran que uno de los factores principales por los cuales muchas personas LGB pueden mostrarse rehacías a participar en investigaciones de este tipo es el temor y la ansiedad a que sus identidades sean puestas al descubierto y personas cercanas a su entorno laboral y familiar puedan enterarse de ello (Wheeler, 2003).

Para el presente estudio, la aplicación de la escala se llevó a cabo de manera online. Se tomó dicha decisión teniendo en consideración que uno de los aspectos más difíciles en investigaciones con personas LGB es el acceso directo a dicha población. Además es considerada como una "población oculta"; por lo cual, una de las estrategias más comunes es el uso de internet para acceder a dicha población (Clarke et al., 2010). Asimismo, Mustanski (2001) señala que el anonimato y el fácil acceso al uso de internet favorecen la conducción de estudios sobre temas de sexualidad. De la misma forma, se plantea que el internet como plataforma para estudios online tiene un impacto positivo en 
investigaciones psicológicas sobre fenómenos o temas que son difíciles de estudiar (Kraut, Olson, Banaji, Bruckman, Cohen y Couper, 2004).

Una vez concluido el periodo de tres semanas para la aplicación de la escala a través de la versión online del instrumento, se contó con la participación de 378 personas. Posteriormente a esto se inició el proceso de análisis estadístico. Los datos recolectados fueron esquematizados en una base de datos haciendo uso del programa SPSS en su versión 23. Además, se realizaron análisis posteriores haciendo uso del programa Factor en su versión 9.3.1 (Lorenzo-Seva y Ferrando, 2015). 


\section{CAPÍTULO V: RESULTADOS}

\subsection{Adaptación de la LGBIS}

Siguiendo las recomendaciones de Beaton, Bombardier, Guillemin y Ferraz (1998) para los procesos de traducción y adaptación cultural de instrumentos en el ámbito de salud, se optó por un proceso de adaptación lingüística de cinco etapas. La primera etapa consistió en realizar la traducción directa del instrumento del idioma inglés al idioma español. Para dicho objetivo se contó con el apoyo de dos traductores certificados bilingües cuya lengua materna necesariamente tenía que ser el idioma español. El primer traductor contaba con experiencia en la traducción técnica de textos, además se le informo sobre los objetivos del estudio y se le instruyó en la temática del instrumento. Posteriormente emitió su traducción, la cual se denominó (T1). Paralelamente se contó con un segundo traductor, a quien se le denomina traductor ciego ya que no tuvo información alguna sobre los objetivos y temática de la investigación. De esta forma, se espera que la segunda traducción; a la cual se le denominó (T2), se encuentre más ajustada al lenguaje coloquial.

En la segunda etapa la persona a cargo del presente estudio en coordinación con los traductores que realizaron la T1 y la T2 llevaron a cabo una síntesis de traducción (T-12) teniendo en cuenta las dos traducciones directas. Para ello, se optó por elegir la propuesta de alguno de los traductores y en otros casos se tomó como base algunas de las traducciones pero realizando modificaciones para mantener el sentido de los ítems originales. Asimismo, con el apoyo de un docente de la Carrera de Psicología con dominio del idioma inglés se realizaron diversas revisiones de la T1, T2 y $\mathrm{T}-12$. El objetivo de esta fase era llegar a un consenso en la selección de la traducción más adecuada. Durante este proceso se elaboró un informe de síntesis en el cual se detalla las razones por las cuales se eligió una de las alternativas de traducción o las razones por las cuales se realizaron modificaciones en los ítems. 
La tercera etapa consistió en la elaboración de las traducciones inversas, para lo cual se contó con la colaboración de dos traductores certificados bilingües cuya lengua materna era el idioma inglés. En este caso a los traductores se les entrego la versión síntesis (T-12) y no se les informó sobre los objetivos o constructo teórico que se estaba investigando. Posteriormente cada uno hizo la entrega de una traducción inversa a las cuales se les denominó BT1 y BT2 respectivamente.

La cuarta etapa consistió en la toma de decisiones con el "Comité de expertos multidisciplinarios"; para este fin se requirió el apoyo de un psicólogo experto en metodología de construcción de instrumentos, un experto en el área de psicología clínica, un psicólogo experto en el área psicométrica, una lingüista y un experto en estudios de género y temática LGBT. A cada uno de los miembros del comité se le entregó un documento indicándoles tener en consideración la base teórica planteada por el autor (ver nexo 5). Asimismo se les pidió tener en cuenta cuatro tipos de equivalencias (Beaton et al., 1998):

a) Equivalencia Semántica: Hace referencia a la equivalencia en el significado de las palabras.

b) Equivalencia Idiomática: De encontrarse frases idiomáticas o coloquialismos en alguno de los ítems, es necesario sustituir dichas expresiones por otras equivalentes.

c) Equivalencia Empírica: La situación evocada o representada en cada uno de los ítems de la versión original debe encajar también en el contexto para el cual se está realizando la adaptación.

d) Equivalencia Conceptual: El concepto explorado también debe ser válido en la cultura o contexto para el cual se está realizando la adaptación.

De la misma forma recibieron una copia de las dos traducciones directas (T1 y T2), la traducción síntesis (T-12) y las dos traducciones inversas (BT1 y BT2). Teniendo en cuenta estos aspectos, los expertos completaron la hoja de sugerencias. Posteriormente se reunieron 
personalmente con la responsable de la presente investigación para plantear una serie de indicaciones adicionales, a partir de las cuales se realizaron algunas modificaciones en los ítems.

Posteriormente se realizó el estudio piloto, el cual contó con una muestra de 11 hombres y 9 mujeres de diferentes niveles educativos, de los cuales 7 eran gays, 6 eran lesbianas y 7 eran bisexuales y que además cumplían con los criterios de inclusión establecidos para la investigación. A cada uno de los participantes se les envió la escala y a su vez se les envió un cuestionario estructurado en el cual se les preguntaba si se había presentado alguna dificultad en la comprensión de las instrucciones, los ítems o las opciones de las respuestas. Además se les preguntó si alguno de los ítems les había generado malestar emocional, o si tenían alguna sugerencia respecto a los ítems o la escala. Asimismo, en función a las respuestas del estudio piloto, se realizaron algunas modificaciones en la escala. Es así que se pudo obtener la versión final en español de la LGBIS (ver anexo 3). Finalmente, el estudio piloto permitió determinar que un tiempo aproximado de aplicación era de 8 a 10 minutos.

\subsection{Evidencias de Validez vinculadas al contenido}

Para obtener evidencias de la validez vinculada al contenido se utilizó el criterio de jueces para de esa forma determinar en qué medida los ítems de la escala representan el constructo que dice medir y además si se cumplen los objetivos de medición del constructo de una manera apropiada (Sireci y Faulkner-Bond, 2014). Con el objetivo de lograr dicho propósito, la versión traducida y adaptada de la LGBIS fue presentada a 6 jueces psicólogos expertos con experiencia en el área de psicología de la sexualidad y la temática LGBT (ver anexo 6). A partir de las respuestas de los jueces, dichos resultados fueron procesados estadísticamente utilizando el coeficiente $\mathrm{V}$ de Aiken, considerando el nivel de significación de V (.70) señalado por Escurra (1998). A continuación se presentan los resultados obtenidos.

En la tabla 5.1 se puede evidenciar que todos los ítems han superado el mínimo valor de $\mathrm{V}$ de Aiken de .70 a un nivel de $p<.05$ para 
ser considerados significativos. Por lo tanto, se evidencia que estos ítems que conforman la escala de la identidad de orientación sexual son una muestra representativa del dominio de contenido que mide la LGBIS.

Tabla 5.1.

Coeficiente V de Aiken para los ítems de la LGBIS

\begin{tabular}{lc|}
\hline Ítem & $\mathrm{V}$ de Aiken \\
\hline Ítem 1 & $.83^{*}$ \\
Ítem 2 & $.80^{*}$ \\
Ítem 3 & $.77^{*}$ \\
Ítem 4 & $.90^{*}$ \\
Ítem 5 & $.90^{*}$ \\
Ítem 6 & $.90^{*}$ \\
Ítem 7 & $.90^{*}$ \\
Ítem 8 & $.90^{*}$ \\
Ítem 9 & $1.00^{*}$ \\
Ítem 10 & $.87^{*}$ \\
Ítem 11 & $1.00^{*}$ \\
Ítem 12 & $.87^{*}$ \\
Ítem 13 & $.93^{*}$ \\
Ítem 14 & $.93^{*}$ \\
Ítem 15 & $1.00^{*}$ \\
Ítem 16 & $.90^{*}$ \\
Ítem 17 & $.97^{*}$ \\
Ítem 18 & $.90^{*}$ \\
Ítem 19 & $.90^{*}$ \\
Ítem 20 & $.80^{*}$ \\
Ítem 21 & $.97^{*}$ \\
Ítem 22 & $.80^{*}$ \\
Ítem 23 & $.97^{*}$ \\
Ítem 24 & $.90^{*}$ \\
Ítem 25 & $.93^{*}$ \\
Ítem 26 & $.97^{*}$ \\
Ítem 27 & $.87^{*}$ \\
\hline P 05 & \\
\hline
\end{tabular}




\subsection{Evidencias de Validez vinculadas a la estructura interna}

La escala original LGBIS es presentada como una escala multidimensional de 8 factores. Por lo tanto se intentará establecer si la misma estructura corresponde con los resultados obtenidos en una muestra peruana. Para ello, se llevó a cabo el análisis de evidencias vinculadas a la estructura interna con el objetivo de establecer el grado de relación entre los ítems de un test y las dimensiones o componentes que conforman el constructo a partir de las cuales se llevan a cabo la calificación e interpretación del test (American Educational Research Association [AERA], American Psychological Association [APA] y National Council on Measurement in Education [NCME], 2014). Al respecto se plantea que para la evaluación de la dimensionalidad de un instrumento uno de los métodos estadísticos más utilizados es el análisis factorial exploratorio (Kline, 2010).

\section{Primer análisis factorial exploratorio}

En primer lugar, antes de factorizar una matriz de correlaciones, es importante demostrar que los datos son adecuados para aplicar el análisis factorial. Para ello se aplican métodos estadísticos como la medida de adecuación muestral de Kaiser, Meyer y Olkin, y el test de esfericidad de Bartlett (Field, 2013; Hair, Anderson, Tatham y Black, 2007; Pérez, 2013). Los resultados de dichos análisis evidencian que existen asociaciones estadísticamente significativas entre los ítems $\left(X^{2}[351, N=\right.$ $378]=5280.2, p<.001)$. Además siguiendo la clasificación de Kaiser (como se citó en Cea D’Ancona, 2002) estas asociaciones serían lo suficientemente buenas para justificar su factorización, $K M O=.91$.

Además, se aplicó del método de Hull (Lorenzo-Seva, Timmerman, y Kiers, 2011) para determinar el número de factores necesarios para explicar las covariaciones entre los datos. Los resultados de dicho análisis se presentan en la tabla 5.2. 
Tabla 5.2

Resultados del método de Hull para determinar el número de factores, primer análisis

\begin{tabular}{cccc}
\hline $\begin{array}{c}\text { Número de } \\
\text { factores }\end{array}$ & $\begin{array}{c}\text { Bondad } \\
\text { de ajuste }\end{array}$ & g.l. & Scree test \\
\hline 0 & .101 & 27 & .000 \\
1 & .264 & 54 & 1.516 \\
2 & .367 & 80 & $2.116^{\mathrm{a}}$ \\
3 & .414 & 105 & 1.526 \\
4 & .443 & 129 & 1.197 \\
5 & .467 & 152 & .000 \\
\hline${ }^{\mathrm{a}}$ Número óptimo de factores, GFI = .97. &
\end{tabular}

Asimismo, cabe señalar que los análisis factoriales exploratorios se llevaron a cabo utilizando el método de extracción de mínimos cuadrados no ponderados (ULS) y el método de rotación equamax. Por lo tanto, en la tabla 5.3 se presentan las cargas factoriales de los 27 ítems en función a una solución bifactorial que explica el $47.67 \%$ de la varianza común compartida. Además, en el caso de los ítems 1, 2, 3, 6, 8, 20 y 27 la diferencia absoluta entre las cargas de los factores de cada ítem es inferior a .20 (Mohr y Kendra, 2011) y los ítems 4, 7, 10, 11, 18, 21, 23 alcanzan cargas factoriales menores de .40 , que es el mínimo recomendado para considerar que un ítem corresponde a un factor (Hair et al., 2007). Por ello se decidió realizar un segundo análisis factorial, eliminando los ítems que no cumplen los criterios señalados. 
Tabla 5.3

Cargas factoriales de los ítems que conforman la LGBIS, primer análisis factorial

\begin{tabular}{|c|c|c|c|}
\hline Ítem & Factor 1 & Factor 2 & Comunalidad \\
\hline Ítem 1 & -.39 & .40 & .31 \\
\hline Ítem 2 & -.55 & .60 & .66 \\
\hline Ítem 3 & -.42 & .61 & .55 \\
\hline Ítem 4 & & .37 & .22 \\
\hline Ítem 5 & & .70 & .49 \\
\hline Ítem 6 & -.56 & -.52 & .58 \\
\hline Ítem 7 & & .24 & .21 \\
\hline Ítem 8 & -.44 & .59 & .67 \\
\hline Ítem 9 & & .57 & .33 \\
\hline Ítem 10 & & .35 & .12 \\
\hline Ítem 11 & & & .03 \\
\hline Ítem 12 & & .53 & .29 \\
\hline Ítem 13 & -.71 & & .56 \\
\hline Ítem 14 & & .65 & .51 \\
\hline Ítem 15 & -.65 & & .43 \\
\hline Ítem 16 & & .75 & .56 \\
\hline Ítem 17 & & .49 & .24 \\
\hline Ítem 18 & & .33 & .14 \\
\hline Ítem 19 & -.42 & .66 & .49 \\
\hline Ítem 20 & .58 & -.61 & .70 \\
\hline Ítem 21 & & .37 & .22 \\
\hline Ítem 22 & -.41 & .74 & .71 \\
\hline Ítem 23 & & & .07 \\
\hline Ítem 24 & .86 & & .73 \\
\hline Ítem 25 & .88 & & .78 \\
\hline Ítem 26 & .75 & $>$ & .64 \\
\hline Ítem 27 & .52 & -.65 & .70 \\
\hline $\begin{array}{l}\text { rianza } \\
\text { plicada }\end{array}$ & $36.18 \%$ & $11.49 \%$ & \\
\hline
\end{tabular}

\section{Segundo análisis factorial exploratorio}

Los resultados del test de esfericidad de Bartlett señalan que existen asociaciones estadísticamente significativas entre los ítems $\left(X^{2}[78\right.$, $N=378]=2414.7, p<.001)$ y la medida de adecuación muestral de Kaiser, Meyer y Olkin indica que nuevamente estas son lo suficientemente buenas para justificar su factorización $K M O=.84$. Por lo tanto, al replicar el método de Hull (Lorenzo-Seva, Timmerman y Kiers, 2011) se corroboró la propuesta de una solución bifactorial, tal y como se aprecia en la tabla 5.4. 


\section{Tabla 5.4}

Resultados del método de Hull para determinar el número de factores, segundo análisis

\begin{tabular}{cccc}
\hline $\begin{array}{c}\text { Número de } \\
\text { factores }\end{array}$ & $\begin{array}{c}\text { Bondad } \\
\text { de ajuste }\end{array}$ & g.l. & Scree test \\
\hline 0 & .155 & 13 & .000 \\
2 & .485 & 38 & $18.380^{\mathrm{a}}$ \\
5 & .507 & 68 & .000 \\
\hline${ }^{\mathrm{a}}$ Número óptimo de factores, GFI $=.99$. &
\end{tabular}

Por otro lado, en la tabla 5.5 se muestran las cargas factoriales de los 13 ítems, dada una solución bifactorial que explica el $60.32 \%$ de la varianza en total. Asimismo, el primer factor explica el $39.89 \%$ y el segundo factor el $20.42 \%$.

Tabla 5.5

Cargas factoriales de los ítems que conforman la prueba, segundo análisis

\begin{tabular}{|c|c|c|c|}
\hline Item & Factor 1 & Factor 2 & Comunalidad \\
\hline Ítem 5 & .76 & & .57 \\
\hline Ítem 9 & .64 & & .41 \\
\hline Ítem 12 & .54 & & .30 \\
\hline Ítem 13 & & .69 & .55 \\
\hline Ítem 14 & .66 & & .50 \\
\hline Ítem 15 & & .65 & .43 \\
\hline Ítem 16 & .79 & & .62 \\
\hline Ítem 17 & .50 & & .25 \\
\hline Ítem 19 & .59 & & .48 \\
\hline Ítem 22 & .71 & & .65 \\
\hline Ítem 24 & & .89 & \\
\hline Ítem 25 & & .89 & .80 \\
\hline Ítem 26 & & .74 & .66 \\
\hline $\begin{array}{l}\text { Varianza } \\
\text { Explicada }\end{array}$ & $39.89 \%$ & $20.42 \%$ & \\
\hline
\end{tabular}

A partir de este segundo AFE se determinó que se mantenía los 13 ítems agrupados en dos factores. Por lo tanto se mantiene el enfoque de dimensiones, a pesar que no se replica la estructura original de la LGBIS. $\mathrm{Al}$ respecto, cabe señalar que los 13 ítems que conforman esta nueva propuesta de instrumento EDOS-LGB (ver anexo 4) fueron ordenados al 
azar, de acuerdo a un programa en línea generador de listas aleatorias (Haahr, 1998). Por lo tanto, a partir de este momento se utilizará la nueva numeración de ítems.

Asimismo, se halló una correlación negativa entre el factor uno y el factor dos, $r=-.33$. Asimismo, siguiendo a Field (2009) se consideró a $r$ como tamaño del efecto. Por lo tanto se puede señalar que la correlación hallada corresponde a un tamaño del efecto mediano (Ellis, 2010).

\subsection{Estimación de la confiabilidad en función de las puntuaciones obtenidas de la aplicación de los ítems que forman la LGBIS}

Con la finalidad de estimar empíricamente la consistencia interna se utilizó el método clásico alfa de Cronbach y el alfa ordinal para cada uno de los dos factores. Por la tanto en la Tabla 5.6 se puede observar que tanto los valores de los alfa de Cronbach como de los alfa ordinales hallados superan el criterio de .70 establecido por Nunnally y Bernstein (1995). Por lo tanto, esto datos evidencian que el instrumento permite obtener puntuaciones confiables.

Tabla 5.6

Alfa de Cronbach, Alfa ordinal y EEM para las puntuaciones derivadas de los factores para toda la muestra

\begin{tabular}{lcccc}
\hline & $\begin{array}{c}\alpha \text { de } \\
\text { Cronbach }\end{array}$ & $\begin{array}{c}\text { EEM } \\
\alpha \text { de } \\
\text { Cronbach }\end{array}$ & $\alpha$ ordinal & $\begin{array}{c}\text { EEM } \\
\alpha \\
\text { ordinal }\end{array}$ \\
\hline Factor 1 & .84 & 3.72 & .88 & 3.29 \\
Factor 2 & .86 & 2.32 & .91 & 1.86 \\
\hline Nota: $N=378$. & & & &
\end{tabular}

Por otro lado, se consideró pertinente calcular el alfa de Cronbach, el alfa ordinal y el EEM para cada uno de los factores según la orientación sexual. Como se puede observar en la Tabla 5.7 se obtuvieron valores de alfa ordinales y alfa de Cronbach superiores al criterio de .70 para los dos factores tanto para los grupos de lesbianas $(n=67)$, gays $(n=214) \mathrm{y}$ bisexuales $(n=97)$. 


\section{Tabla 5.7}

Alfa de Cronbach, Alfa ordinal y EEM para las puntuaciones derivadas de los factores según orientación sexual

\begin{tabular}{llcccc}
\hline Orientación Sexual & Factor & $\begin{array}{c}\alpha \text { de } \\
\text { Cronbach }\end{array}$ & EEM & $\alpha$ ordinal & EEM \\
\hline \multirow{2}{*}{ Lesbianas } & Factor 1 & .91 & 3.15 & .89 & 3.70 \\
& Factor 2 & .91 & 1.94 & .90 & 2.05 \\
\multirow{2}{*}{ Gays } & Factor 1 & .79 & 3.75 & .90 & 2.58 \\
& Factor 2 & .84 & 2.28 & .91 & 1.71 \\
\multirow{2}{*}{ Bisexuales } & Factor 1 & .80 & 3.73 & .88 & 3.43 \\
& Factor 2 & .87 & 2.35 & .91 & 1.95 \\
\hline
\end{tabular}

\subsection{Análisis de la discriminación de los ítems}

Se halló la capacidad de discriminación de cada uno de los ítems según la dimensión a la que pertenecen. Tal y como se puede observar en la tabla 5.8, todos los ítems tienen una correlación ítem-test mayor al mínimo aceptable de .20 establecido por Kline (1995). Por lo cual se evidencia que cada dimensión incluye a los ítems respectivos. 
Tabla 5.8

Correlación ítem-test de la EDOS-LGB

\begin{tabular}{lll}
\hline & Ítem & Correlación Item-test \\
\hline Factor 1 & Ítem 8 & .66 \\
& Ítem 2 & .55 \\
& Ítem 13 & .50 \\
& Ítem 6 & .60 \\
& Ítem 3 & .68 \\
& Ítem 5 & .47 \\
Factor 2 & Ítem 7 & .56 \\
& Ítem 12 & .68 \\
& Ítem 9 & .65 \\
& Ítem 1 & .54 \\
& Ítem 4 & .77 \\
& Ítem 11 & .77 \\
\hline
\end{tabular}

\subsection{Elaboración de Baremos}

Con la finalidad de determinar la pertinencia de elaborar baremos diferenciados según la orientación sexual de los participantes en primer lugar se llevó a cabo la prueba de prueba Shapiro-Wilk de bondad de ajuste, ya que Razali y Wah (2011) han demostrado que es una prueba más potente que otras pruebas estadísticas orientadas al contraste del supuesto de normalidad como es el caso de la Kolmogorov-Smirnov. Posteriormente se llevó a cabo una comparación entre los rangos promedios.

Como se puede observar en la Tabla 5.9, los resultados evidencian que a un nivel de significancia $p<.05$, las puntuaciones de la LGBIS según orientación sexual provienen de una población que no se aproxima a la distribución normal. 
Tabla 5.9

Estadísticos descriptivos y prueba Shapiro-Wilk de bondad de ajuste a la curva normal según orientación sexual para los factores 1 y 2

\begin{tabular}{llcccccc}
\hline & Orientación & $M$ & $D E$ & $n$ & $W$ & $g l$ & $p$ \\
\hline \multirow{3}{*}{ Sexual } & Lesbiana & 27.94 & 1.27 & 67 & .91 & 67 & $<.001$ \\
& Gay & 22.62 & 8.16 & 214 & .96 & 214 & $<.001$ \\
& Bisexual & 29.24 & 9.89 & 97 & .97 & 97 & .22 \\
& Lesbiana & 20.48 & 6.5 & 67 & .96 & 67 & .006 \\
Factor 2 & Gay & 22.56 & 5.71 & 214 & .94 & 214 & $<.001$ \\
& Bisexual & 19.58 & 6.49 & 97 & .93 & 97 & .001 \\
\hline
\end{tabular}

Nota: $N=378$.

Consecuentemente se procedió al uso de una prueba no paramétrica para más de dos grupos; en este caso la prueba $\mathrm{H}$ de KruskalWallis a fin de comparar los rangos promedios según orientación sexual. Como se puede observar en la Tabla 5.10, los resultados evidencias que existen diferencias estadísticamente significativas en los factores 1 y 2 según orientación sexual. Según estos resultados, se puede señalar que en el factor 1 los bisexuales obtuvieron puntajes mayores que las personas lesbianas y que las personas gays. Por otro lado en el factor 2 los participantes gays obtuvieron puntajes más altos que las participantes lesbianas y que los participantes bisexuales.

Tabla 5.10

Comparación de los factores según orientación sexual

\begin{tabular}{lccccc}
\hline & Lesbianas & Gays & Bisexuales & \multirow{2}{*}{$X^{2}$} & \multirow{2}{*}{$p$} \\
\cline { 2 - 4 } & $R m$ & $R m$ & $R m$ & & \\
\hline Factor 1 & 217.32 & 160.4 & 234.48 & 36.01 & $<.001$ \\
Factor 2 & 172.90 & 209.09 & 157.74 & 16.68 & $<.001$ \\
\hline
\end{tabular}

Asimismo también se procedió a llevar a cabo una comparación de pares de acuerdo a orientación sexual aplicando la prueba U de MannWhitney. Por lo tanto, como se puede observar en la tabla 5.11 en el factor 1 existen diferencias significativas entre las personas bisexuales y las personas gays y a su vez entre las personas lesbianas y las personas gays. 
No obstante se evidencia una ausencia de diferencias significativas entre las personas lesbianas y bisexuales. Por otro lado, en relación al factor 2, se observa que solo existen diferencias significativas entre las personas gays y las personas bisexuales. Asimismo, los tamaños del efecto se encuentran entre el mínimo valor de $r=.06$ y el máximo es de $r=.32$ por lo cual según lo propuesto por Cohen (1988) los tamaños del efecto hallado serían considerados nulos y/o pequeños según sea el caso.

\section{Tabla 5.11}

Comparación de pares por orientación sexual

\begin{tabular}{lcccccc}
\hline \multirow{2}{*}{ Orientación Sexual } & \multicolumn{3}{c}{ Factor 1} & \multicolumn{3}{c}{ Factor 2} \\
\cline { 2 - 7 } & $Z$ & $p$ & $r$ & $z$ & $p$ & $r$ \\
\hline Lesbiana - Gay & -3.61 & $<.001$ & .22 & -2.34 & .02 & .14 \\
Lesbiana - Bisexual & -0.77 & .44 & .06 & -0.82 & .41 & .06 \\
Gay - Bisexual & -5.63 & $<.001$ & .32 & -3.87 & $<.001$ & .22 \\
\hline
\end{tabular}

Nota: Se aplicó $r$ de Pearson como medida del tamaño del efecto.

Por lo tanto, en función a los resultados hallados, se consideró pertinente elaborar baremos diferenciados según orientación sexual para cada uno de los factores. Dichos baremos se presentan en la tabla 5.12. 
Tabla 5.12

Percentiles para las puntuaciones obtenidas en el Factor 1 y el Factor 2 según orientación sexual

\begin{tabular}{|c|c|c|c|c|c|c|}
\hline \multirow{3}{*}{ Percentil } & \multicolumn{3}{|c|}{ Factor 1} & \multicolumn{3}{|c|}{ Factor 2} \\
\hline & Lesbianas & Gays & Bisexuales & Lesbianas & Gays & Bisexuales \\
\hline & $(n=67)$ & $(n=214$ & $(n=97)$ & $(n=67)$ & $(n=214)$ & $(n=97)$ \\
\hline 99 & 48 & 44 & 48 & & 30 & 30 \\
\hline 95 & 45 & 39 & 44 & 30 & & \\
\hline 90 & 41 & 34 & 41 & 29 & & 29 \\
\hline 85 & 40 & 32 & 40 & 28 & 29 & 27 \\
\hline 80 & 39 & 29 & 39 & 28 & 28 & 26 \\
\hline 75 & 38 & 27 & 38 & 27 & 27 & 25 \\
\hline 70 & 37 & 26 & 36 & 26 & 26 & 24 \\
\hline 65 & 36 & 24 & 34 & 25 & , & 22 \\
\hline 60 & 35 & 23 & 32 & 24 & 25 & 21 \\
\hline 55 & 32 & 22 & 31 & 21 & 24 & \\
\hline 50 & 27 & 21 & 30 & 20 & & 20 \\
\hline 45 & 25 & 21 & 28 & 19 & 23 & 19 \\
\hline 40 & 23 & 20 & 26 & 18 & 22 & 18 \\
\hline 35 & 22 & 18 & 25 & 17 & 21 & 17 \\
\hline 30 & 19 & 18 & 24 & 15 & 20 & 16 \\
\hline 25 & 18 & 17 & 23 & 14 & 19 & 14 \\
\hline 20 & 17 & 16 & 19 & & 18 & 13 \\
\hline 15 & 16 & 15 & 17 & 13 & 16 & 11 \\
\hline 10 & 14 & 14 & 15 & 12 & 15 & 10 \\
\hline 5 & 11 & 11 & 12 & 11 & 11 & 9 \\
\hline
\end{tabular}

Nota: $N=378$.

Se replicó el mismo procedimiento con finalidad de determinar la pertinencia de elaborar baremos diferenciados según el grado de activismo. Por lo tanto, se aplicó nuevamente la prueba de Shapiro-Wilk a un nivel de significancia $p<.05$ para analizar la bondad de ajuste a la curva normal. Como se puede observar en la tabla 5.13, los resultados evidencian que las puntuaciones de la LGBIS según el involucramiento en el activismo provienen de una población que no se aproxima a la distribución normal. 
Tabla 5.13

Estadísticos descriptivos y prueba Shapiro-Wilk de bondad de ajuste a la curva normal según activismo para el factor 1 y el factor 2

\begin{tabular}{llcccccc}
\hline & & $M$ & $D E$ & $n$ & $W$ & $g l$ & $p$ \\
\hline \multirow{2}{*}{ Factor 1 } & Activistas & 21.13 & 6.23 & 92 & .95 & 67 & $<.001$ \\
& No activistas & 25.6 & 7.76 & 286 & .97 & 214 & .001 \\
\multirow{2}{*}{ Factor 2 } & Activistas & 25.35 & 6.5 & 92 & .91 & 67 & $<.001$ \\
& No activistas & 20.16 & 4.08 & 286 & .97 & 214 & $<.001$ \\
\hline Nota: $N=378$. & & & & & &
\end{tabular}

Consecuentemente se procedió al uso de una prueba no paramétrica para dos grupos; en este caso la prueba U de Mann-Whitney a fin de comparar los rangos promedio de las personas según su grado de involucramiento en el activismo. Como se puede observar en la tabla 5.14, los resultados evidencias que existen diferencias estadísticamente significativas en los factores 1 y 2 dependiendo si la persona es activista o no. Al respecto se puede señalar que en el factor 1 (incertidumbre y preocupación por la aceptación) los activistas obtuvieron puntajes menores que los no activistas. Mientras que en el factor 2 (integración de la identidad) los activistas obtuvieron puntajes mayores. Además según lo planteado por Cohen (1988) los tamaños del efecto hallados serían considerados como pequeños y medianos.

Tabla 5.14

Comparación de los factores según activismo

\begin{tabular}{|c|c|c|c|c|c|c|}
\hline & Activistas & $\begin{array}{c}\text { No } \\
\text { Activistas } \\
\end{array}$ & 0 & \multirow[b]{2}{*}{$Z$} & \multirow[b]{2}{*}{$p$} & \multirow[b]{2}{*}{$r$} \\
\hline & $R m$ & $R m$ & $U$ & & & \\
\hline Factor 1 & 141.38 & 204.98 & 8728.5 & -4.86 & $<.001$ & .25 \\
\hline Factor 2 & 259.64 & 166.94 & 6703 & -7.09 & $<.001$ & .36 \\
\hline
\end{tabular}

Nota: Se aplicó $r$ de Pearson como medida del tamaño del efecto.

En función al análisis trabajado, se considera pertinente elaborar baremos diferenciados para las personas que son activistas y para quienes 
no lo son para cada uno de los factores. Dichos baremos se presentan en la siguiente tabla.

Tabla 5.15

Percentiles para las puntuaciones obtenidas en el factor 1 y el factor 2 de acuerdo a la variable activismo de los participantes

\begin{tabular}{|c|c|c|c|c|}
\hline \multirow[b]{2}{*}{ Percentil } & \multicolumn{2}{|c|}{ Factor 1} & \multicolumn{2}{|c|}{ Factor 2} \\
\hline & $\begin{array}{c}\text { Activistas } \\
\text { LGB }\end{array}$ & $\begin{array}{c}\text { No Activistas } \\
\text { LGB }\end{array}$ & $\begin{array}{c}\text { Activistas } \\
\text { LGB }\end{array}$ & $\begin{array}{c}\text { No Activistas } \\
\text { LGB }\end{array}$ \\
\hline & $(n=286)$ & $(n=92)$ & $(n=286)$ & $(n=92)$ \\
\hline 99 & 44 & 48 & 30 & 30 \\
\hline 95 & 37 & 42 & & \\
\hline 90 & 32 & 41 & & 29 \\
\hline 85 & 30 & 39 & & 27 \\
\hline 80 & 28 & 37 & 29 & 26 \\
\hline 75 & 25 & 35 & & 25 \\
\hline 70 & 24 & 33 & 28 & 24 \\
\hline 65 & 23 & 31 & & 23 \\
\hline 60 & 22 & 28 & 27 & 22 \\
\hline 55 & 21 & 26 & 26 & 21 \\
\hline 50 & 20 & 25 & & \\
\hline 45 & 19 & 24 & 25 & 20 \\
\hline 40 & 18 & 23 & & 19 \\
\hline 35 & 17 & 22 & & 18 \\
\hline 30 & 17 & 21 & 24 & 16 \\
\hline 25 & 16 & 19 & 23 & 15 \\
\hline 20 & 15 & 18 & 22 & 14 \\
\hline 15 & 14 & 16 & 21 & 13 \\
\hline 10 & 13 & 14 & 20 & 11 \\
\hline 5 & 11 & 11 & 17 & 10 \\
\hline Nota: $N=$ & & & & \\
\hline
\end{tabular}




\section{CAPÍTULO VI: DISCUSIÓN}

El presente capitulo contará con dos sub categorías de análisis y resultados. En primer lugar se trabajará la discusión sobre el proceso de adaptación del instrumento y además se llevara a cabo un análisis a modo de interpretación de las propiedades psicométricas trabajadas en el capítulo anterior de Resultados. En segundo lugar, teniendo en consideración lo establecido según los Estándares para la Evaluación Educativa y Psicológica (American Educational Research Association [AERA], American Psychological Association [APA] y National Council on Measurement in Education [NCME], 2014) se llevará a cabo una revisión y selección de aquellos criterios con los cuales el análisis psicométrico de esta investigación cumplen. Finalmente se desarrollarán las limitaciones del presente estudio.

\subsection{Proceso de adaptación y propiedades psicométricas}

El proceso de adaptación según lo propuesto por Beaton, Bombardier, Guillemin y Ferraz (1998) debe contar con cinco etapas que va más allá de una mera traducción y contra traducción. Es a través de este proceso que también deben considerarse aspectos semánticos, idiomáticos, empíricos y conceptuales de los ítems que conforman el test. Dicho procedimiento fue seguido con rigurosidad en la presente investigación para poder asegurarnos que la versión preliminar en español de la LGBIS cumpliera con los criterios de calidad de adaptación tras cultural y lingüística sugeridos por el autor de la prueba original y además fuera un instrumento que cumpliera las características necesarias para ser aplicado a la población LGB en el contexto peruano.

Después de una revisión de los ítems con los integrantes del comité multidisciplinario se consideró necesario llevar a cabo las siguientes modificaciones: El ítem 6, "Me alegra ser una persona LGB" fue modificado a "Me siento bien siendo una persona LGB" pues se consideraba que el ítem en ingles "I am glad to be an LGB person" al 
utilizar el verbo "glad" hace referencia a un estado de satisfacción y bienestar más no a un estado de alegría o felicidad. Asimismo, el ítem 12, "Reconocer que soy una persona LGB ha sido un proceso muy doloroso" es modificado a "Aceptarme como una persona LGB ha sido un proceso muy doloroso", pues el ítem en inglés "Admitting to myself that I am an LGB person has been a very painful process" al utilizar la frase "admitting to myself" buscan que los evaluados den cuenta de un proceso de auto aceptación el cual implicaría un previo reconocimiento de su orientación sexual. Por otro lado el ítem 27, "Creo que es injusto que experimente atracción a personas de mí mismo sexo" es modificado a "Creo que es incorrecto que experimente atracción a personas de mí mismo sexo" pues los jueces consideraron que el ítem en ingles "I believe it is unfair that I am attracted to people of the same sex" más que una cuestión de justicia o injusticia al utilizar la palabra "unfair" daría cuenta de una proceso de censura social que puede llevar a que las personas LGB sientan que una orientación sexual diferente a la heterosexual es algo incorrecto o no normativo. Teniendo en cuenta estos aportes, finalmente se elabora la versión preliminar en español de la "Escala de Identidad para Lesbianas, Gays y Bisexuales (LGBIS)".

Posteriormente, luego del estudio piloto comentado también se llevaron a cabo algunas modificaciones. El ítem 19, "Mi orientación sexual es un asunto muy personal y privado" fue modificado a "Oculto mi orientación sexual por ser una asunto personal muy privado" pues los participantes manifestaron que si se buscaba indagar sobre un tema de visibilidad o invisibilidad gay o lésbica, era relevante preguntarlo de una manera directa en la cual no solo se denotara la privacidad de aspectos de la propia identidad de la personas sino que se remarcara la necesidad de no expresar su propia identidad de orientación sexual. De la misma forma el ítem 21, "Para entender quién soy yo, se tiene que saber que soy una persona LGB" fue modificado a "Para entenderme como persona se tiene que saber que soy LGB" pues la primera versión del ítem era un poco ambiguo y muchos participantes manifestaron no comprender el sentido 
del ítem. Por último el ítem 27 modificado, "Creo que es incorrecto que experimente atracción a personas de mí mismo sexo" es modificado nuevamente a la versión original "Creo que es injusto que experimente atracción a personas de mí mismo sexo" ya que la versión modificada no tuvo una buena aceptación por los participantes del estudio piloto pues algunos señalaron que el adjetivo "incorrecto" es un adjetivo estigmatizador que ahondaría en aspectos de prejuicio y normatividad hacia la población LGB. Además frecuentemente la pregunta que se hacen al cuestionar en un inicio una orientación sexual diferente a lo esperado por la regla heteronormativa es ¿Por qué yo?, lo cual evidentemente si reflejaría estos sentimientos de injusticia. Por otro lado cabe señalar que varios de los participantes notaron con claridad que el ítem 11 y el 15 son ítems que indagan el mismo aspecto señalando que era bastante obvio que uno se encontraba redactado en afirmación y el otro en negación por lo cual les parecía redundante. Lo mismo ocurrió con el ítem 11 y el ítem 24. Asimismo, el ítem 8 les pareció un poco inconsistente pues la mayoría de participantes del estudio piloto, a pesar que algunos aún no habían develado su identidad a otras personas consideraban que la orientación sexual era un aspecto estable de sus identidades.

Por lo tanto, dada la rigurosidad del proceso de adaptación lingüística y siguiendo todos los pasos metodológicos propuestos por Beaton, Bombardier, Guillemin y Ferraz (1998) podemos concluir que se ha llevado a cabo un adecuado proceso de adaptación lingüística de la LGBIS. Asimismo, el análisis llevado a cabo corrobora lo propuesto por Hambleton (1996) respecto a que el proceso de traducción es solo un primer paso para adaptación lingüística.

Por otro lado, a nivel de las evidencias de validez vinculadas al contenido de la LGBIS, se obtuvieron resultados que respaldaban la estructura teórica propuesta por por Mohr y Kendra (2011) quienes basan dicho instrumento en una perspectiva multidimensional de la identidad de orientación sexual. En este sentido, las dimensiones seleccionadas por los 
autores y los ítems que conforman la LGBIS guardan coherencia con los objetivos de la prueba (Sireci y Faulkner-Bond, 2014).

Sin embargo, cabe señalar que las evidencias basadas en la estructura interna de la LGBIS a través del AFE reportó la existencia de 2 factores o dimensiones lo cual contradice la propuesta inicial de los autores. Al respecto, el primer factor hallado en el presente estudio incluye ítems de las dimensiones preocupación por la aceptación, motivación a la invisibilidad e incertidumbre a la identidad, y dificultad en el proceso. Y el segundo factor agrupa los ítems de las dimensiones originales afirmación de la identidad y centralidad de la identidad. Además, los ítems de las dimensiones homonegatividad internalizada y superioridad de la identidad fueron eliminados en su totalidad.

Para poder entender estas diferencias a nivel de la estructura de la escala, es necesario señalar que el análisis factorial exploratorio realizado por Mohr y Kendra (2011) con una rotación ortogonal equamax fue llevado a cabo con una muestra $(N=297)$ menor a la del presente estudio. Además, la LGBIS se aplicó a una muestra de estudiantes universitarios norteamericanos abiertamente LGB y relativamente orgullosos respecto a su identidad de orientaciones sexual. En su contraparte, la versión en español de la LGBIS se aplicó a una muestra bastante diversa de personas LGB con diferentes grados de nivel educativo, diferentes niveles de apertura y aceptación de su propia identidad y diferentes lugares de residencia en todo el Perú. Por lo tanto, es probable que las ocho dimensiones originales propuestas en la versión original del instrumento se cumplan en una población con características similares al del estudio original más no en una población de jóvenes-adultos peruanos LGB residentes en el Perú. Al respecto, Mohr y Kendra (2011) advierten que la estructura factorial y correlaciones de la misma es probable que difiera de un grupo de personas a otro pues los contextos sociales influirán en cómo las personas LGB entienden y responden a su identidad sexual. Estas posibles diferencias a nivel de estructura factorial, consistencia interna y evidencia vinculadas a la validez también son mencionadas por Mohr y 
Fassinger (1996) pues advierten que muchos de los estudios sobre dimensiones de la identidad de orientación sexual cumplen características específicas similares a las mencionadas por Mohr y Kendra (2011), por lo tanto no pueden realizarse generalizaciones del mismo modelo a subgrupos o poblaciones inmersas en contextos diferentes.

Por lo tanto, teniendo en cuenta la nueva estructura factorial hallada se puede señalar que las puntuaciones derivadas calculadas por medio del alfa de Cronbach y alfa ordinal para cada factor a nivel general y según orientación sexual superan el criterio de .70 (Nunnally y Bernstein, 1995). Los coeficientes alfa de Cronbach fluctuaron entre 79 y .91; mientras que los alfas ordinales fluctuaron entre 88 y .91 . Por lo tanto según la clasificación de DeVellis (2012) dichos coeficientes serían categorizados como altos, muy altos y óptimos.

En relación a la confiabilidad, cabe destacar que en muchas investigaciones se asume que la matriz de correlaciones tiene un carácter continuo, sin embargo diversos autores proponen que los datos con los que trabajan en las ciencias sociales no necesariamente cumplen este criterio de continuidad. Consecuentemente, utilizar un modelo para la estimación de la fiabilidad en datos ordinales que asume su continuidad tiene efectos negativos sobre el coeficiente de consistencia interna (Zumbo, Gadermann y Zeiser, 2007). Teniendo en consideración lo antes expuesto, se le dará mayor relevancia y será necesario interpretar la confiabilidad de las puntuaciones halladas en función a los puntajes del alfa ordinal puesto que la escala de la presente investigación cuenta con ítems politómicos o en formato Likert de respuesta (Gadermann, Guhn y Zumbo, 2012; Zumbo et al., 2007).

En ese sentido, a pesar de las notables diferencias entre la LGBIS y la EDOS-LGB aún se mantiene una estructura de dos dimensiones o factores que respalda lo propuesto por Mohr y Fassinger (2000) respecto a que dada la compleja naturaleza de la identidad de las personas, es preferible una conceptualización multidimensional de los sentimientos y creencias de las personas sobre su propia orientación sexual. Además se 
considera que cada dimensión es relevante y significativa a lo largo del desarrollo de la identidad de orientación ya que involucran diferentes aspectos de la vida de cada individuo; favoreciendo así a una aproximación más completa del funcionamiento psicológico de las personas LGB. De la misma forma, Currin, Gibson y Ubach (2015) destacan el uso de un modelo multidimensional para el estudio e investigaciones de la orientación sexual. Asimismo, según la APA (2013) la orientación sexual hace referencia a un patrón duradero de emociones, atracciones románticas y sexuales, el sentido de identidad de uno mismo basado en las atracciones que siente, comportamientos relacionados $\mathrm{y}$ pertenencia a una comunidad o grupo que comparte dichas atracciones. Evidenciándose así una gama de aspectos o dimensiones que involucran la orientación sexual y la identidad de orientación sexual. Finalmente, siguiendo a Ashmore, Deaux y McLaughlin-Volpe (2004) la identidad LGB, al igual que otras identidades colectivas es considerada como multidimensional.

A continuación, teniendo en consideración la nueva estructura bidimensional de la EDOS-LGB, se profundizará en el análisis de cada una de sus dos dimensiones o factores.

El primer factor contiene algunos de los ítems de las dimensiones originales preocupación por la aceptación, motivación a la invisibilidad, incertidumbre a la identidad y dificultad en el proceso. Se decide llamar dicha dimensión "incertidumbre y preocupación por la aceptación” pues se considera que dicho nombre engloba la forma en que dicho factor se manifiesta en la población peruana. Al respecto se infiere que esta dimensión se presenta de una forma ensamblada en el Perú puesto que el contexto peruano no es el más favorable para las personas LGB y muy por el contrario refuerza y promueve una visión heteronomativa. En este sentido darse cuenta que uno tiene una orientación sexual diferente a la heterosexual sería un proceso que implicaría altos niveles de confusión e incertidumbre por no encajar en este ideal heterosexual. Esto a su vez generará gran preocupación en las personas LGB de cómo serán aceptadas 
por su entorno, por lo tanto preferirán no revelar su orientación sexual si se percibe que dicho entorno no es el más favorable. Por lo tanto, esta sería una medida que emplearían para evitar ser discriminados, estigmatizados, rechazados e incluso en el peor de los casos ser víctimas de violencia física. Como se señala en el "Informe anual sobre derechos humanos de las personas trans, lesbianas, gays y bisexuales", la vulneración de los derechos humanos de las poblaciones TLGB se ve constantemente legitimada a través de muestras de indiferencia, burla, menosprecio, humillación y restricción a la libre expresión tanto en espacios públicos y privados (PROMSEX, 2014).

En relación a lo anteriormente mencionado, Worthington, Navarro, Savoy, y Hampton (2008), sugieren que la confusión o incertidumbre respecto a la orientación sexual y el conjunto de interrogantes que se generan en relación a este ámbito son un evento normativo durante el desarrollo de la identidad de orientación sexual de las personas LGB. Asimismo, se puede señalar que dado que las personas LGB conforman una minoría sexual; al darse cuenta que no encajan con la norma heterosexual surgirán una serie de cuestionamientos y deseo de ocultar dicho aspecto de sus vidas. Al respecto McCarn y Fassinger (1996) señalan que cuando la persona se encuentra descubriendo y cuestionando su identidad de orientación sexual no solo se produce un cambio en cómo se etiquetan ellos mismos, sino también se produce una cambio en el significado que ellos y ellas atribuyen a dicha etiqueta que se asignan. Por lo tanto ante una situación de incertidumbre podrían estar más propensas internalizar conceptualizaciones discriminatorias, a partir de las cuales pueden surgir muchos temores de cómo serán aceptados por su entorno y consecuentemente preferir ocultar su orientación. Por lo tanto, es probable que las personas que aún no se muestran abiertamente como lesbianas, gays y bisexuales, experimenten menos eventos cotidianos negativos relacionados a discriminación por su orientación sexual ya que el entorno no sabe sobre su identidad de orientación sexual. No obstante, el estrés interno de estas personas que viven en una constante lucha por ocultar su 
orientación sexual es una fuente interna de estrés predominante en las minorías sexuales que no "salen del closet" y que su vez generan mayores niveles de afecto negativo (Diplacido, 1998).

Lo señalado en los párrafos anteriores debe complementarse con el hecho que el desarrollo de identidad de orientación sexual para las personas LGB es un proceso complejo que en ocasiones hasta puede verse como un reto pues implica ir en contra de las reglas heteronormativas de la nuestra sociedad. Tal y como Rosario, Schrimshaw y Hunter (2011) señalan, el desarrollo de la identidad de las personas LGB además de ser un proceso complejo es un proceso difícil ya que estas personas se desenvuelven en un entorno donde predominantemente existe ignorancia y hostilidad hacia la homosexualidad. Es así que este contexto adverso; tal y como ocurre en el contexto peruano, sería una de las principales razones por las cuales dicho proceso es percibido como complicado y a su vez dificultaría la auto aceptación de las personas LGB. Por lo tanto, no es en vano que en el medio peruano las dimensiones originales que involucraban elementos de dificultad en aceptar su orientación sexual, deseo de ocultar la orientación sexual por miedo a como son juzgados e inseguridades se presenten de manera ensamblada y como un todo y aspecto normativo en algún momento del desarrollo de la identidad de orientación sexual de la muestra peruana pues el entorno social no es favorable para ellos y ellas.

En el caso del segundo factor, conformado por los ítems de las dimensiones centralidad de la identidad y afirmación de identidad se puede inferir que ambas dimensiones se han agrupado de tal forma ya que los ítems de estas dos dimensiones buscan evaluar aspectos de las personas LGB una vez que han alcanzado niveles óptimos de aceptación de su identidad de orientación sexual lo cual a su vez se vincula con la percepción de dicha identidad como una parte fundamental y positiva de sus identidades como personas. Lo mencionado anteriormente a su vez podría facilitar su integración a la comunidad LGB y en conjunto representar el bienestar que la persona siente siendo una persona LGB y 
perteneciendo a dicha comunidad. Asimismo, tal como lo menciona Meyer (2003) la centralidad de la identidad podría ser considerada como un mediador de estrés minoritario. Asimismo la afirmación de la identidad es considerada como una fuente de resiliencia en las personas LGB (Riggle, Whitman, Olson, Rotosky y Strong, 2008). En este sentido lo común de ambas dimensiones es sentirse conforme y satisfecho con su identidad de orientación sexual lo cual favorecer y permite que las personas LGB se encuentren en mejores condiciones de enfrentar de una manera más óptima su situación dentro de grupo minoritario que muchas veces es estigmatizado.

Asimismo, dado a que la centralidad y la afirmación de la identidad son dimensiones nuevas en la escala LGBIS a diferencia de la primera versión del instrumento (LGIS) requieran mayor estudio e investigación para analizar si realmente trabajan aspectos totalmente independientes o si en realidad forman parte de una misma dimensión como se evidencia en la presente investigación. Se decide nombrar esta nueva dimensión como integración de la identidad retomando lo propuesto por Rosario, Schrimshaw, Hunter y Braun (2006). Dichos autores sostienen que la integración de la identidad implica una incorporación de la identidad de orientación sexual dentro del self de la persona y que además implica un compromiso con su identidad LGB. Asimismo, esta integración involucra que las personas se sientan más dispuestas a involucrarse en actividades sociales LGB y que a la vez sean capaces de sentir mayor comodidad respecto a la apertura de su propia identidad de orientación sexual.

Por otro lado, cabe señalar que la eliminación de los ítems de la dimensión homonegativdad internalizada causa cierta sorpresa pues la homofobia internalizada es una de las dimensiones más estudiadas y además considerada como una consecuencia inevitable a la situación de discriminación y rechazo que viven las personas LGB (Davies, 1996). Al respecto, Margnolies, Becker y Jackson-Brewer (1987) señalan que la homofobia internalizada muchas veces opera de una manera poco 
consiente y de manera sutil (Szymanski y Chung, 2003). Además Malyon (1982) sugiere que es un elemento que en ocasiones requiere trabajo terapéutico para poder notar su presencia. Por lo tanto es probable que su identificación requiera una evaluación diferenciada y a mayor profundidad. En este sentido, se podría inferir que un par de ítems dentro de una escala que evalúa también otras áreas, no sería lo óptimo para acceder a las características subyacentes de la homofobia internalizada. Por lo tanto se recomendaría evaluar la homofobia internalizada de manera independiente y tal vez de forma indirecta a través de constructos relacionados como la autoestima ya que la homofobia internalizada se encuentra asociada a elementos de baja autoestima, autocritica y sentimientos de inferioridad (Ross y Rosser, 1996).

Por otro lado, la eliminación de todos los ítems de la dimensión "Superioridad de la identidad", podría deberse a que tanto el ítem 7, "Menosprecio a los heterosexuales"; como el ítem 10, "Considero que las personas LGB son superiores a las personas heterosexuales" y el ítem 18, "Las personas heterosexuales tienen vidas aburridas comparadas con personas LGB" son ítems que se encuentran redactados de una manera muy directa. Asimismo, el verbo "menospreciar" y el adjetivo "superiores" son palabras que denotan no solo una relación de diferencia sino que subyacentemente también pueden transmitir ciertos niveles de rechazo. En la presente muestra, la mayoría de las personas marcó totalmente en desacuerdo y parcialmente en desacuerdo, lo cual podría estar respondiendo al efecto que provoca la deseabilidad social y el deseo de no querer juzgar al otro de una manera abiertamente negativa. Asimismo el tipo de redacción de los ítems induce a respuestas socialmente aceptadas (Warner, 1965).

Finalmente con respecto a la elaboración de baremos, con la finalidad de facilitar la interpretación de los puntajes derivados, se elaboraron normas que faciliten comparar la ubicación de una persona con respecto a un grupo de referencia (Muñiz, 1999). Por lo tanto, se calcularon los percentil según su utilidad para representar el valor debajo 
del cual se encuentra un determinado porcentaje de valores, dada una distribución de dichos puntajes (Clark-Carter, 2005). En este sentido se evaluó la pertinencia de elaborar baremos diferenciados según orientación sexual y grado de activismo. Al respecto fue necesario elaborar baremos diferenciados para cada uno de los factores.

A nivel de orientación sexual, las variaciones en las puntuaciones entre lesbianas, gays y bisexuales era de esperarse ya que estas también han sido reportadas en investigaciones previas. Por ejemplo Mohr y Fassinger (2000) encontraron diferencias entre las puntuaciones de algunas dimensiones en función a la orientación sexual. Al respecto, podría considerarse que las puntuaciones de las personas bisexuales también diferirían de las personas gays y lesbianas ya que a pesar que los tres sub grupos comparten el hecho que son víctimas de prejuicios; en el caso de las personas bisexuales también reciben rechazo por parte de las personas gays y lesbianas (Mohr y Kendra, 2011). Además Herek (2000) halló que las actitudes negativas son predominantes y mayores hacia las personas bisexuales en comparación a las actitudes hacia las personas gays y lesbianas. Por lo tanto, se podría entender que dada esta "doble discriminación" los puntajes más altos en el factor 1 (incertidumbre y preocupación por la aceptación) se presentan en el grupo de personas bisexuales. Por lo tanto, podríamos señalar que la forma en que cada subgrupo de esta minoría sexual vivencia su identidad de orientación sexual sería diferenciada y se vincularía con las diferentes dificultades en relación al estigma social que presentan tanto en común pero también de manera diferenciada.

Por otro lado, a nivel de activismo, se encontró que las personas activistas obtuvieron puntajes más altos en el factor 2 (integración de la identidad) mientras que los no activistas obtuvieron puntajes más altos en el factor 1 (incertidumbre y preocupación por la aceptación). Las variaciones de las puntuaciones según estos dos perfiles de personas guardan relación con los hallazgos obtenidos en otras investigaciones. Al respecto, para Fingerhut, Peplau y Gable (2010) aquellas personas que 
están conectadas a una comunidad LGBT son capaces de encontrar una fuente de soporte para neutralizar estresores vinculados a su estatus de grupo estigmatizado por su orientación sexual. En el caso de nuestro país, esto se logra muchas veces perteneciendo a un grupo de activismo. En este sentido esto podría influir en como ellos vivenciarán aspectos relacionados a la aceptación y a su vez a una integración de su propia identidad. Asimismo, Renn y Bilodeau (2002) encontraron que ser activista en organizaciones LGBT estudiantiles contribuía y tenía un impacto en el desarrollo de las identidades de estas personas.

\subsection{Estándares para la Evaluación Educativa y Psicológica (AERA, APA y NCME, 2014)}

\subsubsection{Estándares para la validez}

1.1. El autor de la prueba tiene que especificar la modalidad en la cual los puntajes de esta se interpretarán y utilizarán. La población para la cual se destinará el instrumento debe determinarse claramente y el constructo o constructos que la prueba pretender evaluar también deben describirse con claridad (p. 23): La EDOS-LGB tiene como objetivo evaluar las dimensiones de la identidad de orientación sexual. Asimismo esta escala ha sido diseñada para ser utilizada con personas lesbianas, gays y bisexuales del Perú, con la finalidad de poder conocer características de las dimensiones de la identidad de orientación en las personas LGB. Cabe destacar que se ha definido y conceptualizado cada una de las dos dimensiones o factores que la conforman. Finalmente, se detalla un proceso estandarizado tanto de administración como de corrección de la EDOS-LGB.

1.6. Cuando el uso de una prueba es recomendada para producir beneficios indirectos, además de la información que respalda la utilidad de las interpretaciones de los puntajes, se debe argumentar esta anticipación de beneficios indirectos con evidencias empíricas y también señalando efectos no esperados o contradictorios. Argumentos lógicos y teóricos así 
como evidencias empíricas de los beneficios indirectos deben ser proporcionados (p. 24): La EDOS-LGB puede ser utilizada en un futuro en complemento con otros instrumentos que miden constructos tales como depresión, ansiedad, bienestar, estrés, autoestima, auto-concepto etc. para de esta forma obtener correlaciones directas e inversas entre las dimensiones de la escala presentada y otros constructos. De esta forma se podría tener una aproximación más cercana a posibles áreas de dificultad en las personas LGB asociadas a su vez a su estatus de grupo minoritario y discriminación. En este sentido una vez llevado a cabo este proceso es factible elaborar intervenciones especificas desde el área clínica y según sea el caso teniendo en consideración un enfoque afirmativo de la psicología. Al respecto, en la justificación y el marco teórico se detallan evidencias al respecto.

1.8. La composición de cualquier muestra de evaluados a partir de la cual se obtienen las evidencias de validez deben ser descritas de la manera más detallada posible. A su vez se deben incluir los datos socioeconómicos relevantes y características de desarrollo (p. 25): En la sección de método estos datos fueron presentados a detalle. Los participantes fueron peruanos residentes en Lima con una orientación sexual de lesbiana, gay y bisexual que se encontraran en un rango de edades entre 18 y 45 años. Asimismo, a partir de la ficha sociodemográfica se puedo detallar las características relevantes de las personas que participaron en este estudio. Principalmente se puede señalar que se contó con una muestra conformada por 384 personas con un promedio de edad de 26.67 años $(D E=7.25)$. Con relación a la variable sexo, el $31.3 \%$ de la muestra es de sexo femenino mientras que el $68.8 \%$ es de sexo masculino. Con respecto a la variable orientación sexual; el $22.4 \%$ de personas se identifican como personas bisexuales, el $59.9 \%$ se identifican como hombres gays, el $17.7 \%$ se identifican como mujeres lesbianas. 
1.9. Cuando la validación recae sobre las decisiones u opiniones de un grupo de jueces expertos, observadores o evaluadores, es necesario especificar a detalle el proceso de selección de dichos expertos así como el medio por el cual se pueden registrar sus juicios. Se debe presentar sus cualificaciones y experiencia. Se debe reportar cualquier tipo entrenamientos e instrucciones provistas, además se indicar si los jueces llegaron a sus juicios de manera independiente y finalmente reportar el grado de acuerdo. Si los jueces interactuaron uno con el otro o intercambiaron información también debe detallarse. (p. 25): Se contó con la participación de once jueces para dos procedimientos independientes. En primer lugar para el proceso de adaptación del instrumentos fueron seis los jueces que formaron parte del comité de expertos multidisciplinarios; para este fin se requirió el apoyo de un psicólogo experto en metodología de construcción de instrumentos, un experto en el área de psicología clínica, un psicólogo experto en el área psicométrica, una lingüista y un experto en estudios de género y temática LGBT. En cada uno de los casos al momento de entregarles el instrumento a evaluar se les entrego una hoja de información en donde se recaudaron datos sobre su experiencia profesional y académica. En segundo lugar, para poder obtener evidencias de validez vinculadas al contenido, se contó con el apoyo de seis jueces psicólogos con experiencia en el área de sexualidad y la temática LGBT. Asimismo cabe señalar que para ambos procedimiento se les pidió a los jueces completaron las matrices de calificación, para lo cual se les proporcionó instrucciones escritas (ver anexo 6). A partir de las calificaciones de los seis jueces se obtuvo un coeficiente V de Aiken para los 27 ítems superior al mínimo valor de V (.70).

1.10. Cuando las evidencias de validez incluyen análisis estadísticos de los resultados de la prueba; de manera individual o en conjunto con los datos de otras variables, las condiciones bajo las cuales se recolectó la información debe describirse de manera detallada para que los usuarios puedan juzgar la relevancia de los hallazgos estadísticos (p. 26): en la sección de método, específicamente en el área de procedimiento y 
posteriormente en resultados se ha descrito a detalle todo el procedimiento llevado a cabo desde la preparación, recolección de datos y análisis psicométrico.

1.13. Si la base para las interpretaciones de las puntuaciones de un test para un uso determinado depende de la relación entre los ítems o entre partes del test, es necesario consignar evidencias vinculadas a la estructura interna (p. 26): Al respecto, en el capítulo de Resultados como a su vez en la primera parte de este capítulo de Discusión, se han proporcionado evidencias que respaldan la estructura bidimensional de la EDOS-LGB. En este sentido se presentaron datos que permitirán analizar e interpretar las puntuaciones de cada una de las dos dimensiones o factores.

\subsubsection{Estándares para la confiabilidad}

2.0. Se debe proporcionar apropiadas evidencias de confiabilidad/precisión para las interpretaciones de las puntuaciones para cada uso (p. 42): Al respecto, se ha llevado a cabo un análisis de confiabilidad tanto usando el alfa de Cronbach y alfa ordinal los cuales superan el criterio de .70 establecido por Nunnally y Bernstein (1995).

2.3. Para cada puntaje total, sub puntaje, o combinación de puntajes que se van a interpretar, se deben reportar índices relevantes de confiabilidad ( $\mathrm{p}$. 43): Los niveles de confiabilidad para cada una de las dos dimensiones de la EDOS-LGB han sido debidamente reportados en el capítulo de Resultados.

2.5. Los procedimientos para la estimación de la confiabilidad debe ser consistente con la estructura del test (p. 43): Después de haber hallado una estructura factorial de dos dimensiones a partir del análisis factorial exploratorio, se procedió a estimar la confiabilidad para cada dimensión de la EDOS-LGB. 
2.11. El autor del instrumento debe reportar la estimación de la confiabilidad para cada uno de los subgrupos relevantes para el cual se recomienda el test (p. 45): En el capítulo de Resultados los niveles de confiabilidad estimados para el subgrupo de lesbianas, gays y bisexuales es reportado.

2.13. El Error Estándar de Medición (EEM), tanto el general como el condicional (si es reportado), debe proporcionarse en unidades para cada puntuación reportada (p. 45): Al momento de llevar a cabo el procedimiento para hallar la confiabilidad también se calculó el EEM tanto para el alfa de Cronbach como para el alfa ordinal a nivel general y para cada sub-grupo de lesbianas, gays y bisexuales.

\subsubsection{Estándares para el diseño y desarrollo de la prueba}

4.0. Los test y programas de evaluación deben de diseñarse y desarrollarse de tal modo que sustenten la validez de las interpretaciones de las puntuaciones de la prueba para los usos para los que ha sido propuesta. Los diseñadores de la prueba deben documentar todos los pasos realizados durante el proceso de diseño y desarrollo de la prueba para así poder proporcionar evidencias de validez y confiabilidad para los usos y población que se ha definido. (p. 85): Todo el procedimiento llevado a cabo para la adaptación y análisis de las propiedades psicométricas de la LGBIS han sido reportados a lo largo de la presente investigación en el capítulo de métodos y resultados. Asimismo en los anexos presentados se proporciona la documentación que ha sido utilizada a lo largo del proceso de traducción y adaptación de dicho instrumento. De la misma forma, finalmente se reporta la nueva versión adaptada denominada EDOS-LGB (Ver Anexo 4).

4.1. Se deben describir las especificaciones del test tales como: propósito o propósitos de la prueba, la definición del constructo o dominio que será 
evaluado, la población a la que está dirigida y las interpretaciones para cada uso (p. 85): Al respecto, estos datos han sido reportados de forma detallada en el capítulo de Marco Teórico y en el capítulo de Método. Además se cuenta con las especificaciones de la ficha técnica del instrumento LGBIS y posteriormente EDOS-LGB (Ver Anexo 4).

4.2. Además de los puntos anteriores mencionados, es necesario especificar el contenido del test, la duración que toma la aplicación, el formato de los ítems, las propiedades psicométricas de los ítems y del test, así como también el orden de los ítems y secciones. Además debe reportarse el tiempo permitido para la aplicación, las instrucciones para quienes llevan a cabo las instrucciones, los procedimientos a usarse para su administración, las variaciones, el material a utilizar y el procedimiento de calificación (p. 85): En relación a los ítems, estos se encuentran detallados en la sección de método así como también el tipo de formato. Por otro lado estos fueron ordenados al azar a través de un software que llevo a cabo esta tarea. Con fines de reportar algunos de los requerimientos mencionados en este estándar, se elaboró una ficha técnica donde dichas especificaciones han sido detalladas (ver anexo 4). Por otro lado en relación a los aspectos psicométricos, estos se encuentran en el capítulo de Resultados como también en la ficha técnica.

4.8. El proceso de revisión del test debe incluir un análisis empírico o los aportes de los juicios de expertos para la revisión de ítems y los criterios de puntuación. Cuando se utiliza el juicio de expertos es relevante reportar información sobre las cualificaciones de los jueces, su experiencia y característica demográficas. Asimismo el entrenamiento o instrucciones dadas para el proceso de evaluación de los ítems debe ser detallas (p. 88): Estos datos han sido reportados y tomados en consideración durante la presente investigación como se ha mencionado reiteradas veces a lo largo de este documento en la sección de procedimiento. Asimismo las instrucciones y matriz de calificación se encuentran reportadas en los anexos (ver anexo 6). 
4.10. Cuando el autor o creador del test evalúan las propiedades psicométricas de los ítems, se debe de señalar cual ha sido el modelo psicométrico empleado. Además, se debe describir la muestra utilizada para estimar las propiedades psicométrica. Se recomienda que esta muestra sea de un adecuado número y diversidad (p. 89): El análisis psicométrico de la LGBIS partió del modelo psicométrico de la teoría clásica de los test. Igualmente, la muestra utilizada para la presente investigación se encuentra detallada en el capítulo de Método. Cabe señalar que el tamaño de la muestra sobrepasa el tamaño recomendado según el criterio de Nunnally (1987) de diez sujetos por ítem. Por último, la escala fue aplicada a personas LGB de diferentes lugares del Perú, así como también de diferentes características sociodemográficas.

4.15. Se debe presentar con claridad las indicaciones de administración para que otros puedan replicar las condiciones bajo las cuales los datos de confiabilidad, validez y normas fueron obtenidos. De haber variaciones en los procedimientos de administración estos deben ser especificados ( $\mathrm{p}$. 90): El procedimiento llevado a cabo para la aplicación de la LGBIS a través del cual posteriormente se pudieron estimar propiedades de confiabilidad, validez y las normas pertinentes para cada grupo se encuentra descrito a detalle en el capítulo de Métodos y posteriormente en Resultados. Asimismo, las instrucciones, el mensaje adicional que permite a las personas LGB que se auto-identifiquen con otras etiquetas, la información relacionada a las tablas trabajadas por los jueces, las aclaraciones a los traductores y jueces se encuentran detallas en el capítulo de Método así como también en los anexos (ver anexo 4).

4.16. Las instrucciones presentadas para las personas quienes tomaran la evaluación deben contener suficientes detalles para que de esta forma puedan desenvolverse y responder a la tarea de la manera en la que el creador de la prueba espera. Estos detalles deben formar parte de la estandarización de las instrucciones al momento de administración del test 
(p. 90): En el caso de la LGBIS como también en la propuesta de prueba se utilizan dos instrucciones que son consideradas como obligatorias al momento de la aplicación de la prueba. Estas instrucciones se encuentran detallas en la sección de Método así como también en la ficha técnica.

4.17. Si un test o parte de él se utiliza con fines de investigación y no para un uso operacional, se debe proporcional enunciados sobre la finalidad del uso de los materiales de administración e interpretación entregados al usuario del test (p. 91): En el documento del consentimiento informado de especifica de manera clara que la aplicación de la LGBIS tenía fines académicos y que los datos que se obtendrían y el uso de ellos formaban parte de la presente investigación. Asimismo, se garantizó el anonimato de los participantes, se dio las facilidades para que se comunicaran con la investigadora de presentarse algún inconveniente y a su vez se les ofreció la oportunidad para desistir en la participación de la presente investigación si lo consideraban pertinente (ver anexo 7).

\subsubsection{Estándares para la elaboración de normas}

5.8. De utilizarse normas, estas deben hacer referencia a poblaciones claramente descritas. Estas poblaciones deben incluir individuos o grupos con los cuales los evaluadores querrían comparar a sus propios examinados (p. 104): Tal y como se reporta en los análisis estadísticos en la parte de elaboración de baremos en la sección de Resultados; se consideró pertinente elaborar baremos diferenciados teniendo en consideración si los participantes eran activistas o no y según la orientación sexual.

\subsubsection{Estándares para la administración, puntuación, reporte e interpretación}

6.1. Los evaluadores tienen que seguir cuidadosamente los procedimientos estandarizados para administrar y puntuar que han sido especificados por el desarrollador de la prueba y otras instrucciones que indique (p. 114): La 
investigadora llevo a cabo el mismo procedimiento utilizado por el autor de la prueba siguiendo todas las instrucciones de aplicación señaladas, utilizando a su vez la consigna adicional que el autor de la prueba indicó para el caso de investigaciones.

Finalmente, la principal limitación de la presente investigación ha sido la imposibilidad de poder contar con una muestra más grande dada la dificultad de acceso a personas de la comunidad LGB. Esto conllevaría a una limitada capacidad de generalización de los resultados. No obstante, a pesar de dicha limitación se debe destacar que todos los objetivos de la presente investigación han sido cumplidos con rigurosidad dando como resultado la posibilidad de poner a la disposición de la comunidad científica un instrumento multidimensional que evalúa aspectos de la identidad de orientación sexual adaptado a la población LGB peruana. 


\section{CONCLUSIONES}

- En primer lugar, se puede señalar que la LGBIS fue traducida al idioma español a través del método de contra traducción y a su vez fue adaptada satisfactoriamente al contexto peruano.

- En segundo lugar, mediante la evaluación de seis jueces se pudo obtener evidencias de validez vinculadas al contenido, corroborándose así que los ítems que conforman la LGBIS son una muestra representativa del dominio de contenido de lo que mide dicha escala. A pesar que el posterior análisis de la estructura interna del instrumento ofrece información que contradice la estructura según la calificación de los jueces.

- En tercer lugar, a través del análisis factorial exploratorio se alcanzó una estructura interna diferente a la estructura de ocho dimensiones planteadas por Mohr y Kendra (2011). No obstante cabe destacar que se mantiene una estructura dimensional, a pesar que la diferencia radica en que los ítems retenidos de la LGBIS se reagrupan en dos factores o dimensiones.

- En cuarto lugar, se elabora una nueva propuesta de instrumento llamada Escala de Dimensiones de Orientación Sexual para Lesbianas, Gays y Bisexuales (EDOS-LGB) conformado por 13 ítems y organizados en dos sub-dimensiones. Si bien a nivel teórico la EDOS-LGB aún se respaldan teóricamente por lo propuesto por Mohr y Kendra (2011), a su vez también se complementa la propuesta con aportes llevados a cabo por Rosario, Schrimshaw y Hunter (2011)

- En función a las evidencias y resultados hallados en el trabajo de la presente investigación, se puede señalar que se han encontrado evidencias de confiabilidad y validez para los usos e interpretaciones de las puntuaciones obtenidas tras la aplicación de la EDOS-LGB en personas adultas LGB residentes en el Perú. 


\section{RECOMENDACIONES}

- Se recomienda llevar a cabo un análisis factorial confirmatorio con la finalidad de valorar si las dimensiones establecidas en la EDOS-LGB son corroboradas.

- Con la finalidad de presentar nuevas evidencias de validez de contenido complementarias a las ya trabajadas en el presente trabajo, se recomendaría replicar el proceso de criterio de jueces con la nueva estructura factorial propuesta de la EDOS-LGB.

- Para futuros estudios se recomendaría contar con una mayor cantidad de participantes de provincia y a su vez del sexo femenino.

- Asimismo, se recomendaría llevar a cabo futuros estudios que analicen a la mayor profundidad las diferencias entre las diferentes sub-muestras trabajadas: mujeres lesbianas, hombres gays y personas bisexuales; y por otro lado activistas y no activistas.

- Llevar a cabo estudios que correlacionen las dimensiones de la identidad de orientación sexual con otras variables psicológicas. Ya que la literatura existente al respecto proviene de otras realidades como la americana, inglesa, europea y australiana. Por lo que el comportamiento psicológico y resultados varían a los de nuestra realidad. De tal forma, se lograría un mayor acercamiento a las personas LGB peruanas desde la psicología utilizando una perspectiva afirmativa.

- Cualquier uso que quiera tomarse a partir de la aplicación de este instrumento con personas menores de edad o que no sean residentes peruanos tendrá que estar sujeto a un nuevo trabajo de análisis de propiedades psicométricas del presente instrumento. 


\section{REFERENCIAS}

Alarcón, R. (2008). Métodos y diseño de investigación del comportamiento (2 ${ }^{\mathrm{a}}$ ed.). Lima: Universidad Ricardo Palma.

American Educational Research Association, American Psychological Association, \& National Council on Measurement in Education (2014). Standards for educational and psychological testing. Washington: American Educational Research Association.

Ashmore, R. D., Deaux, K., \& McLaughlin-Volpe, T. (2004). An organizing framework for collective identity: Articulation and significance of multidimensionality. Psychological Bulletin, 130(1), 80-114. doi: 10.1037/0033-2909.130.1.80

Balsam, K., \& Mohr, J. (2007). Adaptation to sexual orientation stigma: A comparison of bisexual and lesbian/gay adults. Journal of Counseling Psychology, 54, 306319. doi: http://dx.doi.org/10.1037/0022-0167.54.3.306

Beaton, D. E., Bombardier, C., Guillemin F., \& Ferraz, M. B. (2002). Recommendations for the Cross-Cultural Adaptation of Health Status Measures. Rosemont: American Academy of Orthopedic Surgeons.

Bregman, H. R., Malik, N. M., Page, M. J. L., Makynen, E., \& Lindahl, K. M. (2013). Identity profiles in lesbian, gay, and bisexual youth: The role of family influences. Journal of Youth and Adolescence, 42, 417-430. doi: $10.1007 / \mathrm{s} 10964-012-9798-\mathrm{z}$

Cass, V. (1979). Homosexual identity formation: Testing a theoretical model. The Journal of Sex Research, 20(2), 143-167. Recuperado de https://www.jstor.org/stable/3812348?seq=1\#page_scan_tab_contents

Cea D’Ancona, M. A. (2002). Análisis multivariable, Teoría y práctica en la investigación. Madrid: Sintesis.

Clark-Carter, D. (2005). Percentiles. En B. S. Everitt y D. C. Howell (Eds.), Encyclopedia of Statistics in Behavioral Science (Vol. 3, pp. 1539-1540). Chichester: John Wiley \& Sons.

Clarke. V, Ellis, S. J., Peel, E., \& Riggs, D. W. (2010). Lesbian, gay, bisexual, trans and queer psychology: An introduction. Cambridge: Cambridge University Press.

Cohen, J. (1988). Statistical power analysis for the behavioral sciences ( $2^{\mathrm{a}}$ ed.). Hillsdale, N.J.: Lawrence Erlbaum. 
Cohler, B. J., \& Hammack, P. L. (2007). The psychological world of the gay teenager: social change, narrative, and 'normality'. Journal of Youth and Adolescence, 36(1), 47-59. doi: 10.1007/s10964-006-9110-1

Coleman, E. (1982). Developmental stages of the coming out process. Journal of Homosexuality, 7(2-3), 31-43. doi: 10.1177/000276482025004009

Conger, J. (1975). Proceedings of the American Psychological Association Incorporated, for the year 1974: minutes of the annual meeting of the Council of Representatives. American Psychologist, 60, 620-51. doi: http://dx.doi.org/10.1037/h0078455

Currin, J. M., Gibson, L., \& Hubach, R. D. (2015). Multidimensional assessment of sexual orientation and the fraternal birth order effect. Psychology of Sexual Orientation and Gender Diversity, 2(2), 113-122. doi: http://dx.doi.org/10.1037/sgd0000103

D’Augelli, A. R. (1994). Identity development and sexual orientation: Toward a model of lesbian, gay, and bisexual development. En E. J. Trickett, R. J. Watts y D. Birman (Eds.), Human diversity: Perspectives on people in context (pp. 312333). San Francisco: Jossey-Bass.

Davies, D. (1996). Homophobia and heterosexism. En D. Davies y C. Neal (Eds.), Pink therapy (pp. 41-65). Buckingham: Open University Press.

DeVellis, R.F. (2012). Scale development: Theory and applications. ( $3^{\mathrm{a}}$ ed.). Los Angeles: Sage.

Diamond, L. M. (2008). Bisexuality from adolescence to adulthood: Results from a 10year longitudinal study. Developmental Psychology, 44, 5-14. doi: 10.1037/0012-1649.44.1.5

DiPlacido, J. (1998). Minority stress among lesbians, gay men and bisexuals: a consequence of heterosexism, homophobia and stigmatization. In Herek, G. (Ed.), Stigma and sexual orientation (pp. 138-159). Thousand Oaks: Sage.

Eliason, M. (1996). Identity formation for lesbian, bisexual, and gay persons: Beyond a "minoritazing" view. Journal of Homosexuality, 30(3), 31-58. doi: 10.1300/J082v30n03_03

Escurra, L. (1998). Cuantificación de la validez de contenido por criterio de jueces. Revista de Psicología, 6, 103-111.

Field, A. (2009). Discovering statistics using SPSS (and sex and drugs and rock «n» roll) $\left(3^{\mathrm{a}}\right.$ ed.). Londres: Sage Publications.

Fingerhut, A. W., Peplau, L. A., \& Gable, S. L. (2010). Identity, minority stress and psychological well-being among gay men and lesbians. Psychology and Sexuality, 1, 101-114. doi:10.1080/19419899.2010.484592 
Gadermann, A. M., Guhn, M., \& Zumbo, B. D. (2012). Estimating ordinal reliability for Likert-type and ordinal item response data: A conceptual, empirical, and practical guide. Practical Assessment, Research \& Evaluation, 17(3), 1-13. Recuperado de http://www.pareonline.net/getvn.asp?v=17\&n=3

Glassgold, J. M., Beckstead, L., Drescher, J., Greene, B., Miller, R. L., \& Worthington, R. L. (2009). Report of the American Psychological Association task force on appropriate therapeutic responses to sexual orientation. Washington, D.C.: American Psychological Association.

Haahr, M. (1998). Random.org. [Software de computación en línea]. Irland: Trinity College-School of Computer Science and Statistics. Recuperado de https://www.random.org/

Hair, J. F., Anderson, R. E Tatham, R. L., \& Black, W. C. (2007). Análisis Multivariante ( $5^{\mathrm{a}}$ ed.). Madrid: Pearson.

Hambleton, R. K. (1996). Adaptación de tests para su uso en diferentes idiomas y culturas: Fuentes de error, posibles soluciones y directrices prácticas. En J. Muñiz (Ed.), Psicometría (pp. 207-238). Madrid: Universitas.

Herek, G. M. (2000). Sexual prejudice and gender: do heterosexuals' attitudes toward lesbians and gay men differ? Journal of Social Issues, 56(2), 251-266. Recuperado de http://psc.dss.ucdavis.edu/rainbow/html/jsi2000.pdf

Herek, G. M. (1988). Heterosexuals'attitudes towards lesbians and gay men: Correlates and gender differences. Journal of Sex Research, 25, 451-477. Recuperado de http://www.jstor.org/stable/3812894

Hernández, R., Fernández, C., y Baptista, M. (2014). Metodología de la investigación. (6 ${ }^{\mathrm{a}}$ ed.). México D.F.: McGraw-Hill.

Hill, C. A. (2008). Human sexuality: Personality and social psychological perspectives. Los Angeles, CA: Sage.

Hooker, E. (1957). The adjustment of the male overt homosexual. Journal of Projective Techniques, 21, 18-31. Recuperado de http://www.well.com/ aquarius/hooker.htm

Hopkins, J. H. (1969). The lesbian personality. British Journal of Psychiatry, 115, 1433-1436. Recuperado de http://www.ncbi.nlm.nih.gov/pubmed/5358533

Oliveira, J. M., Lopes, D., Goncalves C., \& Nogueira, C. (2012). Lesbian, Gay, and Bisexual Identity Scale (LGBIS): Construct validation, sensitivity analyses and other psychometric properties. Spanish Journal of Psychology, 15(3), 334-347. doi: http://dx.doi.org/10.5209/rev_.2012.v15.n1.37340 
Kendra, M. S., \& Mohr, J. J. (Mayo, 2008). Development of the Lesbian, Gay, and Bisexual Identity Scale. Paper presented at the Annual Meeting of the American Psychological Association, Washington, DC.

Kerlinger, F., y Lee, H. (2002). Investigación del comportamiento (4 ${ }^{\mathrm{a}}$ ed.). México: McGraw-Hill.

Kline, P. (1995). The handbook of psychological testing. Londres: Routledge.

Kline, R. B. (2010). Principles and practice of structural equation modeling ( $3^{\mathrm{a}}$ ed.). New York: Guilford Press.

Kraut, R., Olson, J., Banaji, M., Bruckman, A., Cohen, J., \& Couper, M. (2004). Psychological research online: Report of board of scientific affairs' advisory group on the conduct of research on the Internet. American Psychologist, 59(2), 105-117. doi: 10.1037/0003-066x.59.2.105

Lorenzo-Seva, U. y Ferrando, P. J. (2015). Factor (Versión 10.3.01) [Software de computación]. España: Universitat Rovira i Virgili. Recuperado de http://psico.fcep.urv.es/utilitats/factor/soft/factor10.3.64bits.zip

Lorenzo-Seva, U., Timmerman, M. E., \& Kiers, H. A. L. (2011). The Hull method for selecting the number of common factors. Multivariate Behavioral Research, 46(2), 340-364. doi: 10.1080/00273171.2011.564527

Maguen, D., Floyd, F. J., Bakeman, R., \& Armistead, L. (2002). Developmental milestones and disclosure of sexual orientation among gay, lesbian, and bisexual youths. Journal of Applied Developmental Psychology, 23, 219-233.

Malyon, A. (1982). Psychotherapeutic implications of internalized homophobia in gay men. Journal of Homosexuality, 7, 59-70. doi:10.1300/j082v07n02_08

Margnolies, L., Becker, M., \& Jackson-Brewer. K. (1987). Internalized homonegativity: Identifying and treating the oppressor within. En Boston Lesbian Psychologies Colective (Eds.), Lesbian psychologies: Exploration and challenges (pp. 229-243). Urbana: University of Illinois Press.

Maslow, A. H. (1943). A Theory of Human Motivation. Psychological Review, 50(4), 370-96. doi: http://dx.doi.org/10.1037/h0054346

McCarn, S. R., \& Fassinger, R. E. (1996). Revisioning sexual minority identity formation: A new model of lesbian identity and its implications for counseling and research. Counseling Psychologist, 24, 508-534. doi: 10.1177/0011000096243011

Meyer, I. H. (2003). Prejudice, social stress, and mental health in lesbian, gay, and bisexual populations: Conceptual issues and research evidence. Psychological Bulletin, 129, 674-697. doi: 10.1037/0033-2909.129.5.674 
Meyer, I. H., \& Dean, L. (1998). Internalized homophobia, intimacy, and sexual behavior among gay and bisexual men. En G. M. Herek (Ed.), Stigma and sexual orientation: Understanding prejudice against lesbians, gay men, and bisexuals (pp. 160-186). Thousand Oaks, CA: Sage.

Mohr, J. J., \& Fassinger, R. E. (2006). Sexual orientation identity and romantic relationship quality in same-sex couples. Personality and Social Psychology Bulletin, 32, 1085-1099. doi: 10.1177/0146167206288281

Mohr, J. J., \& Kendra, M. S. (2011). Revision and extension of a multidimensional measure of sexual minority identity: The Lesbian, Gay, and Bisexual Identity Scale. Journal of Counseling Psychology, 58, 234-245. doi: 10.1037/a0022858

Mohr, J., \& Fassinger, R. (2000). Measuring dimensions of lesbian and gay male experience. Measurement \& Evalutation in Counseling \& Development, 33, 6690.

Molnar, I. (2015). Aspects regarding the reliability of the translated and adapted version of the Gay/Lesbian Identity Scale. Journal of Experiential Psychotherapy, 18(2), 3-13. Resumen recuperado de http://connection.ebscohost.com/c/articles/103738256/aspects-regardingreliability-translated-adapted-version-gay-lesbian-identity-scale

Muñiz, J. (1999). Teoría clásica de los tests (2ª ed.). Madrid: Pirámide.

Mustanski, B. (2001). Getting wired: Exploiting the Internet for the collection of valid sexuality data. Journal of Sex Research. 38(4), 292-301. doi:10.1080/00224490109552100

Nunnally, J. C. (1987). Teoría psicométrica. México D. F.: Trillas.

Nunnally, J. C., y Bernstein, I. H. (1995). Teoría psicométrica (2a ed.). México D. F.: McGraw Hill.

Pérez, César. (2013). Estadística: Problemas resueltos y aplicaciones. Madrid: Pearson Educación.

PROMSEX (2012). Informe anual 2012 sobre derechos humanos de personas trans, lesbianas, gays, y bisexuales. Lima: Autor.

PROMSEX (2014). Informe anual 2014 sobre derechos humanos de personas trans, lesbianas, gays, y bisexuales. Lima: Autor.

Razali N. M., \& Wah Y. B. (2011). Power comparison of Shapiro-Wilk, KolmogorovSmirnov, Lilliefors and Anderson Darling tests. Journal of Statistical Modeling and Analytics, 2(1), 21-33. Recuperado de https://www.researchgate.net/publication/267205556_Power_Comparisons_of_ Shapiro-Wilk_Kolmogorov-Smirnov_Lilliefors_and_Anderson-Darling_Tests 
Renn, K. A., \& Bilodeau, B. (Noviembre, 2002). Queer student leaders: A case study of leadership development and lesbian, gay, bisexual, and transgender student involvement. Paper presented at the Annual Meeting of the Association for the Study of Higher Education, Sacramento, California. Recuperado de https://msu.edu/ renn/Queer\%20Leaders\%20ASHE\%202002.htm

Riggle, E. D. B., Whitman, J. S., Olson, A., Rostosky, S. S., \& Strong, S. (2008). The positive aspects of being a lesbian or gay man. Professional Psychology: Research and Practice, 39, 210-217. doi: 10.1037/0735-7028.39.2.210

Riggle, E., \& Rotosky, S. (2012). A positive view of LGBTQ. Embracing Identity and Cultivating Well-Being. United Kindom: Rowman \& Littlefield Publisher.

Ross, M. W. \& Rosser, B. R. S. (1996). Measurement and correlates of internalized homophobia: A Factor analytic study. Journal of Clinical Psychology,52(1), 1521. doi: 10.1002/(sici)1097-4679(199601)52:1<15::aid-jclp2>3.0.co;2-v

Rosario, M., Schrimshaw, E. W., Hunter, J. (2011). Different patterns of sexual identity development over time: Implications for the psychological adjustment of lesbian, gay and bisexual youths. Journal of Sex Research, 48(1), 3-15. doi: $10.1080 / 00224490903331067$

Rosario, M., Schrimshaw, E. W., Hunter, J., \& Braun, L. (2006). Sexual identity development among lesbian, gay, and bisexual youths: Consistency and change over time. The Journal of Sex Research, 43, 46-58. doi: $10.1080 / 00224490609552298$

Shidlo, A. \& Schroeder, M. (2002). Changing sexual orientation: A consumer's report. Professional Psychology: Research and Practice, 33, 249-259. doi: http://dx.doi.org/10.1037/0735-7028.33.3.249

Shidlo A. (1994). Internalized homophobia: Conceptual and empirical issues in measurement. En B. Greene y G. M. Herek (Eds.), Lesbian and gay psychology: Theory, research and clinical applications (Vol. 1, pp. 176-205). Thousand Oaks, CA: Sage.

Siegelman, M. (1972). Adjustment of homosexual and heterosexual women. British Journal of Psychiatry, 120, 447-81. doi:10.1007/BF01541232

Sireci, S., \& Faulkner-Bond, M. (2014). Validity evidence based on test content. Psicothema, 26(1), 100-107. doi: 10.7334/psicothema2013.256.

Sophie, J. (1987). Internalized homophobia and lesbian identity. Journal of Homosexuality, 14(1), 53-65. doi: 10.1300/j082v14n01_05

Szymanski, D. M., \& Chung, Y. B. (2003). Internalized homophobia in lesbians. Journal of Lesbian Studies, 7(1), 115-125. Recuperado de http://www.ncbi.nlm.nih.gov/pmc/articles/PMC2678796/pdf/nihms59525.pdf 
Thompson, N. L., McCandless, B. R., \& Strickland, B. R. (1971). Personal adjustment of male and female homosexuals and heterosexuals. Journal of Abnormal Psychology, 78(2), 237-40. Recuperado de http://psycnet.apa.org/index.cfm?fa=fulltext.journal\&jcode=abn\&vol=78\&issue $=2 \&$ page $=237 \&$ format $=$ PDF

Troiden, R. (1979). Becoming homosexual: A model of gay identity. Psychiatry, 42, 362-373. doi:10.1521/00332747.1979.11024039

Warner, S. L. (1965). Randomized Response: A Survey Technique for Eliminating Evasive Answer Bias. Journal of the American Statistical Association, 60, 6369. doi: $10.2307 / 2283137$

Weinberg, M. S., Williams, C. J., \& Pryor, D. W. (1994). Dual attraction: Understanding bisexuality. New York: Oxford University Press.

Wheeler, D. P. (2003). Methodological issues in conducting community-based health and social services research among urban Black and African-American LGB populations. Journal of Gay and Lesbian Social Services, 15(1-2), 65-78. doi:10.1300/j041v15n01_05

Worthington, R. L., Navarro, R. L., Savoy, H. B., \& Hampton, D. (2008). Development, reliability and validity of the Measure of Sexual Identity Exploration and Commitment (MoSIEC). Developmental Psychology, 44, 2233. doi: 10.1037/0012-1649.44.1.22

Zumbo, B. D., Gadermann, A. M., \& Zeisser, C. (2007). Ordinal versions of coefficients alpha and theta for Likert Rating Scales. Journal of Modern Applied Statistical Methods, 6(1), 21-29. Recuperado de http://digitalcommons.wayne.edu/cgi/viewcontent.cgi?article=1121\&context=j masm 
ANEXOS

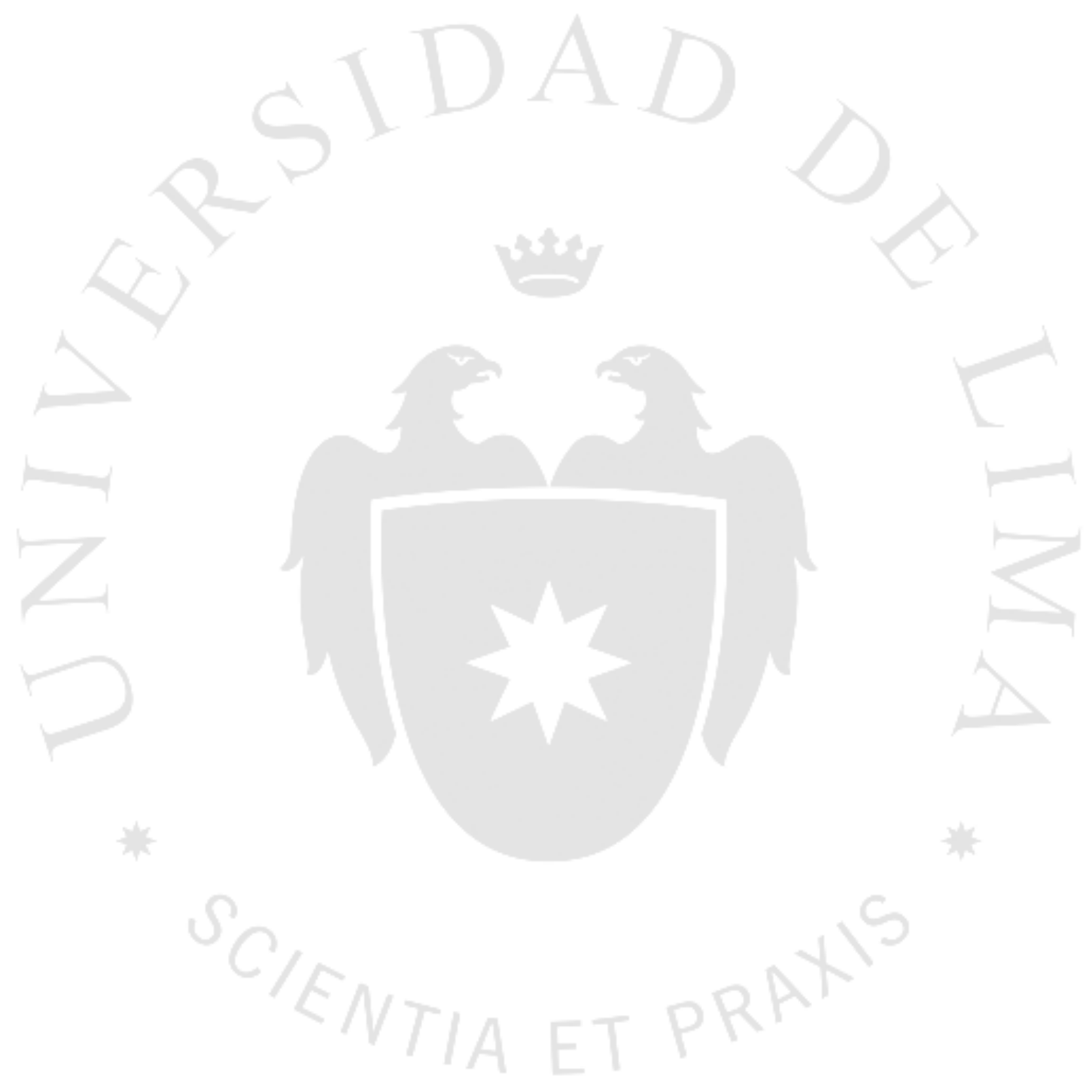




\section{ANEXO 1: FICHA SOCIODEMOGRAFICA}

Edad:

Lugar de nacimiento:

Lima ( )

Distrito:

Grado de instrucción:

1) Primaria

2) Secundaria Incompleta

3) Secundaria Completa

4) Universitario Incompleto

5) Universitario Completo

5) Técnica Completo

6) Técnica Incompleta

7) Postgrado

8) Otros:

\section{Activismo LGBT}

¿Pertenece a alguna organización o institución LGBTIQ?

$\mathrm{Si}($ )

No ( )

Masculino ( )

Femenino ( )
Sexo

Otro:

Otro:
Sexo: $M($ ) $F(~)$

Edad ( )

\section{Nivel Socioeconómico}
A ( )
B ( )
C ( )
$\mathrm{D} \quad($ )
E ( )

\section{Orientación Sexual}

¿Cuál es el término que mejor describe su Orientación Sexual?
1) Lesbiana ( )
3) Gay ( )
2) Bisexual ( )
4) Pansexual ( )

Si usted es una personas transexual responda la siguiente pregunta, de lo contrario no la responda:

¿Cómo se define usted?
1) Trans Masculino ( )
2) Trans Femenino ( )
3) Otros: 


\section{Apertura de Orientación Sexual}

¿Quiénes saben sobre su identidad de orientación sexual?
1) Nadie, solo yo
2) Solo mi pareja
3) Mis familiares más cercanos
4) Mis amigos más cercanos
5) Todos mis amigos

6) Todos mis familiares

7)Todas las personas más cercanas a mi entorno

8) La mayoría de las personas que me conocen

9) Todos

\section{Información adicional}

¿Alguna vez ha vivido por un período mayor a 3 meses en algún país donde su cultura era más tolerante e inclusiva con las personas LGB?

\section{$\mathrm{Si} \quad($ )}

No ( )

(Si su respuesta fue NO en la pregunta anterior; omita la siguiente pregunta) ¿Considera que esto ha tenido un impacto positivo en usted?

\section{$\mathrm{Si}($ ) \\ No ( )}




\section{ANEXO 2: LGBIS VERSION ORGINAL}

\section{Lesbian, Gay, and Bisexual Identity Scale (LGBIS)}

For each of the following questions, please mark the response that best indicates your current experience as an LGB person. Please be as honest as possible: Indicate how you really feel now, not how you think you should feel. There is no need to think too much about any one question. Answer each question according to your initial reaction and then move on to the next.

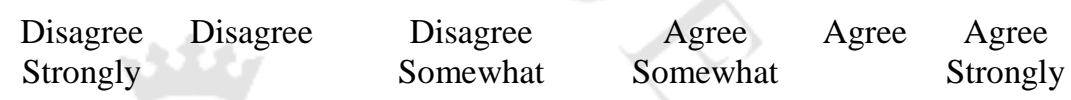

1. I prefer to keep my same-sex romantic relationships rather private.

2. If it were possible, I would choose to be straight.

$$
1
$$

2

3

3

1

2

3. I'm not totally sure what my sexual orientation is
2

2
3

3
4

5

6

4. I keep careful control over who knows about my same-sex romantic relationships.

5. I often wonder whether others judge me for my sexual orientation.

6. I am glad to be an LGB person.

2

3

4

5

6

7. I look down on heterosexuals.

1

2

3

4

5

6

8. I keep changing my mind about my sexual orientation.

2

3

4

5

6 


\begin{tabular}{|c|c|c|c|c|}
\hline $\begin{array}{l}\text { gree } \\
\text { ngly }\end{array}$ & Disagree & & $\begin{array}{l}\text { Agree } \\
\text { Somewha }\end{array}$ & Agree \\
\hline
\end{tabular}

9. I can't feel comfortable knowing that others judge me negatively for my sexual orientation.

10. I feel that LGB people are superior to heterosexuals.

11. My sexual orientation is an insignificant part of who I am.

12. Admitting to myself that I'm an LGB person has been a very painful 1

4 5 6 process.

13. I'm proud to be part of the LGB community.

$2-3$

4

$5 \quad 6$

14. I can't decide whether I am bisexual or homosexual.

15. My sexual orientation is a central part of my identity.

16. I think a lot about how my sexual orientation affects the way people see me.

17. Admitting to myself that I'm an LGB person has been a very slow

7
process.

18. Straight people have boring lives compared with LGB people.

19. My sexual orientation is a very personal and private matter. 


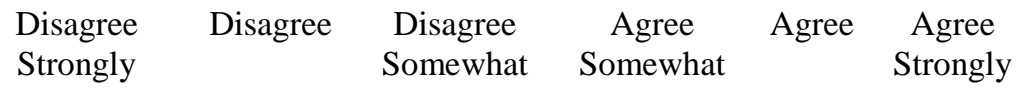

20. I wish I were heterosexual.

21. To understand who I am as a person, you have to know that I'm LGB.

22. I get very confused when I try to figure out my sexual orientation.

23. I have felt comfortable with my sexual identity just about from the start.

1

2

3

4

5

6

Being an LGB person is a very important aspect of my life.

25. I believe being LGB is an important part of me.

4

$5 \quad 6$

26. I am proud to be LGB.

27. I believe it is unfair that I am attracted to people of the same sex. 


\section{ANEXO 3: LGBIS EN ESPAÑOL}

\section{Escala de Identidad para Lesbianas, Gays y Bisexuales}

Para cada uno de los siguientes enunciados, marque la respuesta que mejor se ajusta a sus vivencias actuales como una persona LGB. Se le pide que por favor sea lo más honesto posible: Indique cómo se siente realmente en la actualidad y no como cree que debería sentirse. No hay necesidad de pensar demasiado ninguna de sus respuestas. Responda cada pregunta de acuerdo a la primera reacción que le genera y luego continúe con la siguiente.

Consigna adicional: En esta escala se utiliza las siglas LGB por conveniencia. Sabemos que algunos y algunas de ustedes en vez de identificarse como "Lesbiana, gay o bisexual" para describir su orientación sexual; podrían preferir utilizar otros nombres. Por esta razón pedimos su compresión en el caso que este término no represente su identidad sexual en su totalidad

1. Prefiero mantener en privado mis relaciones sentimentales con personas de mí mismo

$\begin{array}{ccc}\text { Totalmente } & \text { En } & \text { Parcialmente } \\ \text { en } & \text { desacuerd } & \text { en desacuerdo } \\ \text { desacuerdo } & 0 & \end{array}$

$\begin{array}{ccc}\begin{array}{c}\text { Parcialmente } \\ \text { de acuerdo }\end{array} & \begin{array}{c}\text { De } \\ \text { acuerdo }\end{array} & \begin{array}{c}\text { Totalmente } \\ \text { de acuerdo }\end{array}\end{array}$
sexo

2. Si fuera posible, elegiría ser heterosexual.

2

3

3. Tengo dudas acerca de cuál es mi orientación sexual.

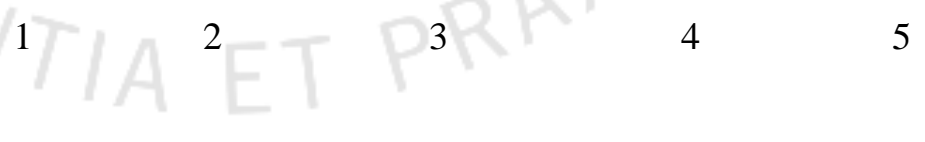

6

4. Tengo un cuidadoso control sobre quienes saben acerca de mis relaciones sentimentales con personas de mí mismo sexo. 


$\begin{array}{lccccc}\begin{array}{l}\text { Totalmente } \\ \text { en } \\ \text { desacuerdo }\end{array} & \begin{array}{c}\text { En } \\ \text { desacuerdo }\end{array} & \begin{array}{c}\text { Parcialmente } \\ \text { en } \\ \text { desacuerdo }\end{array} & \begin{array}{c}\text { Parcialmente } \\ \text { de acuerdo }\end{array} & \begin{array}{c}\text { De } \\ \text { acuerdo }\end{array} & \begin{array}{c}\text { Totalmente } \\ \text { de acuerdo }\end{array} \\ & & & \end{array}$

5. Con frecuencia me pregunto si los demás me juzgan por mi orientación sexual.

6. Me siento bien siendo una persona LGB.

2

3

4

7. Menosprecio a los heterosexuales.

1

2

3

4

5

6

8. Continuamente cambio de opinión acerca de mi orientación sexual.

\section{2}

3

9. Siento incomodidad sabiendo que otros me juzgan de manera negativa debido a mi orientación sexual.

10. Considero que las personas LGB son superiores a las personas heterosexuales.

11. Mi orientación sexual es una parte insignificante de quién soy yo.

12. Aceptarme como una persona LGB ha sido un proceso muy doloroso.

2

3

Siento orgullo de formar parte de la comunidad LGB.

14. Me es difícil decidir si soy bisexual u homosexual.

15. Mi orientación sexual es una parte central de mi identidad. 
16. Pienso mucho sobre

$\begin{array}{cccccc}\begin{array}{c}\text { Totalmente } \\ \text { en } \\ \text { desacuerdo }\end{array} & \begin{array}{c}\text { En } \\ \text { desacuerdo }\end{array} & \begin{array}{c}\text { Parcialmente } \\ \text { en } \\ \text { desacuerdo }\end{array} & \begin{array}{c}\text { Parcialmente } \\ \text { de acuerdo }\end{array} & \begin{array}{c}\text { De } \\ \text { acuerdo }\end{array} & \begin{array}{c}\text { Totalmente } \\ \text { de acuerdo }\end{array} \\ & & & \end{array}$

como mi orientación

sexual afecta la forma en que los otros me

perciben.

17. Haber aceptado que soy una persona LGB ha sido un proceso muy lento.

18. Las personas heterosexuales tienen vidas aburridas comparadas con personas LGB.

19. Oculto mi orientación sexual por ser un asunto personal muy privado.

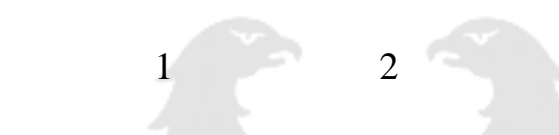

20. Desearía ser heterosexual.

21. Para entenderme como
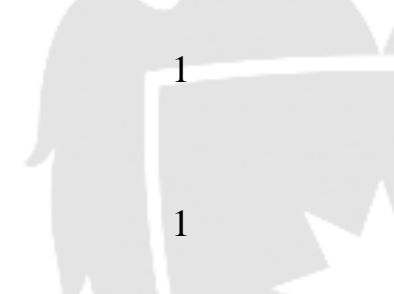

2 personas se tiene que saber que soy LGB.

22. Me confundo mucho cuando trato de entender mi orientación sexual.

Desde un inicio he sentido mucha comodidad con mi

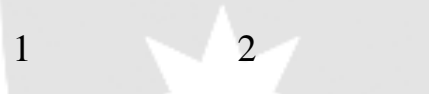
3 4 5 6 identidad sexual.
1

2 3 4 5 6

Ser una persona LGB es

24. un aspecto muy importante de mi vida. 
25. Yo creo que ser LGB es

$\begin{array}{cccccc}\begin{array}{c}\text { Totalmente } \\ \text { en } \\ \text { desacuerdo }\end{array} & \begin{array}{c}\text { En } \\ \text { desacuerdo }\end{array} & \begin{array}{c}\text { Parcialmente } \\ \text { en } \\ \text { desacuerdo }\end{array} & \begin{array}{c}\text { Parcialmente } \\ \text { de acuerdo }\end{array} & \begin{array}{c}\text { De } \\ \text { acuerdo }\end{array} & \begin{array}{c}\text { Totalmente } \\ \text { de acuerdo }\end{array} \\ & & & \end{array}$
una parte importante de mí.

1

2

3

4

5

6

26. Tengo orgullo de ser LGB

1

2

3

4

5

6

27. Creo que es injusto que sienta atracción por personas de mí mismo sexo.
2

4

5

6

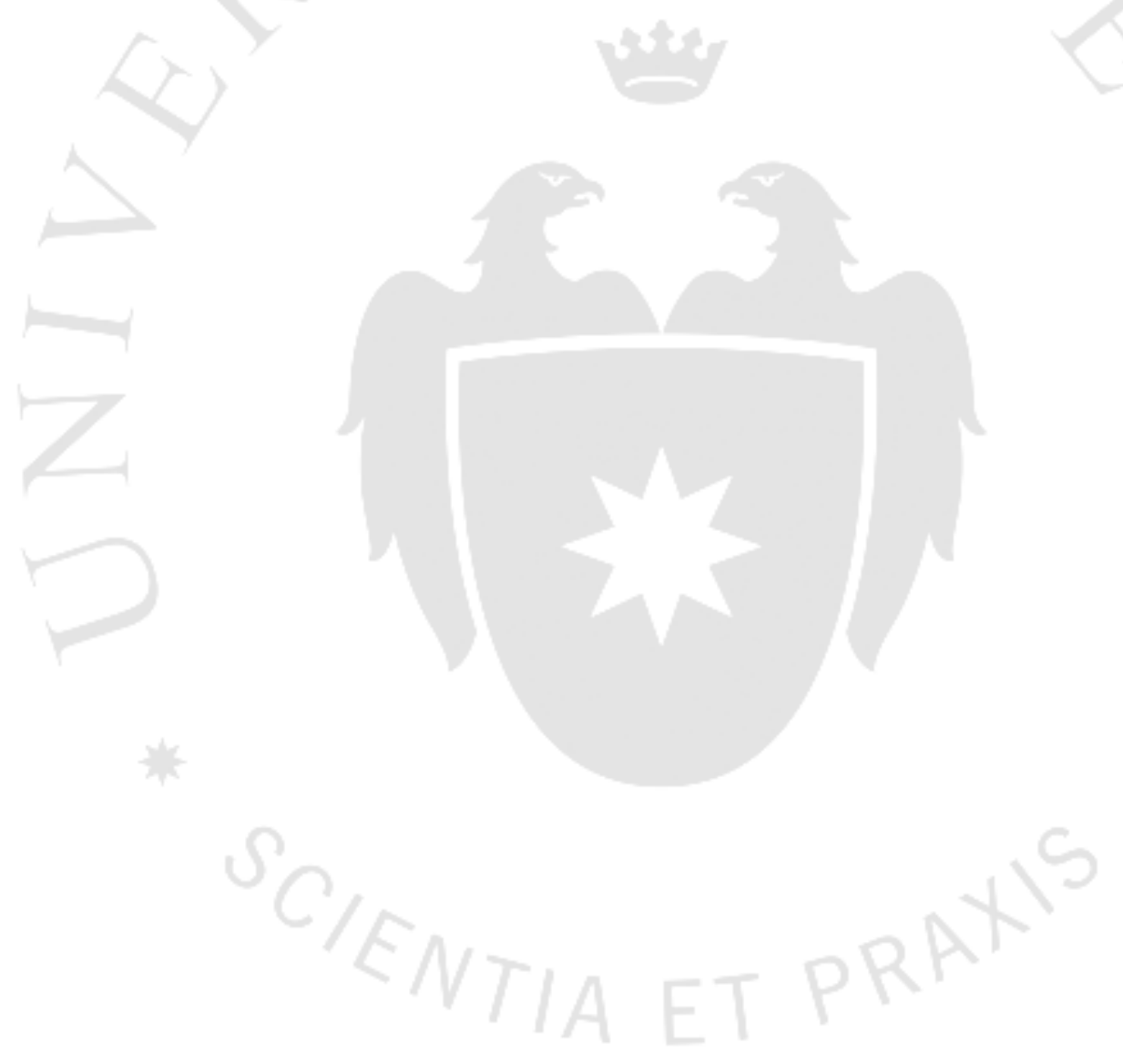




\title{
ANEXO 4: FICHA TECNICA Y NUEVA PROPUESTA DE PRUEBA EDOS-LGB
}

\author{
Ficha Técnica EDOS-LGB
}

Nombre de la Escala

Adaptada por

Basado en

Constructo a evaluar

Población Objetivo

Modo de aplicación

Vías de aplicación

Tiempo de aplicación

Tipo de respuesta

Numero de ítems

Numero de dimensiones

Dimensiones e ítems

Consigna adicional
: Escala de Dimensiones de Identidad de Orientación

Sexual para Lesbianas, gays y bisexuales.

: Jessica Vinces Guillén (2016)

: LGBIS de Mohr y Kendra (2011)

: Identidad de orientación sexual

: Adultos y adultas lesbianas, gays y bisexuales

: Individual o colectiva

: Física o virtual

: 8-10 minutos

: Escala Likert

: 13 ítems con calificación directa

: 2 factores o dimensiones

: F1: Incertidumbre y preocupación por la aceptación (i2, i3, i5, i6, i7, i8, i12, i13)

F2: Integración de la identidad (i1, i4, i9, i10, i11)

: En esta escala se utiliza las siglas LGB por conveniencia. Sabemos que algunos y algunas de ustedes en vez de identificarse como "Lesbiana, gay o bisexual" para describir su orientación sexual; podrían preferir utilizar otros nombres. Por esta razón pedimos su compresión en el caso que este término no represente su identidad sexual en su totalidad 


\section{Escala de Dimensiones de Identidad de Orientación Sexual para Lesbias, Gays y \\ Bisexuales (EDOS-LGB)}

Para cada uno de los siguientes enunciados, marque la respuesta que mejor se ajusta a sus vivencias actuales como una persona LGB. Se le pide que por favor sea lo más honesto posible: Indique cómo se siente realmente en la actualidad y no como cree que debería sentirse. No hay necesidad de pensar demasiado ninguna de sus respuestas. Responda cada pregunta de acuerdo a la primera reacción que le genera y luego continúe con la siguiente.

1. Mi orientación sexual es una parte central de mi identidad.

\begin{tabular}{c|c|cccc}
$\begin{array}{c}\text { Totalmente } \\
\text { en }\end{array}$ & $\begin{array}{c}\text { En } \\
\text { desacuerdo }\end{array}$ & $\begin{array}{c}\text { Parcialmente en } \\
\text { desacuerdo }\end{array}$ & $\begin{array}{c}\text { Parcialmente } \\
\text { de acuerdo }\end{array}$ & $\begin{array}{c}\text { De } \\
\text { acuerdo }\end{array}$ & $\begin{array}{c}\text { Totalmente de } \\
\text { acuerdo }\end{array}$ \\
desacuerdo & &
\end{tabular}

2. Siento incomodidad sabiendo que otros me juzgan de manera negativa debido a mi orientación sexual.

3. Pienso mucho sobre cómo mi orientación sexual afecta la forma en que los otros me perciben.

4. Ser una persona LGB es un aspecto muy importante de mi vida.

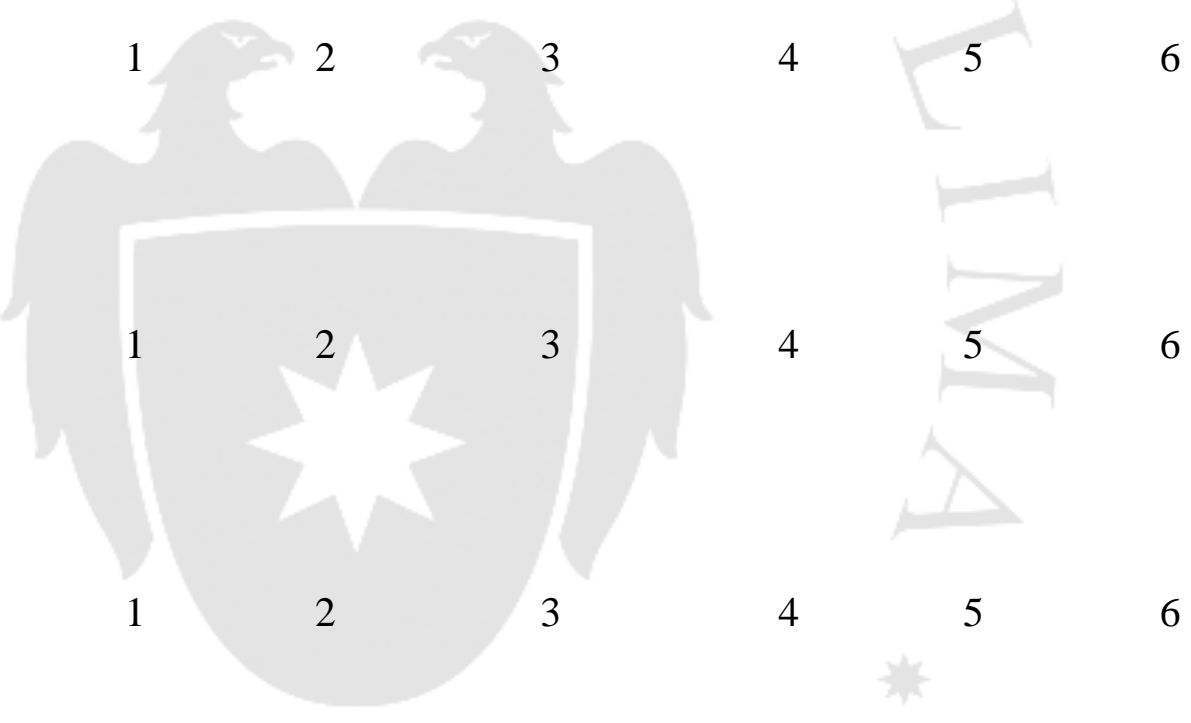

5. Haber aceptado que soy una persona LGB ha sido un proceso 12 23 \begin{tabular}{l}
$3 \sim 4$ \\
\hline
\end{tabular} muy lento.

6. Me es difícil decidir si soy bisexual u homosexual.

1 2 3 4 5 6

7. Oculto mi orientación sexual por ser un asunto personal muy 1 privado 


$\begin{array}{cccccc}\begin{array}{c}\text { Totalmente en } \\ \text { desacuerdo }\end{array} & \text { En } & \text { Parcialmente } & \text { Parcialmente } & \text { De } & \text { Totalmente de } \\ \text { de acuerdo } & \text { acuerdo } & \text { acuerdo }\end{array}$

8. Con frecuencia me pregunto si los demás me juzgan por mi orientación sexual.

9. Siento orgullo de formar parte de la comunidad LGB

10 Tengo orgullo de ser

. LGB

11 Yo creo que ser LGB es una parte importante de mí.

12 Me confundo mucho

- cuando trato de entender mi orientación sexual.

13 Aceptarme como una persona LGB ha sido un proceso muy doloroso. 


\section{ANEXO 5: CRITERIO DE JUECES “COMITÉ MULTIDISCIPLINARIO”}

Profesor/Profesora:

Presente.-

De mi consideración:

Teniendo en cuenta su experiencia; tengo el agrado de dirigirme a usted para solicitar su participación como parte del "COMITÉ MULTIDISCIPLINARIO DE EXPERTOS" en el proceso de adaptación de la escala psicológica “The Lesbian, Gay, and Bisexual Identity Scale (Mohr y Kendra, 2011)", la cual será adaptada y validada en una muestra peruana, como parte de mi proyecto de tesis para obtener el Título Profesional de Licenciada en Psicología bajo la modalidad de Tesis.

El proyecto de Tesis se titula: “ADAPTACIÓN DE LA ESCALA DE IDENTIDAD DE LESBIANAS, GAYS Y BISEXUALES (LGBIS) EN UN GRUPO DE LESBIANAS, GAYS Y BISEXUALES DEL PERÚ". La muestra se encontrará conformada por personas lesbianas, gays y bisexuales del Perú que se encuentren en el rango de edades de 18 y 45 años.

De antemano agradezco su colaboración.

Atentamente,

Jessica Marialaura Vinces Guillén 


\section{"The Lesbian, Gay, and Bisexual Identity Scale " "La Escala de Identidad para Lesbianas, Gays y Bisexuales"}

Se le pide que tenga en consideración cada una de las dimensiones de la identidad de las personas lesbianas, gays y bisexuales (LGB), de acuerdo a las conceptualizaciones que se muestran en el siguiente cuadro.

\begin{tabular}{|l|l|}
\hline DIMENSIONES & DESCRIPCIÓN \\
\hline $\begin{array}{l}\text { Preocupación por la } \\
\text { aceptación }\end{array}$ & $\begin{array}{l}\text { Hace referencia al conjunto de expectativas o temores de ser } \\
\text { evaluados por los otros negativamente debido a la orientación } \\
\text { sexual de la persona. Es decir que hay una propensión o } \\
\text { sensibilidad a sentirse estigmatizado. }\end{array}$ \\
\hline Motivación a la Invisibilidad & $\begin{array}{l}\text { Muestra la preocupación y necesidad de las personas por proteger } \\
\text { su vida privada y no develar públicamente su orientación sexual. }\end{array}$ \\
\hline Incertidumbre de Identidad & $\begin{array}{l}\text { Hace alusión a la inseguridad/confusión/incertidumbre respecto a la } \\
\text { orientación sexual de uno mismo. Para algunas personas esta } \\
\text { interrogante puede referirse a dudar si son homosexuales o } \\
\text { bisexuales; mientras que en otros casos este cuestionamiento se da } \\
\text { entre la heterosexualidad y la homosexualidad. }\end{array}$ \\
\hline $\begin{array}{l}\text { Homonegatividad } \\
\text { Internalizada }\end{array}$ & $\begin{array}{l}\text { Hace referencia al fenómeno a través del cual la persona internaliza } \\
\text { las creencias y pensamientos anti-LGB y los aplica a las } \\
\text { conceptualizaciones del sí mismo. Con frecuencia, internalizar este } \\
\text { tipo de pensamientos conlleva a que la persona se devalué a sí } \\
\text { misma. }\end{array}$ \\
\hline Dificultad en el proceso & $\begin{array}{l}\text { Demuestra la percepción de cada una de las personas respecto a lo } \\
\text { difícil que ha sido el proceso de desarrollo de su identidad. }\end{array}$ \\
\hline Superioridad de identidad & $\begin{array}{l}\text { Muestra un conjunto de estrategia compensatoria para poder } \\
\text { incrementar la autoestima; como forma de enfrentar la } \\
\text { estigmatización e incluso encubrir sentimientos subyacentes de } \\
\text { inferioridad por ser una persona homosexual. }\end{array}$ \\
\hline Afirmación de identidad & $\begin{array}{l}\text { Refleja el grado en el cual las personas LGB experimentan } \\
\text { pensamientos y sentimientos positivos hacia su orientación sexual y } \\
\text { hacia su integración y participación como miembros de } \\
\text { comunidades LGB. }\end{array}$ \\
\hline $\begin{array}{l}\text { Muestra el grado en el cual un determinado aspecto de la identidad } \\
\text { de la persona; en este caso la identidad de orientación sexual, es } \\
\text { central y determinante para definir su identidad integral. Siendo } \\
\text { esto es un factor moderador de los efectos del estrés minoritario. }\end{array}$ \\
\hline
\end{tabular}

Mohr, J. J., \& Kendra, M. S. (2011). Revision and extension of a multidimensional measure of sexual minority identity: The Lesbian, Gay, and Bisexual Identity Scale. Journal of Counseling Psychology, 58, 234-245. doi: 10.1037/a0022858

Mohr, J., \& Fassinger, R. (2000). Measuring dimensions of lesbian and gay male experience. Measurement \& Evalutation in Counseling \& Development, 33, 66-90. 
Asimismo se le pide que tenga a bien revisar los siguientes documentos para poder realizar su evaluación:

1) Versión Original de Instrumento LGBIS (Morh y Kendra, 2011)

2) Traducción Directa 1 (T1)

3) Traducción Directa 2 (T2)

4) Síntesis de traducciones (T12)

5) Traducción Inversa 1 (BT1)

6) Traducción Inversa 2 (BT2)

Finalmente, para poder lograr una equivalencia transcultural del presente instrumento; se le solicita tener en cuenta los siguientes criterios de equivalencia (Beaton et al., 1998):

1) Equivalencia Semántica: Equivalencia en el significado de las palabras.

2) Equivalencia Idiomática: De encontrarse frases idiomáticas o coloquialismos en alguno de los ítems, es necesario sustituir dichas expresiones por otras equivalentes.

3) Equivalencia Empírico: La situación evocada o representada en cada uno de los ítems de la versión original debe encajar también en el contexto para el cual se está realizando la adaptación.

4) Equivalencia Conceptual: El concepto explorado también debe ser válido en la cultura o contexto para el cual se está realizando la adaptación. 


\begin{tabular}{|l|}
\hline CONSIGNA \\
\hline Para cada uno de los siguientes enunciados, marque \\
la respuesta que mejor se ajusta a sus vivencias \\
actuales como una persona LGB. Se le pide que sea \\
lo más honesto posible: Indique cómo se siente \\
realmente en la actualidad y no como cree que \\
debería sentirse. No hay necesidad de pensar \\
demasiado ninguna de sus respuestas. Responda \\
cada pregunta de acuerdo a la primera reacción que \\
le genera y luego continúe con la siguiente.
\end{tabular}

\begin{tabular}{|c|c|}
\hline ITEMS & SUGERENCIAS \\
\hline $\begin{array}{l}\text { 1. Prefiero mantener en privado mis relaciones } \\
\text { sentimentales con personas de mí mismo } \\
\text { sexo }\end{array}$ & 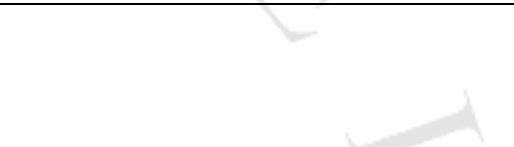 \\
\hline 2. Si fuera posible, elegiría ser heterosexual. & 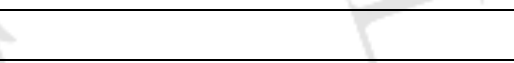 \\
\hline $\begin{array}{l}\text { 3. Tengo dudas acerca de cuál es mi } \\
\text { orientación sexual. }\end{array}$ & 要 \\
\hline $\begin{array}{l}\text { Tengo un cuidadoso control sobre quienes } \\
\text { saben acerca de mis relaciones sentimentales } \\
\text { con personas de mí mismo sexo }\end{array}$ & \\
\hline $\begin{array}{l}\text { 5. Con frecuencia me pregunto si los demás me } \\
\text { juzgan por mi orientación sexual. }\end{array}$ & $x_{n}$ \\
\hline 6. Me alegra ser una persona LGB. & \\
\hline 7. Menosprecio a los heterosexuales. & +2 \\
\hline $\begin{array}{l}\text { 8. Continuamente cambio de opinión acerca de } \\
\text { mi orientación sexual. }\end{array}$ & $\nabla$ \\
\hline $\begin{array}{l}\text { 9. Siento incomodidad sabiendo que otros me } \\
\text { juzgan de manera negativa debido a mi } \\
\text { orientación sexual. }\end{array}$ & \\
\hline $\begin{array}{l}\text { 10. Considero que las personas LGB son } \\
\text { superiores a las personas heterosexuales. }\end{array}$ & \\
\hline $\begin{array}{l}\text { 11. Mi orientación sexual es una parte } \\
\text { insignificante de quién soy yo. }\end{array}$ & \\
\hline $\begin{array}{l}\text { 12. Reconocer que soy una persona LGB ha } \\
\text { sido un proceso muy doloroso. }\end{array}$ & \\
\hline $\begin{array}{l}\text { 13. Siento orgullo de formar parte de la } \\
\text { comunidad LGB }\end{array}$ & \\
\hline $\begin{array}{l}\text { 14. Me es difícil decidir si soy bisexual u } \\
\text { homosexual. }\end{array}$ & \\
\hline $\begin{array}{l}\text { 15. Mi orientación sexual es una parte central de } \\
\text { mi identidad. }\end{array}$ & \\
\hline $\begin{array}{l}\text { 16. Pienso mucho sobre como mi orientación } \\
\text { sexual afecta la forma en que los otros me }\end{array}$ & \\
\hline
\end{tabular}




\begin{tabular}{|c|c|}
\hline perciben. & \\
\hline $\begin{array}{l}\text { 17. Haber aceptado que soy una persona LGB } \\
\text { ha sido un proceso muy lento. }\end{array}$ & \\
\hline $\begin{array}{l}\text { 18. Las personas heterosexuales tienen vidas } \\
\text { aburridas comparadas con personas LGB. }\end{array}$ & \\
\hline $\begin{array}{l}\text { 19. Mi orientación sexual es un asunto muy } \\
\text { personal y privado }\end{array}$ & \\
\hline 20. Desearía ser heterosexual & \\
\hline $\begin{array}{l}\text { 21. Para entender quién soy yo, se tiene que } \\
\text { saber que soy una persona LGB. }\end{array}$ & \\
\hline $\begin{array}{l}\text { 22. Me confundo mucho cuando trato de } \\
\text { entender mi orientación sexual. }\end{array}$ & \\
\hline $\begin{array}{l}\text { 23. Desde un inicio he sentido mucha } \\
\text { comodidad con mi identidad sexual. }\end{array}$ & \\
\hline $\begin{array}{l}\text { 24. Ser una persona LGB es un aspecto muy } \\
\text { importante de mi vida }\end{array}$ & \\
\hline $\begin{array}{l}\text { 25. Yo creo que ser LGB es un parte importante } \\
\text { de mí. }\end{array}$ & \\
\hline 26. Tengo orgullo de ser LGB & \\
\hline $\begin{array}{l}\text { 27. Creo que es injusto que experimente } \\
\text { atracción a personas de mí mismo sexo. }\end{array}$ & \\
\hline
\end{tabular}

\begin{tabular}{|l|l|}
\hline ALTERNATIVAS DE RESPUESTA & SUGERENCIAS \\
\hline 1. Totalmente en desacuerdo & \\
\hline 2. En desacuerdo & \\
\hline 3. Parcialmente en desacuerdo & \\
\hline 4. Parcialmente de acuerdo & \\
\hline 5. De acuerdo & \\
\hline 6. Totalmente de acuerdo & \\
\hline
\end{tabular}

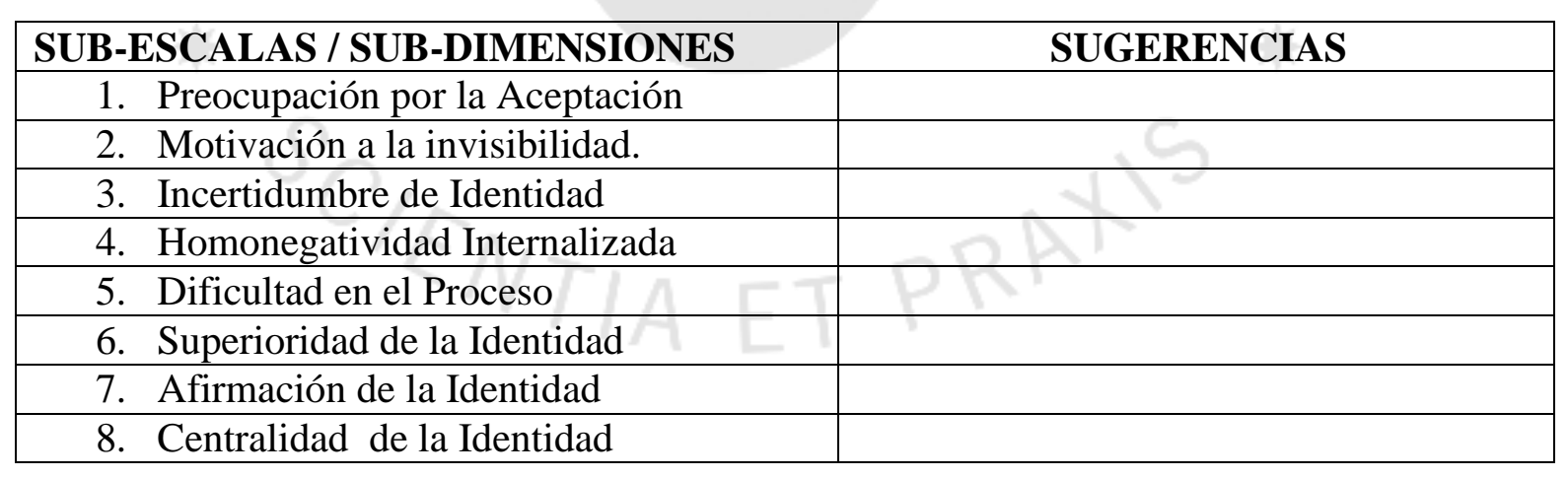




\begin{tabular}{|c|c|}
\hline $\begin{array}{l}\text { CONSIGNA ADICIONAL A } \\
\text { CONSIDERAR POR INSTRUCCIONES } \\
\text { DEL AUTOR: }\end{array}$ & SUGERENCIAS \\
\hline $\begin{array}{l}\text { Algunos y algunas de ustedes en vez de } \\
\text { identificarse como "Lesbiana, gay o bisexual" } \\
\text { para describir su orientación sexual; podrían } \\
\text { preferir utilizar otras etiquetas como por } \\
\text { ejemplo: "Queer", "Dyke", "Questioning". En } \\
\text { esta escala se utiliza las siglas LGB por } \\
\text { conveniencia, por lo cual pedimos su } \\
\text { compresión en el caso que este término no } \\
\text { represente en su totalidad su identidad sexual. }\end{array}$ & \\
\hline
\end{tabular}




\section{ANEXO 6: CRITERIO DE JUECES}

Profesor/Profesora:

Presente.-

De mi consideración:

Teniendo en cuenta su experiencia; tengo el agrado de dirigirme a usted para solicitar su participación como juez experto en el proceso de validación de contenido de la escala psicológica "The Lesbian, Gay, and Bisexual Identity Scale (Mohr y Kendra, 2011)", la cual será adaptada y validada en una muestra peruana, como parte de mi proyecto de tesis para obtener el Título Profesional de Licenciada en Psicología bajo la modalidad de Tesis.

El proyecto de Tesis se titula: “ADAPTACIÓN DE LA ESCALA DE IDENTIDAD PARA LESBIANAS, GAYS Y BISEXUALES (LGBIS) EN UN GRUPO DE LESBIANAS, GAYS Y BISEXUALES DEL PERÚ". La muestra se encontrará conformada por lesbianas, gays y bisexuales del Perú que se encuentren en el rango de edades de 18 y 45 años.

De antemano agradezco su colaboración.

Atentamente,

Jessica Marialaura Vinces Guillén 


\section{"The Lesbian, Gay, and Bisexual Identity Scale " "La Escala de Identidad para Lesbianas, Gays y Bisexuales"}

Se le pide que tenga en consideración cada una de las dimensiones de la identidad de las personas Lesbianas, Gays y Bisexuales (LGB), de acuerdo a las conceptualizaciones que se muestran en el siguiente cuadro.

\begin{tabular}{|l|l|}
\hline \multicolumn{1}{|c|}{ DIMENSIONES } & \multicolumn{1}{|c|}{ DESCRIPCIÓN } \\
\hline $\begin{array}{l}\text { Preocupación por la } \\
\text { aceptación }\end{array}$ & $\begin{array}{l}\text { Hace referencia al conjunto de expectativas o temores de ser } \\
\text { evaluados por los otros negativamente debido a la orientación } \\
\text { sexual de la persona. Es decir que hay una propensión o } \\
\text { sensibilidad a sentirse estigmatizado. }\end{array}$ \\
\hline Motivación a la invisibilidad & $\begin{array}{l}\text { Muestra la preocupación y necesidad de las personas por proteger } \\
\text { su vida privada y no develar públicamente su orientación sexual. }\end{array}$ \\
\hline Incertidumbre de Identidad & $\begin{array}{l}\text { Hace alusión a la inseguridad/confusión/incertidumbre respecto a la } \\
\text { orientación sexual de uno mismo. Para algunas personas esta } \\
\text { interrogante puede referirse a dudar si son homosexuales o } \\
\text { bisexuales; mientras que en otros casos este cuestionamiento se da } \\
\text { entre la heterosexualidad y la homosexualidad. }\end{array}$ \\
\hline Homonegatividad & $\begin{array}{l}\text { Hace referencia al fenómeno a través del cual la persona internaliza } \\
\text { las creencias y pensamientos anti-LGB y los aplica a las } \\
\text { conceptualizaciones del sí mismo. Con frecuencia, internalizar este } \\
\text { tipo de pensamientos conlleva a que la persona se devalué a sí } \\
\text { misma. }\end{array}$ \\
\hline Dificultad en el proceso & $\begin{array}{l}\text { Demuestra la percepción de cada una de las personas respecto a lo } \\
\text { difícil que ha sido el proceso de desarrollo de su identidad. }\end{array}$ \\
\hline Superioridad de identidad & $\begin{array}{l}\text { Muestra un conjunto de estrategia compensatoria para poder } \\
\text { incrementar la autoestima; como forma de enfrentar la } \\
\text { estigmatización e incluso encubrir sentimientos subyacentes de } \\
\text { inferioridad por ser una persona homosexual. }\end{array}$ \\
\hline Afirmación de identidad & $\begin{array}{l}\text { Refleja el grado en el cual las personas LGB experimentan } \\
\text { pensamientos y sentimientos positivos hacia su orientación sexual y } \\
\text { hacia su integración y participación como miembros de } \\
\text { comunidades LGB. }\end{array}$ \\
\hline $\begin{array}{l}\text { Muestra el grado en el cual un determinado aspecto de la identidad } \\
\text { de la persona; en este caso la identidad de orientación sexual, es } \\
\text { central y determinante para definir su identidad integral. Siendo } \\
\text { esto es un factor moderador de los efectos del estrés minoritario. }\end{array}$ \\
\hline
\end{tabular}

Mohr, J. J., \& Kendra, M. S. (2011). Revision and extension of a multidimensional measure of sexual minority identity: The Lesbian, Gay, and Bisexual Identity Scale. Journal of Counseling Psychology, 58, 234-245. doi: 10.1037/a0022858

Mohr, J., \& Fassinger, R. (2000). Measuring dimensions of lesbian and gay male experience.

Measurement \& Evalutation in Counseling \& Development, 33, 66-90. 
A continuación, según considere; marque en qué grado los ítems presentados evalúan cada una de las dimensiones a las que pertenecen.

Nota: Para cada ítem se considera la escala del 1 al 5 donde:

\begin{tabular}{|l|l|l|l|l|}
\hline $\begin{array}{l}\text { 1.- Muy poco } \\
\text { representativo }\end{array}$ & $\begin{array}{l}\text { 2.- Poco } \\
\text { representativo }\end{array}$ & $\begin{array}{l}\text { 3.- } \\
\text { Medianamente } \\
\text { Representativo }\end{array}$ & $\begin{array}{l}\text { 4.- } \\
\text { Representativo }\end{array}$ & $\begin{array}{l}\text { 5.- Muy } \\
\text { Representativo }\end{array}$ \\
\hline
\end{tabular}

\begin{tabular}{|c|c|c|c|c|c|c|}
\hline $\begin{array}{l}\text { Sub-escala 1: Preocupación por } \\
\text { la aceptación. }\end{array}$ & & & & & & SUGERENCIAS \\
\hline $\begin{array}{l}\text { Con frecuencia me pregunto si los } \\
\text { demás me juzgan por mi } \\
\text { orientación sexual. }\end{array}$ & neter & 2 & 3 & 4 & 5 & \\
\hline $\begin{array}{l}\text { Siento incomodidad sabiendo que } \\
\text { otros me juzgan de manera } \\
\text { negativa debido a mi orientación } \\
\text { sexual. }\end{array}$ & $\Rightarrow$ & 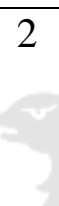 & 3 & 4 & 5 & \\
\hline $\begin{array}{l}\text { Pienso mucho sobre como mi } \\
\text { orientación sexual afecta la forma } \\
\text { en que los otros me perciben. }\end{array}$ & 1 & 2 & 3 & 4 & 5 & \\
\hline $\begin{array}{l}\text { Sub-escala 2: Motivación a la } \\
\text { Invisibilidad }\end{array}$ & & 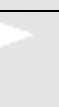 & & & W & SUGERENCIAS \\
\hline $\begin{array}{l}\text { Prefiero mantener en privado mis } \\
\text { relaciones sentimentales con } \\
\text { personas de mí mismo sexo. }\end{array}$ & 1 & 2 & 3 & 4 & 5 & \\
\hline $\begin{array}{l}\text { Tengo un cuidadoso control sobre } \\
\text { quienes saben acerca de mis } \\
\text { relaciones sentimentales con } \\
\text { personas de mí mismo sexo. }\end{array}$ & 1 & 2 & 3 & 4 & 5 & \\
\hline $\begin{array}{l}\text { Mi orientación sexual es un asunto } \\
\text { muy privado. }\end{array}$ & 1 & 2 & 3 & 4 & 5 & \\
\hline $\begin{array}{l}\text { Sub-escala 3: Incertidumbre de } \\
\text { Identidad }\end{array}$ & & & & & & SUGERENCIAS \\
\hline $\begin{array}{l}\text { Tengo dudas acerca de cuál es mi } \\
\text { orientación sexual. }\end{array}$ & 1 & 2 & 3 & 4 & 5 & \\
\hline $\begin{array}{l}\text { Continuamente cambio de opinión } \\
\text { acerca de mi orientación sexual. }\end{array}$ & 1 & 2 & 3 & 4 & 5 & \\
\hline
\end{tabular}




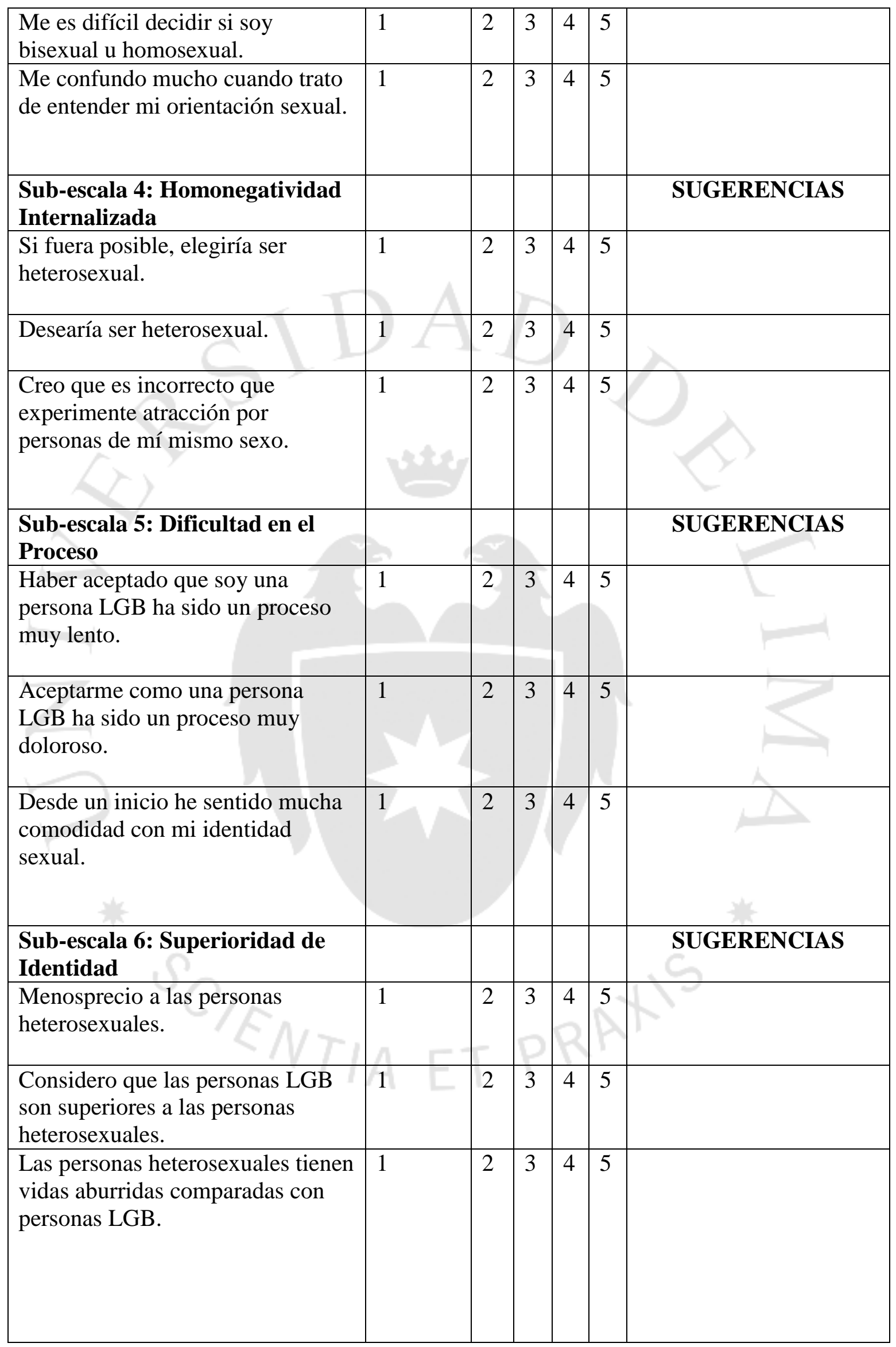




\begin{tabular}{|c|c|c|c|c|c|c|}
\hline $\begin{array}{l}\text { Sub-escala 7: Afirmación de la } \\
\text { Identidad }\end{array}$ & & & & & & SUGERENCIAS \\
\hline $\begin{array}{l}\text { Me siento bien siendo una persona } \\
\text { LGB. }\end{array}$ & 1 & 2 & 3 & 4 & 5 & \\
\hline $\begin{array}{l}\text { Siento orgullo de formar parte de } \\
\text { la comunidad LGB }\end{array}$ & 1 & 2 & 3 & 4 & 5 & \\
\hline Tengo orgullo de ser LGB. & 1 & 2 & 3 & 4 & 5 & \\
\hline $\begin{array}{l}\text { Sub-escala 8: Centralidad de la } \\
\text { Identidad }\end{array}$ & & & & & & SUGERENCIAS \\
\hline $\begin{array}{l}\text { Mi orientación sexual es una parte } \\
\text { insignificante de quién soy yo. }\end{array}$ & 1 & 2 & 3 & 4 & 5 & \\
\hline $\begin{array}{l}\text { Mi orientación sexual es una parte } \\
\text { central de mi identidad. }\end{array}$ & 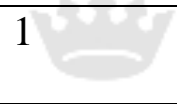 & 2 & 3 & 4 & 5 & \\
\hline $\begin{array}{l}\text { Para entenderme como persona, se } \\
\text { tiene que saber que soy LGB. }\end{array}$ & 1 & 2 & 3 & 4 & 5 & \\
\hline $\begin{array}{l}\text { Ser una persona LGB es un } \\
\text { aspecto muy importante de mi } \\
\text { vida }\end{array}$ & 1 & 2 & 3 & 4 & 5 & + \\
\hline $\begin{array}{l}\text { Yo creo que ser LGB es una parte } \\
\text { importante de mí. }\end{array}$ & 1 & 2 & 3 & 4 & 5 & $\sum^{2}$ \\
\hline
\end{tabular}




\section{ANEXO 7: CONSENTIMIENTO INFORMADO}

A través de la presente, se le pide su participación en una investigación académica conducida por la alumna Jessica Vinces Guillén, estudiante de Pre Grado de la Facultad de Psicología de la Universidad de Lima. La meta de este estudio es la validación de un instrumento que permita conocer a mayor profundidad las dimensiones de identidad de orientación sexual de las personas lesbianas, gays y bisexuales (LGB).

La importancia de este estudio recae en que se observa poca iniciativa desde el campo de la psicología por llevar a cabo investigaciones que tengan como principal objetivo lograr una aproximación más cercana a sus demandas reales y dificultades asociadas a la discriminación. Es así, que debido a la carencia de investigaciones de este tipo, su participación es sumamente importante, valiosa y necesaria.

La presente investigación se realizará vía online contando además con las herramientas necesarias que aseguren que todas sus respuestas son completamente anónimas. Asimismo, su identidad no será revelada ni compartida con nadie. Y la información obtenida será utilizada con fines académicos y de investigación.

$\mathrm{Su}$ participación en esta investigación es completamente voluntaria e igualmente, puede retirarse de la misma en cualquier momento sin que eso lo perjudique en ninguna forma. Si alguno de los enunciados le parecen incómodos, tiene el derecho de hacérselo saber a la investigadora o de no responderlos.

Para participar en esta encuesta usted debe:

a. Encontrarse en un rango de edad de 18-45 años.

b. Considerarse lesbiana, gay, bisexual o encontrarse en un periodo de duda respecto a su orientación sexual.

c. Tener un tipo de orientación sexual diferente a la heterosexual a pesar que prefiera no auto etiquete como lesbiana, gay o bisexual. 
d. Haber nacido el Perú

e. Encontrarse residiendo en el Perú actualmente.

f. Completar los datos de la ficha demográfica; al menos edad y orientación sexual.

Por otro lado, se le sugiere que tenga la amabilidad de transmitir el link de la presente investigación a sus amigos y conocidos que también se identifican como lesbianas, gays, bisexuales.

Si usted tiene alguna pregunta con respecto a la investigación, por favor póngase en contacto con Jessica Vinces Guillen a los correos 1gbis.adaptacion.lima@gmail.com o 20053060@aloe.ulima.edu.pe y al número telefónico: 952608482

1) Confirmo que he leído y comprendido la información dada en el "Consentimiento Informado"

2) Entiendo que mi participación es voluntaria y que soy libre de retirarme en cualquier momento de la investigación.

3) Entiendo que los datos que proporcione durante este estudio serán anónimos.

4) Estoy de acuerdo en permitir que los datos recogidos se utilicen con fines académicos.

Acepto

No Acepto 